\title{
Trip-induced Transition Measurements in a Hypersonic Boundary Layer Using Molecular Tagging Velocimetry
}

\author{
Brett F. Bathel*, Paul M. Danehy ${ }^{\dagger}$, Stephen B. Jones ${ }^{\star}$ \\ NASA Langley Research Center, Hampton, Virginia, 23681-21991 \\ Craig T. Johansen ${ }^{\S}$ \\ University of Calgary, Calgary, AB, T2N 1N4 \\ and \\ Christopher P. Goyne \\ University of Virginia, Charlottesville, Virginia, 22904
}

\begin{abstract}
Measurements of mean streamwise velocity, fluctuating streamwise velocity, and instantaneous streamwise velocity profiles in a hypersonic boundary layer were obtained over a 10-degree half-angle wedge model. A laser-induced fluorescence-based molecular tagging velocimetry technique was used to make the measurements. The nominal edge Mach number was 4.2. Velocity profiles were measured both in an un-tripped boundary layer and in the wake of a 4-mm diameter cylindrical tripping element centered $75.4 \mathrm{~mm}$ downstream of the sharp leading edge. Three different trip heights were investigated: $k=0.53 \mathrm{~mm}, k=$ $1.0 \mathrm{~mm}$ and $k=2.0 \mathrm{~mm}$. The laminar boundary layer thickness at the position of the measurements was approximately $1 \mathrm{~mm}$, though the exact thickness was dependent on Reynolds number and wall temperature. All of the measurements were made starting from a streamwise location approximately $18 \mathrm{~mm}$ downstream of the tripping element. This measurement region continued approximately $30 \mathrm{~mm}$ in the streamwise direction. Additionally, measurements were made at several spanwise locations. An analysis of flow features show how the magnitude, spatial location, and spatial growth of streamwise velocity instabilities are affected by parameters such as the ratio of trip height to boundary layer thickness and roughness Reynolds number. The fluctuating component of streamwise velocity measured along the centerline of the model increased from approximately $\pm 75 \mathrm{~m} / \mathrm{s}$ with no trip to $\pm 225 \mathrm{~m} / \mathrm{s}$ with a $0.53-\mathrm{mm}$ trip, and to $\pm 240 \mathrm{~m} / \mathrm{s}$ with a $1-\mathrm{mm}$ trip, while holding the freestream Reynolds number constant. These measurements were performed in the 31-inch Mach 10 Air Tunnel at the NASA Langley Research Center.
\end{abstract}

\section{Nomenclature}

$\begin{array}{ll}\delta_{L} & =\text { laminar boundary layer thickness, } \mathrm{mm} \\ \rho & =\text { density, } \mathrm{kg} / \mathrm{m}^{3} \\ \sigma & =\text { standard deviation } \\ \mu & =\text { dynamic viscosity, } \mathrm{kg} / \mathrm{m} \cdot \mathrm{s} \\ F W H M & =\text { full-width at half maximum } \\ k & =\text { cylindrical trip height, } \mathrm{mm} \\ L I F & =\text { laser-induced fluorescence } \\ \dot{m}_{\text {Blowing }} & =\text { blowing rate of seeded gas, } \mathrm{mg} / \mathrm{s}\end{array}$

* Graduate Student, University of Virginia and NASA Graduate Co-op, Hampton, Virginia, AIAA Student Member. ${ }^{\dagger}$ Research Scientist, Advanced Sensing and Optical Measurement Branch, MS 493, AIAA Associate Fellow.

${ }^{\ddagger}$ Research Technician, Advanced Sensing and Optical Measurement Branch, MS 493.

${ }^{\S}$ Assistant Professor, Department of Mechanical and Manufacturing Engineering, Member AIAA.

** Research Assistant Professor, Mechanical and Aerospace Engineering, Aerospace Research Laboratory, PO Box 400248, AIAA Associate Fellow.

1

American Institute of Aeronautics and Astronautics 


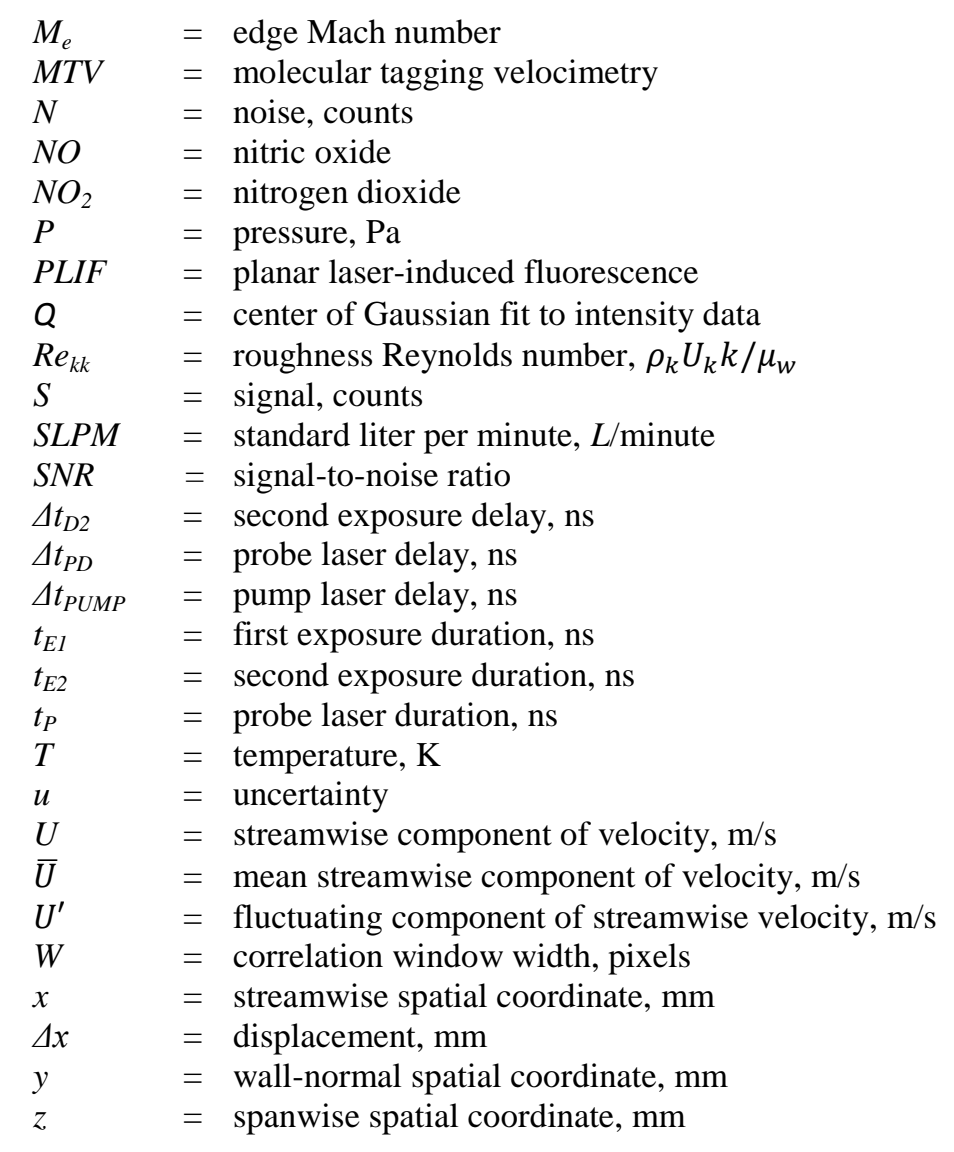

\section{Subscripts}

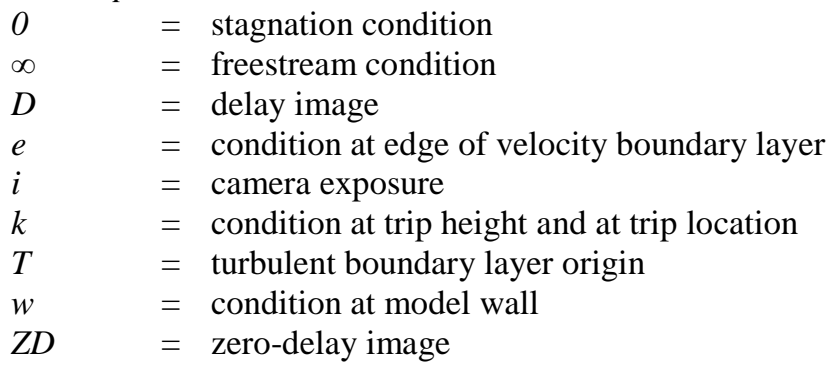

\section{Introduction}

$\mathrm{H}$ ypersonic boundary layer laminar-to-turbulent transition affects high-speed vehicle flight through control, surface heating rates, material selection, vehicle weight, and combustion efficiencies. Understanding the nature and cause of transition through experimentation will lead to developing predictive computational capabilities that will identify the location of transition based upon the dominant physical mechanisms. A physics-based approach to predicting the formation and growth of instabilities, which can lead to a laminar boundary layer breaking down to turbulence, would reduce vehicle development costs. A particular area of interest in the hypersonic transition research community is hypersonic boundary layer transition-to-turbulence in the presence of discrete roughness elements. Specifically, an understanding is sought of the role a discrete protuberance with a height, $k$, on an otherwise laminar hypersonic flow as it passes over a flight vehicle's surface.

One purpose of this paper is to provide experimental hypersonic velocity boundary layer data in the wake of a cylindrical tripping element by measuring the streamwise velocity component using a laser-induced fluorescencebased molecular tagging velocimetry (MTV) technique. Another purpose of this paper is to report on the successful application of the $\mathrm{NO}_{2}$-to-NO photolysis MTV technique to a hypersonic boundary layer flow. In the experiment reported herein, the trip height relative to boundary layer thickness, $k / \delta_{L}$, and the roughness Reynolds number, $\operatorname{Re}_{k k}$, 
were varied with a constant edge Mach number, $M_{e}$, of 4.2 to determine their effect on the mean streamwise velocity, $\bar{U}$, and the fluctuating component of streamwise velocity, $U^{\prime}$. A comparison with flow visualization images obtained at similar flow conditions as those reported by Danehy et al. ${ }^{1}$ is also made.

\section{A. Wind Tunnel Facility}

\section{Experimental Setup and Data Analysis}

The 31-Inch Mach 10 Air Tunnel is an electrically-heated blowdown facility located at NASA Langley Research Center in Hampton, Virginia, USA. The full details of this facility can be found in the paper by Micol, ${ }^{2}$ a brief summary of which is provided here. The facility has a nominal Mach number of 10 and a 31 -inch square test section and operates on electrically heated, compressed air. Large windows - transparent in the ultraviolet down to approximately $190 \mathrm{~nm}$ - form three walls (including top, side and bottom) of the test section, with the fourth wall formed by the model injection system. The top window allows the laser sheet to pass through the test section, while the side window allows for imaging of the flow region of interest. The model is attached at the rear to a sting, which is subsequently side-mounted to the fourth wall. Run durations for the experiments were typically one to two minutes. Two nominal facility stagnation pressures, $P_{0}$, of $3.45 \mathrm{MPa}(500 \mathrm{psia})$ and $4.98 \mathrm{MPa}(720 \mathrm{psia})$ were investigated. The nominal stagnation temperature, $T_{0}$, was $1000 \mathrm{~K}$ (1,800 Rankine). Based upon the stagnation conditions, the approximate freestream Mach number was 9.8, the approximate freestream velocity was $1400 \mathrm{~m} / \mathrm{s}$. The approximate freestream unit Reynolds numbers $\left(R e_{\infty}\right)$ for the $3.45 \mathrm{MPa}$ and $4.98 \mathrm{MPa}$ stagnation pressure conditions were $2.4 \times 10^{6} \mathrm{~m}^{-1}$ and $3.3 \times 10^{6} \mathrm{~m}^{-1}$, respectively.

\section{B. PLIF Imaging System}

The $\mathrm{NO}_{2}$-to-NO photolysis molecular tagging velocimetry (MTV) technique was previously developed and demonstrated by several researchers. ${ }^{3-7} \mathrm{~A}$ thorough description of the planar laserinduced fluorescence (PLIF) imaging and MTV system is provided in Ref. 8, with further improvements to the system described in Refs. 9 and 10. Briefly, the system used for the experiments described in this paper consisted of two Nd:YAGpumped dye laser systems. The output of the dye lasers is sum-frequency mixed to generate tunable UV light near $226 \mathrm{~nm}$. A 355-nm third-harmonic beam from one $\mathrm{Nd}$ :YAG laser is used as a pump beam to generate $\mathrm{NO}$ via photolysis of $\mathrm{NO}_{2}$; the

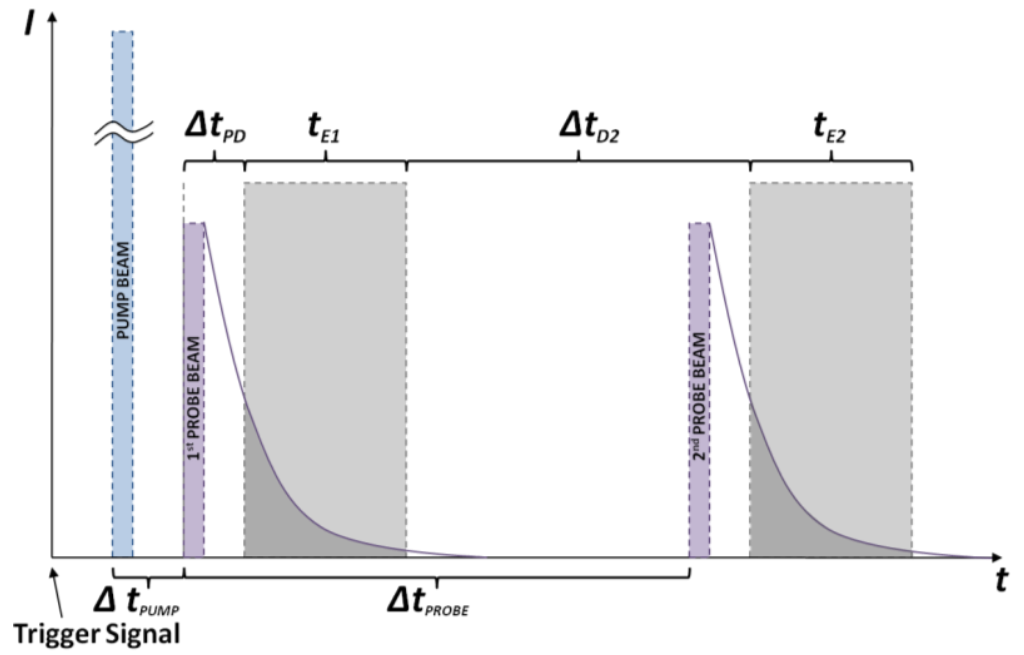

Figure 1. Timing schematic for three-laser $\mathrm{NO}_{2}$-to-NO photolysis experiment. two $226 \mathrm{~nm}$ beams from the dye lasers are used as temporally-separated probe beams to induce NO fluorescence. The temporal relationship of these three beams is illustrated in Fig. 1.

The photolysis of $\mathrm{NO}_{2}$ induced by the high-intensity $355 \mathrm{~nm}$ UV pump beam occurs along multiple vertical lines so that a spatial pattern of $\mathrm{NO}$ is "written" onto a gas flowfield containing $\mathrm{NO}_{2}$. After a short delay period $\left(\Delta t_{P U M P}\right)$, the first probe beam, which is formed into a laser sheet, generates fluorescence where there is NO. After a delay period, $\triangle t_{P R O B E}$, the second probe beam again generates fluorescence in the NO pattern, which has been convected by the motion of the boundary layer gas in the streamwise direction, $x$. The magnitude of this displacement is related to the delay period, $\triangle t_{P R O B E}$, and local streamwise velocity, $U$, according to $\Delta x=U \cdot \Delta t_{P R O B E}$.

The fluorescence signal, which decays exponentially with time, is captured using an intensified 12-bit Cooke DiCAM-PRO interline double-frame camera. This camera is capable of capturing two sequential frames with exposure durations of $t_{E I}$ and $t_{E 2}$, respectively. These exposures are separated in time by a delay, $\Delta t_{D 2}$. The start of each exposure is delayed from the probe beam excitation by $\Delta t_{P D}$ to minimize laser scatter off of the wind tunnel model surface. A spectral filter is placed in front of the camera lens (Layertec $\mathrm{GmbH}$ : $<1 \%$ transmission at $226 \mathrm{~nm}$; $>80 \%$ from $235 \mathrm{~nm}-280 \mathrm{~nm}$ ) to further block any laser scatter. Figure 2 shows the approximate orientation of the pump laser beam, probe laser beams, profile- and sheet-forming optics, velocity measurement plane, and camera. This particular configuration of the camera and velocity measurement plane is referred to as a side-view orientation. 


\section{Wind Tunnel Model}

The experiments were conducted using a $10^{\circ}$ half-angle wedge model with a sharp leading edge. The measurements were made above the upper surface of the model, referred to herein as the plate surface. The plate surface was $127.0-\mathrm{mm}$ wide by $162.5-\mathrm{mm}$ long. In this experiment, the plate surface was oriented at a $20^{\circ}$ plate angle, defined so that when the plate angle is zero, the plate is parallel to the flow. A thorough description of this wind tunnel model - shown in Fig. 3-is provided in Refs. 8 and 9. For the tripped experiments, a cylindrical trip having a diameter of $4.0 \mathrm{~mm}$ was positioned along the centerline, $75.4 \mathrm{~mm}$ downstream of the leading edge (measured to the center axis-of-symmetry of the trip) to deflect and perturb the boundary layer gas. Three different trip heights, $k$, were used in the experiments: $k=0.53 \mathrm{~mm}, k=1.0 \mathrm{~mm}$, and $k=2.0$ $\mathrm{mm}$.

The $100 \% \mathrm{NO}_{2}$ gas is seeded into the boundary layer from an 11-mm-long, 0.81-mm-wide spanwise seeding slot insert located $29.4 \mathrm{~mm}$ downstream of the leading edge. The gas flowrate is metered by both a 1 standard liter per minute (SLPM) and a 10 SLPM mass flow controller configured in parallel with one another. These controllers supply the $\mathrm{NO}_{2}$ gas to a plenum inside the model through a stainless steel tube, with the top of the plenum being covered by the seeding slot insert. A leak in the $\mathrm{NO}_{2}$ supply line, described in Ref. 9, was estimated to be less than $1 \%$ of the supplied $\mathrm{NO}_{2}$ mass flow rate.

The photolysis process and subsequent MTV measurements occur in a region of the flow above a quartz window that is mounted flush with the top surface. This window is centered about the spanwise axis of symmetry, $114.3 \mathrm{~mm}$ downstream of the leading edge. The window has a $50.8 \mathrm{~mm}$ diameter and is $6.4 \mathrm{~mm}$ thick. The pump beams used to generate $\mathrm{NO}$ via photolysis are nominally perpendicular (a nominal $0^{\circ}$ angle-of-incidence) to this window. Another quartz window, identical to the one on the upper measurement surface, is mounted to the bottom surface, which is parallel to the freestream flow. The leading edge of this window is positioned $95.4 \mathrm{~mm}$ downstream of the leading edge of the model. The purpose of the windows is to reduce the amount of spurious scattered laser light imaged by the camera by allowing most of the laser light to pass through the model and out the bottom of the tunnel.

A J-type thermocouple was attached to the underside of the model's 5-mm thick stainless steel surface with Kapton® tape to measure the plate temperature, $T_{w}$. The placement of the thermocouple provides only an estimate of the true plate temperature. The temperature measurement does not account for heat transfer effects occurring through the thickness of the plate. The plate surface pressure, $P_{w}$, is measured with a Druck pressure gauge (model PDCR 4060, 0.04\% accuracy to $34.5 \mathrm{kPa}$ ).

\section{Experimental Conditions}

Table 1 below provides a list of measurement conditions that are analyzed in this paper. In this table, each run corresponds to a set of measurements in which the freestream Reynolds number, $R e_{\infty}$, trip height, $k$, or both are unique. The relatively long run times (1-2 minutes) are necessary in order to make measurements at several spanwise locations, $z$, while also ensuring adequate data volume for computing flow statistics. However, long run times result in an increasing plate temperature over the duration of each run. This variation in plate temperature changes the boundary layer velocity and temperature profiles, which in turn changes the ratio of trip height to boundary layer thickness $\left(k / \delta_{L}\right)$ and roughness Reynolds number $\left(R e_{k k}\right)$. Table 1 provides $P_{w}, T_{w}, \mathrm{NO}_{2}$ blowing rate $\left(\dot{m}_{\text {Blowing }}\right), k / \delta_{L}$, and $R e_{k k}$ for each spanwise measurement location, $z$. In this paper, only runs for which $\dot{m}_{\text {Blowing }}$ was less than or equal to approximately $60 \mathrm{mg} / \mathrm{s}$ were

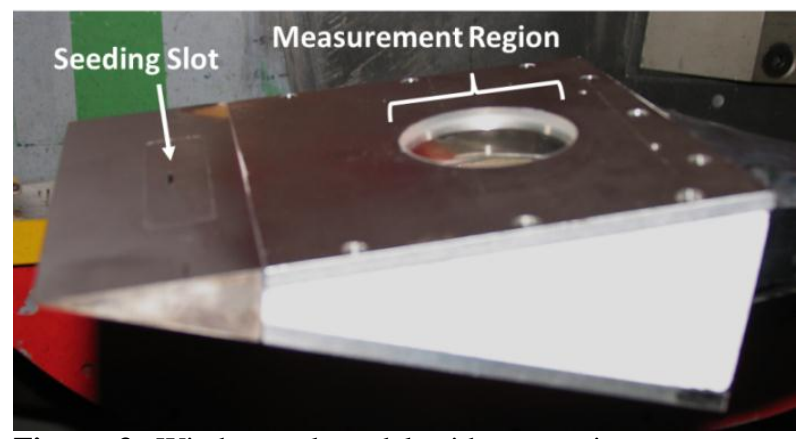

Figure 3. Wind tunnel model with quartz insert on upper (measurement) surface. 
analyzed. This maximum flow rate is based on results presented in Ref. 9 that suggested that blowing rates less than approximately $60 \mathrm{mg} / \mathrm{s}$ would minimally perturb the boundary layer flow while providing sufficient seeding to allow velocity measurements.

In this paper, the roughness Reynolds number is given by the relation $R e_{k k}=\rho_{k} U_{k} k / \mu_{w}$. The subscript $k$ refers to the value of the relevant property at the trip height (e.g. density, $\rho_{k}$, and streamwise velocity, $U_{k}$ ). The subscript $w$ on the dynamic viscosity, $\mu_{w}$, indicates that the quantity is to be evaluated at the measured wall temperature, $T_{w}$. These parameters, along with the estimated boundary layer thickness, $\delta_{l}$, are obtained by computing the compressible laminar boundary layer profiles for the specified wall pressures and wall temperatures using the method outlined in Ref. 11. This computation requires knowledge of the measured wall temperature, $T_{w}$, the edge Mach number, $M_{e}$, edge pressure, $P_{e}$, and edge temperature, $T_{e}$, in the absence of the trip. The values for $M_{e}, P_{e}$, and $T_{e}$, given in Table 2, are computed using the Virginia Tech oblique shock calculator. ${ }^{\dagger}$ This calculator requires the values for freestream parameters, which were computed according to Ref. 12.

Table 1. Experimental conditions.

\begin{tabular}{|c|c|c|c|c|c|c|c|c|c|}
\hline Run & $\operatorname{Re}_{\infty}\left(m^{-1}\right)$ & $\mathrm{P}_{\mathrm{w}}(\mathrm{kPa})$ & $\mathrm{T}_{\mathrm{w}}(\mathrm{K})$ & $\Delta \mathrm{t}_{\mathrm{PROBE}}(\mu \mathrm{s})$ & $\dot{\mathrm{m}}_{\text {Blowing }}(\mathrm{mg} / \mathrm{s})$ & $\mathrm{k}(\mathrm{mm})$ & $\mathrm{k} / \delta$ & $\mathrm{Re}_{\mathrm{kk}}$ & $\mathrm{z}(\mathrm{mm})$ \\
\hline 12 & $3.3 \times 10^{6}$ & 2.77 & 340 & 1 & 62.4 & 0 & 0 & 0 & 0 \\
\hline 30 & $2.4 \times 10^{6}$ & $2.08,2.07,2.06$ & $379,365,350$ & 2 & $22.9,22.5,22.7$ & 0.53 & 0.41 & $293,265,284$ & $0.0,4.5,6.0$ \\
\hline 16 & $3.3 \times 10^{6}$ & $2.91,2.89$ & 395,379 & 2 & $30.5,30.4$ & 0.53 & 0.47 & 393,420 & $0.0,-4.5$ \\
\hline 14 & $3.3 \times 10^{6}$ & $\begin{array}{c}2.94,2.92,2.90 \\
2.89\end{array}$ & $419,401,386$, & 1 & $\begin{array}{c}46.6,46.8,46.7 \\
46.7\end{array}$ & 1.00 & $\begin{array}{c}0.86,0.87,0.88 \\
0.90\end{array}$ & $\begin{array}{c}1698,1798,1891, \\
1999\end{array}$ & $\begin{array}{c}0.0,-4.5,-6.0 \\
-7.5\end{array}$ \\
\hline 13 & $3.3 \times 10^{6}$ & $\begin{array}{c}2.87,2.86,2.75 \\
2.89,2.91\end{array}$ & $\begin{array}{c}310,329,348 \\
367,391\end{array}$ & 1 & $\begin{array}{c}30.0,30.3,30.6 \\
30.6,30.6\end{array}$ & 2.00 & $\begin{array}{c}1.89,1.86,1.83, \\
1.80,1.76\end{array}$ & $\begin{array}{c}5535,5296,5072, \\
4881,4665\end{array}$ & $\begin{array}{c}-3.5,-4.5,-5.5 \\
-6.5,-7.5\end{array}$ \\
\hline
\end{tabular}

Table 2. Estimated edge conditions.

\begin{tabular}{cccc}
\hline \hline Run & $\mathrm{M}_{\mathrm{e}}$ & $\mathrm{P}_{\mathrm{e}}(\mathrm{kPa})$ & $\mathrm{T}_{\mathrm{e}}(\mathrm{K})$ \\
\hline 12 & 4.18 & 2.77 & 237 \\
30 & 4.17 & 1.97 & 234 \\
16 & 4.18 & 2.76 & 237 \\
14 & 4.18 & 2.77 & 239 \\
13 & 4.18 & 2.77 & 237 \\
\hline \hline
\end{tabular}

\section{E. Image Processing}

General details of the image processing method used to obtain velocity and uncertainty data are described in Refs. 8 and 9. Three modifications were made to the methods described in these references. The first modification concerned the small physical downward displacement of the model that is observed over the course of a run. Presumably, the displacement is a result of non-uniform thermal loading on the sting, which causes it to bend downward. Using the image processing software Image ${ }^{\$+}$ and the function reslice, a 10-pixel-wide slice spanning the vertical extent of the image set is centered horizontally on a region where some residual laser scatter off of the stainless steel portion of the model surface is observed. This slice is used to generate a single image through the image volume showing the location of the scatter, and hence location of the model surface, as a function of frame number. A $2^{\text {nd }}$-order polynomial fit to the location of the laser scatter is then used to characterize the model displacement over the course of a run. The raw images are then vertically shifted using a bicubic image transform function in MATLAB ${ }^{\circledR}$ such that the plate surface appears stationary in all of the images. In previous work, this correction was accomplished by shifting the images in whole-pixel increments. By using a bicubic image transform, spatial errors resulting from shifting the images in whole-pixel increments are avoided.

The second change involves how the signal-to-noise ratio $(S N R)$ is calculated. In previous work, the signal, $S_{i}$, in a given camera exposure, $i=E 1$ or $E 2$, was computed by taking the difference between the maximum and minimum counts within a 21-pixel-wide by 1-pixel-high window centered about the peak value of the tagged gas line. The noise, $N_{i}$, was then estimated by computing the standard deviation of the signal counts within a $5 \times 5$-pixel square window centered about the location of the peak signal count. The problem with this methodology is that noise from regions above and below the profile being analyzed was included in the SNR computation. This made the computation susceptible to errors because it included signal levels from above and below the measurement region. Since the computed $S N R$ was used to estimate both the single-shot uncertainty and fluctuating streamwise velocity component, any errors associated with the $S N R$ estimate were further propagated to other calculations. To avoid this error, the $S N R$ in this paper is computed by fitting a Gaussian function to the tagged gas lines over a 39-pixel-wide by 1-pixel-high window. This window has the same width, $W_{i}$, and height as the window used to correlate data

\footnotetext{
†DDevenport, W.J., Compressible Aerodynamics Calculator 2.0, http://www.dept.aoe.vt.edu/ devenpor/aoe3114/calc.html [accessed November 27, 2012].

\# Software available at http://rsb.info.nih.gov/ij/ [version 1.43 retrieved January 2010]
} 
collected in the first and second exposures. The window is centered about the peak signal along the tagged line. The Gaussian function is obtained by using MATLAB's ${ }^{\circledR}$ fminsearch and fminbnd functions to perform an iterative least-squares fit to the experimental data. The noise is computed as twice the standard deviation of the difference between the resulting Gaussian fit and the experimental data, with any linear trend in this difference removed using the function detrend. The peak-to-valley magnitude of the Gaussian fit is then used as the signal level, $S_{i}$. This approach is very similar to that outlined in Ref. 13.

The third and final change to the image processing involves the data rejection method. In this paper, a three-step process for accepting or rejecting a data point is used. In the first step, the three parameters returned from the Gaussian fit to the experimental data are required to be within a specified range of values. The first of these parameters, the fitted peak-to-valley signal level, $S_{i}$, is assigned an acceptable range (in counts) of $1 \leq S_{i} \leq 2500$. This range is selected so that signal saturation and phosphor artifact effects from the camera (e.g. ghosting) are avoided. The acceptable range for the full-width at half-maximum parameter, $F W H M_{i}$, of the fit (in pixels) is set to $2 \leq$ $F W H M_{i} \leq W_{i} / 2$, where $W_{i}$ is the width of the correlation window. This range is chosen to prevent poor fits to the data which have widths that are either much narrower (less than or equal to 2 pixels) or much wider (greater than or equal to half the correlation window size) than what is typically observed in the experimental MTV profiles. The final parameter is the center of the fit with respect to the correlation window in pixels, $Q_{i}$. This parameter had an acceptable range of $1 \leq Q_{i} \leq W_{i}$. This range is chosen to exclude fits which are centered outside of the correlation window.

The second rejection step involves the computed composite $S N R\left(S N R=\sqrt{S N R_{1} \cdot S N R_{2}}\right)$ and the $S N R$ computed for the zero-delay and delayed profiles $\left(S N R_{i}=S_{i} / N_{i}\right)$. Analysis of both mean and single-shot velocity data indicate that a lower threshold of $S N R>3.5$ and $S N R_{i}>3.5$ is still adequate to ensure that data points obtained from erroneous cross-correlation results are rejected without unnecessarily discarding useable data with low SNR. The use of the first two steps in the rejection process result in a higher data yield at lower SNR levels.

The third and final step in this process rejects data points based on the uncertainty in the mean velocity. For most runs, points with an uncertainty in the mean greater than $\pm 125 \mathrm{~m} / \mathrm{s}$ are removed. For Run 12 data, any point with an uncertainty in the mean streamwise velocity greater than $\pm 60 \mathrm{~m} / \mathrm{s}$ is removed since there was no trip present and the seeding was much more uniform.

Figure 4(a) shows experimental MTV profile signal intensity distributions from the zero-delay (red diamond data points) and delayed (blue diamond data points) exposures and the corresponding Gaussian fits to these data (solid red and blue lines), obtained in quiescent wind tunnel conditions. Also shown in this figure are the differences between the fit and the experimental data after the MATLAB $®$ function detrend is applied (circle data points). This

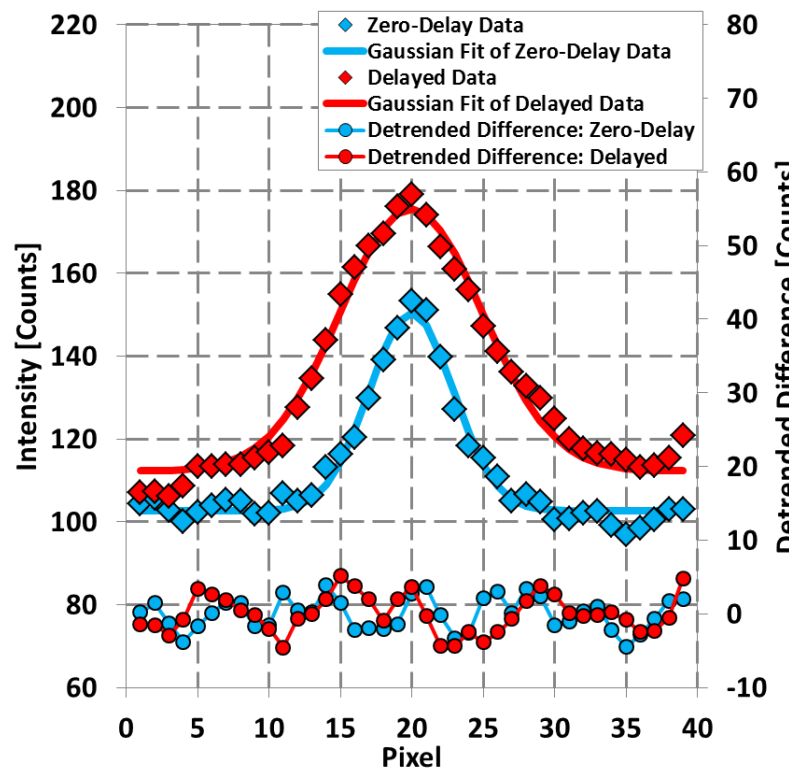

(a)

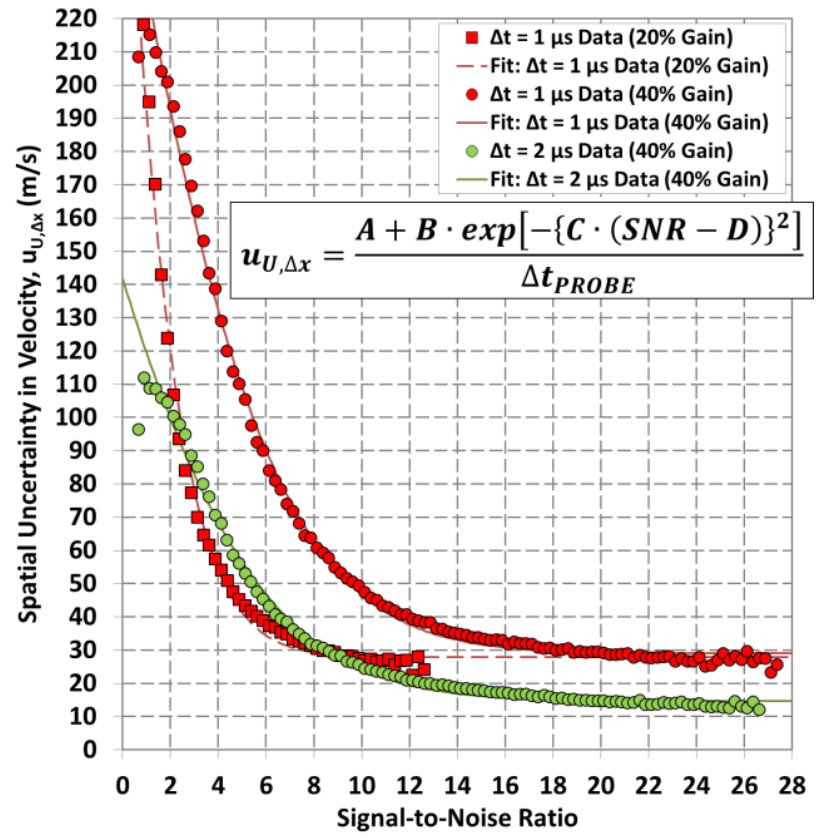

(b)

Figure4. (a) Sample experimental profile data, corresponding Gaussian fit, and linearly detrended difference between fit and experimental data used for noise calculation. (b) Spatial velocity uncertainty and corresponding fit as a function of signal-to-noise ratio, $S N R$. 
function is used after computing the difference between the fit and the experimental data and removes any linear trend present in the difference data that would contribute to an artificially high estimate of noise. The noise is defined in each exposure as being twice the standard deviation of the detrended difference values. Figure 4(b) shows the spatial component of uncertainty in velocity, or spatial uncertainty, $u_{U, \Delta x}$, as described in Ref. 9, for camera gain settings of $20 \%$ (Run 12) and $40 \%$ (all other runs). At the highest SNR levels for the $20 \%$ gain setting, a reduction in $u_{U, \Delta x}$ on the order of $5 \mathrm{~m} / \mathrm{s}$ is observed relative to previous work, owing to the modified $S N R$ calculation method. ${ }^{8,9}$ The fits to these spatial uncertainty data are given by the solid lines in Fig. 4(b), with the fit described by the equation shown. The parameters $\boldsymbol{A}, \boldsymbol{B}, \boldsymbol{C}$, and $\boldsymbol{D}$ depend on the probe beam delay, $\Delta t_{P R O B E}$, and gain setting. For $\triangle t_{P R O B E}=1 \mu \mathrm{s}$ (Gain 20\%): $\boldsymbol{A}=27.87, \boldsymbol{B}=14.70 \times 10^{3}, \boldsymbol{C}=13.14 \times 10^{-2}$, and $\boldsymbol{D}=-15.13$. For $\Delta t_{P R O B E}=1 \mu \mathrm{s}$ (Gain $40 \%): A=29.09, \boldsymbol{B}=677.49, \boldsymbol{C}=8.98 \times 10^{-2}$, and $\boldsymbol{D}=-11.28$. For $\Delta t_{P R O B E}=2 \mu \mathrm{s}(\mathrm{Gain} 40 \%): \boldsymbol{A}=29.32, \boldsymbol{B}=830.65$, $\boldsymbol{C}=8.54 \times 10^{-2}$, and $\boldsymbol{D}=-12.73$.

In Fig. 4(b), the spatial uncertainty reduces significantly as the $S N R$ increases. Furthermore, it is reduced by roughly a factor of two when the $\triangle t_{P R O B E}$ is doubled, though the spatial resolution is decreased by using a longer time separation. Also, the lower gain setting provided a lower uncertainty, though higher gain settings were required to study the tripped flows because of the low signal levels that were expected with lower $\dot{m}_{\text {Blowing }}$ used in the tripped runs (see Table 1). The increase in gain is estimated to have increased signal levels by as much as a factor of 2.5 when analyzing the quiescent flow images, assuming constant laser energy and $\mathrm{NO}_{2}$ concentration. However, the increase in gain also makes the images susceptible to increased shot noise.

\section{Results}

\section{Overview of Velocity Measurement Presentation Format}

This section summarizes some of the streamwise velocity measurement results presented in the appendix. The figures in the appendix are first organized according to trip height (smallest to largest), $k$, then by freestream Reynolds number, $R e_{\infty}$, and then spanwise measurement location, $z$. This order of figures is similar to that outlined in Table 1. For each $z$ location in a given run, three separate figures are provided. The first figure includes the measured mean streamwise velocity profiles $(\bar{U}, \mathrm{~m} / \mathrm{s})$, fluctuating streamwise velocity component profiles $\left(U^{\prime}, \mathrm{m} / \mathrm{s}\right)$, and sample single-shot streamwise velocity profiles $(U, \mathrm{~m} / \mathrm{s})$. The second figure shows an average of the zero-delay and delayed images acquired during the first and second exposures, $t_{E I}$ and $t_{E 2}$, respectively. These are followed by seven single-shot images corresponding to the single-shot $U$ profiles shown in the first figure. The final image is of the standard deviation of the delayed raw images acquired during the second exposure, $t_{E 2}$. The third figure shows three single-shot velocity profiles with corresponding measurement uncertainty acquired at a single streamwise location, $x$.

In figures presenting $\bar{U}$ measurements, the horizontal centers of the black rectangles represent the measured mean streamwise velocities while the width represents the uncertainty in the mean at $95 \%$ confidence. The gray solid line represents the computed hypersonic laminar boundary layer profile for a flat plate with no trip at the same freestream and edge flow conditions. The horizontal axis gives the streamwise position at which the measurement is made. The point at which the computed laminar profiles intersect with the horizontal axis represents the location that the pump beams (used to write the NO pattern onto the flowfield) were incident to the model surface. At this point, the computed laminar velocity is assumed to be zero (no-slip boundary condition). The vertical gridlines occur in $250 \mathrm{~m} / \mathrm{s}$ increments. The vertical axis gives the wall-normal or $y$ position of the measurement.

In figures presenting $U^{\prime}$ profiles, the point at which the vertical red dashed lines intersect with the horizontal axis are the locations at which the pump beams are incident to the model surface. These lines serve as the zero reference for the respective $U^{\prime}$ profile (i.e. where $U^{\prime}=0$ ). The vertical gridlines occur in either $62.5 \mathrm{~m} / \mathrm{s}$ or $125 \mathrm{~m} / \mathrm{s}$ increments (indicated in the figure). The red data points are the $U^{\prime}$ values with respect to the reference.

In the figures presenting $U$ profiles, the single-shot profiles are color-coded according to image number. For reference, the measured $\bar{U}$ profiles (black profiles) and computed laminar profiles (gray profiles) are also shown.

The figures containing average zero-delay $\left(t_{Z D}\right)$, average delayed $\left(t_{D}\right)$, single-shot delayed (numbered), and standard deviation delayed $\left(\sigma_{D}\right)$ images have been cropped to include only the region processed. The brightness and contrast have been adjusted arbitrarily in the images. These images are intended to be used for qualitative comparison with the velocity data. No additional processing has been performed on these images. The box containing the image number corresponding to the raw single-shot images is color coded in the same manner as the single-shot velocity profiles presented in other figures.

In the figure with three sample $U$ profiles, the centers of the rectangles correspond to the single-shot velocity while the width represents the single-shot uncertainty. The coloration signifies the single-shot image from which the 
data were obtained. The streamwise $x$ location at which the single-shot profiles were obtained is listed in the legend, as well as being indicated in the figure containing the average zero-delay raw image.

\section{Discussion of Selected Velocity Data Sets and Comparison with Flow Visualization}

Figures 5(a) and 5(b) show both $\bar{U}$ and $U^{\prime}$ profiles, respectively, obtained along the centerline $(z=0.0 \mathrm{~mm})$ of the model for no trip with $\dot{m}_{\text {Blowing }}=62.4 \mathrm{mg} / \mathrm{s}$ and $R e_{\infty}=3.3 \times 10^{6} \mathrm{~m}^{-1}$. A version of this data was presented in Ref. 9 and is discussed here briefly for comparison with the tripped profiles. The $\bar{U}$ profiles closely match the computed laminar profiles for $y$ less than approximately $0.6 \mathrm{~mm}$. Above this position, the measured profiles still trend with (i.e. have a similar shape to) the computed laminar solution, but a velocity deficit is observed. At worst, this deficit is on the order of $125 \mathrm{~m} / \mathrm{s}$, and is typically on the order of $100 \mathrm{~m} / \mathrm{s}$ along the upper extent of the profiles. It is not clear if the velocity deficit was caused by instrument error, by error in estimating the edge conditions, or by the lowvelocity gas seeded into the boundary layer altering the boundary layer profile downstream. Computations performed in Ref. 14 for this model at a $5^{\circ}$ plate angle and with NO seeding at $3 \mathrm{mg} / \mathrm{s}$ showed that deficits on the order of $50 \mathrm{~m} / \mathrm{s}$ were possible near the edge of the velocity boundary layer, due to the addition of the low-velocity gas. These computations suggest that the method of seeding the boundary layer may have some effect on the measured boundary velocity profiles presented in this paper. Additional computations are needed to simulate the plate angle $\left(20^{\circ}\right)$, Reynolds numbers, and blowing rates examined in this paper to verify that seeding is responsible for the observed distortion of the velocity boundary layer relative to theory.

In Fig. 5(b), the $U^{\prime}$ profiles for no trip at $R e_{\infty}=3.3 \times 10^{6} \mathrm{~m}^{-1}$ exhibit peaks at approximately $y=0.7 \mathrm{~mm}$ across all profiles. This is approximately the same location at which the corresponding $\bar{U}$ profiles begin to diverge from the computed laminar profiles. This behavior was also observed in Ref. 9. The maximum magnitude of $U^{\prime}$ across all profiles is approximately $75 \mathrm{~m} / \mathrm{s}$.

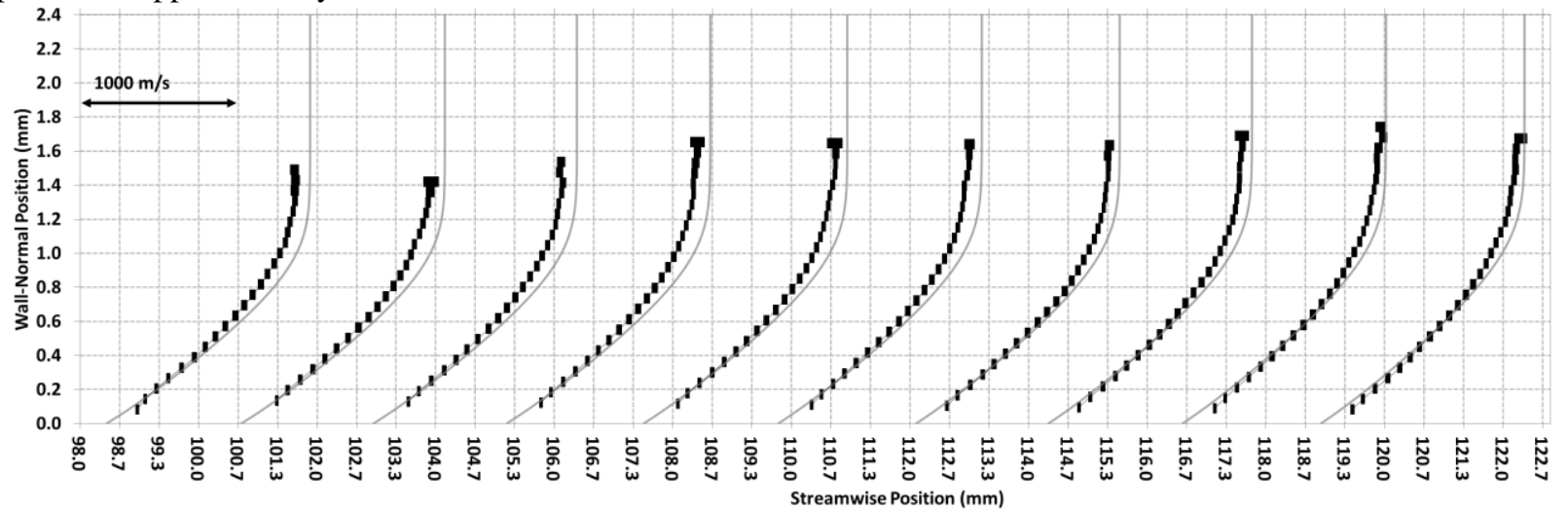

(a)

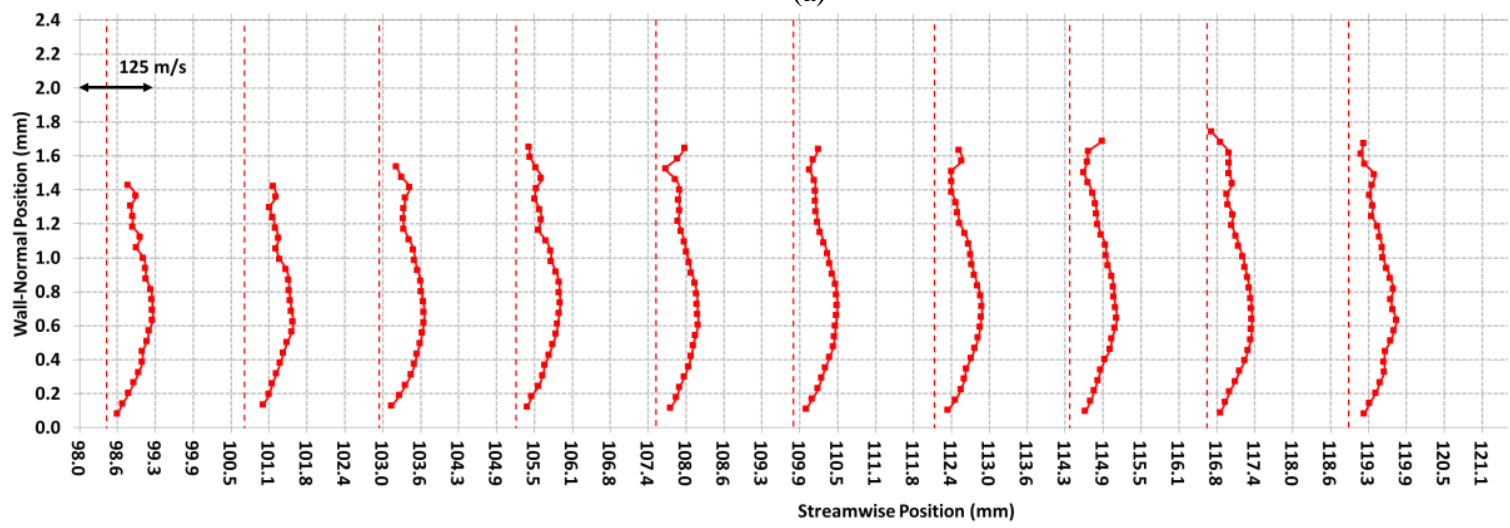

(b)

Figure 5. Side-view (a) mean streamwise velocity $(\bar{U})$ profiles and (b) streamwise fluctuating velocity component $\left(U^{\prime}\right)$ profiles at $z=0.0 \mathrm{~mm}$ (centerline) with no trip, $\dot{m}_{\text {Blowing }}=62.4 \mathrm{mg} / \mathrm{s}, R e_{\infty}=3.3 \times 10^{6} \mathrm{~m}^{-1}$.

Figures 6(a) - (e) show five single-shot flow visualization images presented in Ref. 1 (Fig. 10) using a singlelaser NO PLIF flow visualization technique. These images were acquired at flow conditions nominally the same as Run 14. The blowing rate of pure $\mathrm{NO}$ gas (rather than $\mathrm{NO}_{2}$, as in this experiment) in Figs. 6(a) - (e) was $6.1 \mathrm{mg} / \mathrm{s}$. 
The laser sheet in these images was oriented parallel to the plate surface and was directed from top to bottom in the image. The camera used to acquire these images was oriented perpendicular to the laser sheet such that it imaged the entire plate surface and accompanying laser-induced fluorescence. This particular combination of laser sheet and camera orientation is referred to as a plan-view orientation. In Figs. 6(a) - (e), the position of the laser sheet was varied from $y=0.0 \mathrm{~mm}$ to $2.0 \mathrm{~mm}$ above the plate surface in $0.5 \mathrm{~mm}$ increments, respectively. The superimposed transparent blue circle shows the approximate location of the quartz window insert used in the current velocity experiment (but not used in the flow visualization experiment), above which the velocity measurements described in this paper were obtained. Also shown in Fig. 6(a) are the approximate spanwise locations of some of the side-view velocity measurement planes in this experiment (dashed white lines). The off-centerline spanwise measurement locations $(z=-4.5 \mathrm{~mm},-6.0 \mathrm{~mm}$, and $-7.5 \mathrm{~mm})$ were chosen because they encompassed a region containing large streamwise streaks observed in the flow visualization images presented in Ref. 1. A surface oil flow image, obtained at the same flow condition as the flow visualization images, is shown in Figure 6(f) (also taken from Ref. 1).

The $\bar{U}$ profiles in Fig. 7 are from Run 14 and were acquired at the same nominal flow conditions as the flowvisualization images shown in Fig. 6. The spanwise measurement locations in Figs. 7(a) through (d) correspond to $z$ $=0.0 \mathrm{~mm}$ (centerline), $-4.5 \mathrm{~mm},-6.0 \mathrm{~mm}$ and $-7.5 \mathrm{~mm}$, respectively. Along the centerline, an increased $\bar{U}$ velocity relative to the computed laminar solution is observed below approximately $y=0.7 \mathrm{~mm}$, which is the approximate location at which the measured $\bar{U}$ profiles cross the computed laminar solutions. The fuller velocity profile behavior near the wall, relative to the computed laminar profile, resembles that of a turbulent boundary layer profile. This behavior is discussed in detail in section IV. Above this height, the profiles exhibit a velocity deficit relative to the computed laminar profile but begin to trend with this computed profile in the $+y$ direction. This deficit could be caused by the trip, the seeded $\mathrm{NO}_{2}$ gas that has been injected into the boundary layer, or a combination of these factors.

The off-centerline measurements in Fig. 7(b) through (d) are aligned with a large streak running along the model surface observed in Fig. 6(a). This streak is thought to be indicative of a streamwise vortex emanating from a horseshoe vortex formed in front of the tripping element. ${ }^{1}$ In Fig. 6(c), with the laser sheet at $y=1.0 \mathrm{~mm}$, a secondary streak also appears at approximately $z=-4.5 \mathrm{~mm}$. Approximately halfway between the leading and trailing edges of the window insert, this streak exhibits waviness and starts to breakdown farther downstream. Comparing this plan-view image with the $\bar{U}$ measurements at $z=-4.5 \mathrm{~mm}$ in Fig. 7(b), it appears that the profiles exhibit an increased velocity relative to the laminar profiles below approximately $y=0.8 \mathrm{~mm}$. Between approximately $y=0.9 \mathrm{~mm}$ and $1.7 \mathrm{~mm}$, a velocity deficit relative to the computed laminar profiles occurs, possibly influenced by the wake of the tripping element. Above $y=1.7 \mathrm{~mm}$, no mean velocity data were obtained. The flow visualization images in Fig. 6 seem to also show that little to no NO gas is present above $y=1.5 \mathrm{~mm}$ at $z=-4.5 \mathrm{~mm}$.

Moving farther from the centerline, the $\bar{U}$ measurements at $z=-6.0 \mathrm{~mm}$ [Fig. 7(c)] and $-7.5 \mathrm{~mm}[\mathrm{Fig}$. 7(d)] appear to trend more with the computed laminar profiles, although each profile has a noticeable velocity deficit compared to the computed laminar profiles. Comparing with the flow visualization results in Figs. 6(a)-(c), the flow at these two locations does appear more laminar than either at the centerline or $z=-4.5 \mathrm{~mm}$.

Figures $8(\mathrm{a})-(\mathrm{d})$ show the $U^{\prime}$ profiles for the $k=1.0-\mathrm{mm}$ trip at $z=0.0 \mathrm{~mm},-4.5 \mathrm{~mm},-6.0 \mathrm{~mm}$, and $-7.5 \mathrm{~mm}$, respectively. Note that the scale has changed from Figure 7 and that the maximum $U^{\prime}$ magnitudes along the centerline approach $250 \mathrm{~m} / \mathrm{s}$ for some profiles, compared to $\sim 80 \mathrm{~m} / \mathrm{s}$ in the case with no trip - about a factor of 3 increase in $U^{\prime}$. Near the left-hand side of Fig. 8(a), the centerline $U^{\prime}$ profiles show a broad, flat peak ranging from approximately $y=0.2 \mathrm{~mm}$ to $0.8 \mathrm{~mm}$. Proceeding downstream, the upper $y$ extent of this broad $U^{\prime}$ feature appears to slowly decrease, with the profiles at the right-hand side of the figure exhibiting a relatively narrower magnitude peak centered about $y=0.3 \mathrm{~mm}$. The upstream profiles at $z=-4.5 \mathrm{~mm}$ in Fig. 8(b) also exhibit a broad, flat peak ranging from approximately $y=0.2 \mathrm{~mm}$ to $0.6 \mathrm{~mm}$. At $x=95.9 \mathrm{~mm}$, the $U^{\prime}$ profile drops to half of the maximum at approximately $y=0.9 \mathrm{~mm}$. However, these profiles begin to exhibit a peak $U^{\prime}$ at $y=0.25 \mathrm{~mm}$ beginning with the profile located at $x=107.3 \mathrm{~mm}$, which is approximately $17 \%$ of $\delta_{L}$. The maximum $U^{\prime}$ magnitudes at this spanwise location are approximately $200-250 \mathrm{~m} / \mathrm{s}$. The profiles measured along $z=-6.0 \mathrm{~mm}$ in Fig. 8(c) again exhibit a broad, flat $U^{\prime}$ behavior near the left-hand edge of the measurement region. However, the range of this feature is between $y=0.4 \mathrm{~mm}$ and $1.0 \mathrm{~mm}$. Proceeding downstream, it appears that this $U^{\prime}$ behavior continues to broaden and never develops a distinguishable peak, with the profiles having maximum magnitudes of less than $200 \mathrm{~m} / \mathrm{s}$. At $z=-$ $7.0 \mathrm{~mm}$, the magnitudes and shapes of the $U^{\prime}$ profiles are very similar to those measured for the no trip case shown in Fig. 5(b), with maximums being located at approximately $y=0.7 \mathrm{~mm}$ and magnitudes less than $100 \mathrm{~m} / \mathrm{s}$, confirming that the flow is laminar in this region, as suggested by the flow visualization. 


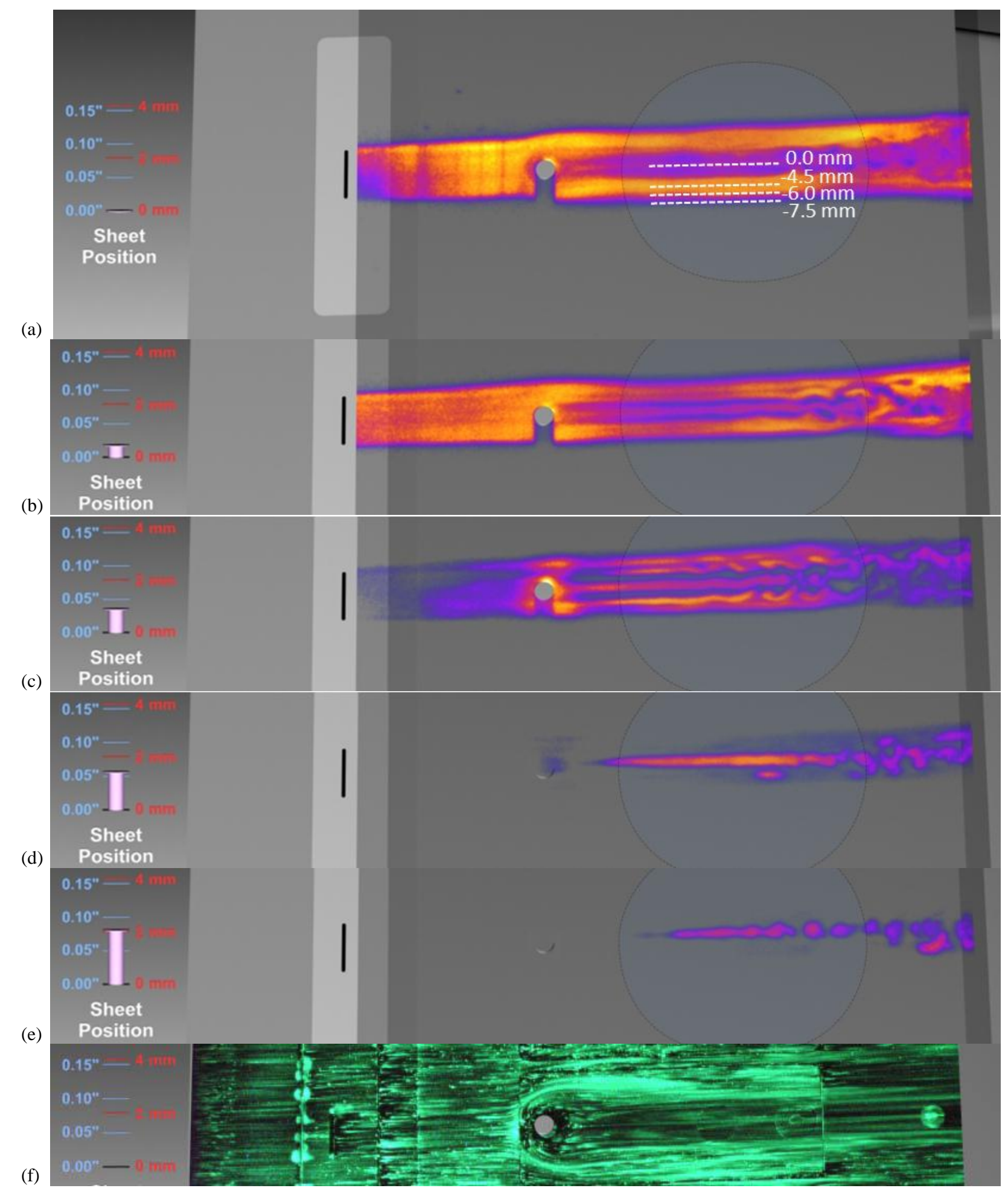

Figure 6. Plan-view flow visualization images for a $1-\mathrm{mm}$ tall by $4-\mathrm{mm}$ wide cylinder, $\mathrm{NO} \dot{m}_{\text {Blowing }}=6.09 \mathrm{mg} / \mathrm{s}, R e_{\infty}=$ $3.3 \times 10^{6} \mathrm{~m}^{-1}$. Laser sheet $(y)$ position varies from (a) 0.0 to (e) $2.0 \mathrm{~mm}$ above the plate surface in $0.5 \mathrm{~mm}$ increments. Approximate locations of MTV measurements are provided in (a). Approximate location of window insert used in MTV runs is shown in (a) through (e). Plan-view oil flow image provided in (f) for the same run conditions. Images taken from Ref. 1. 


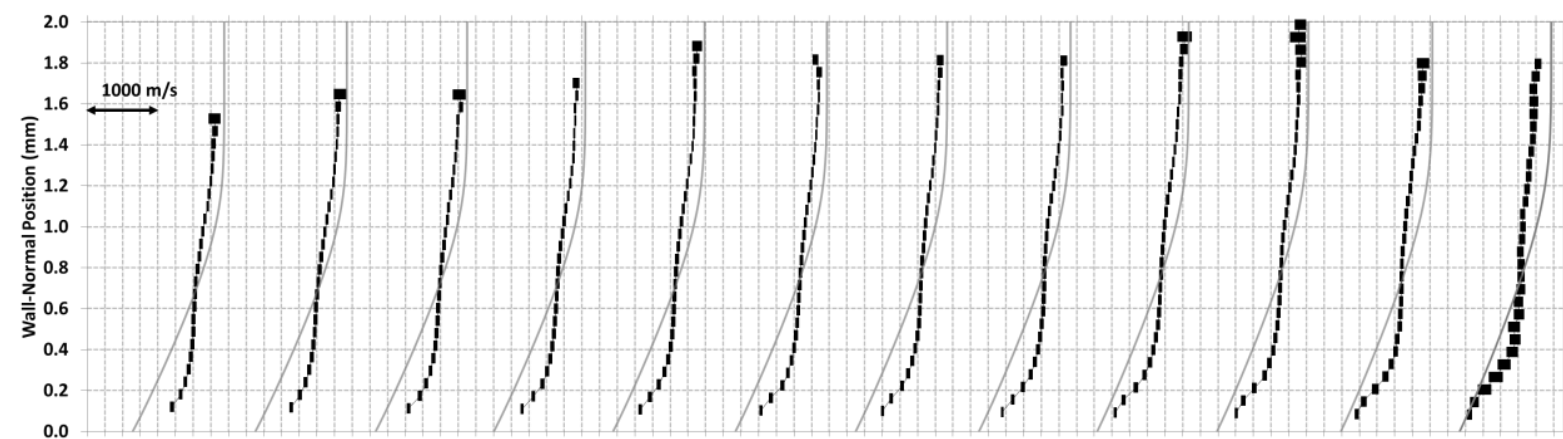

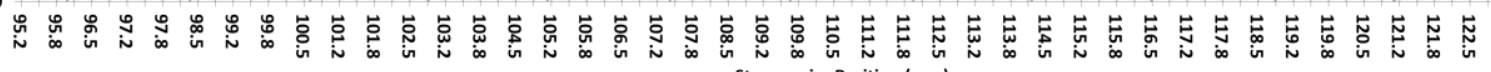

(a)

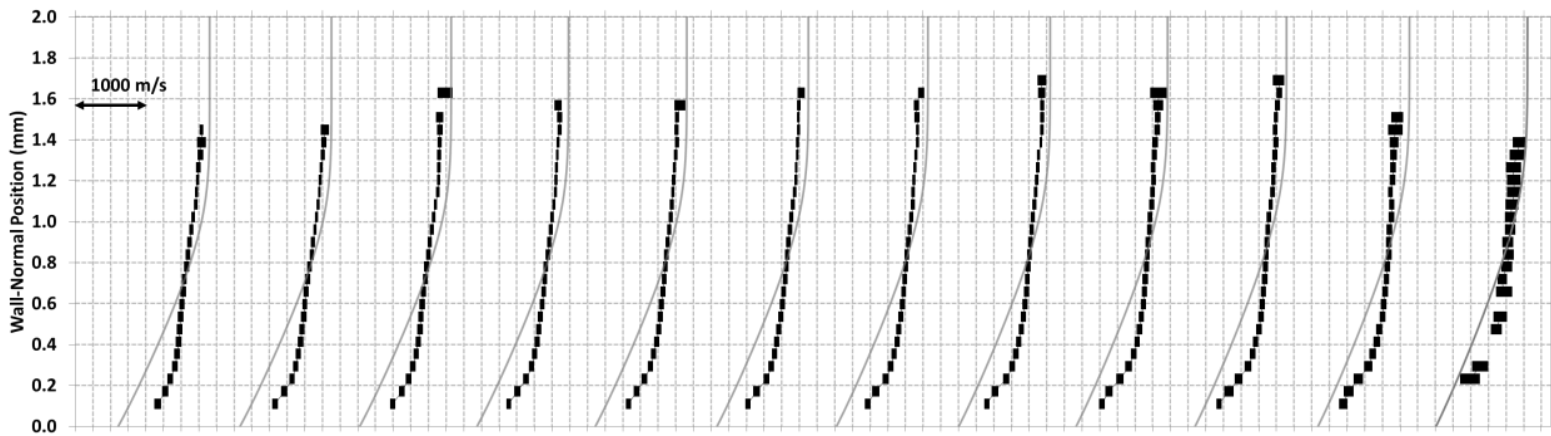

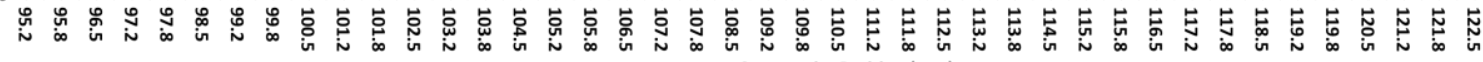

(b)

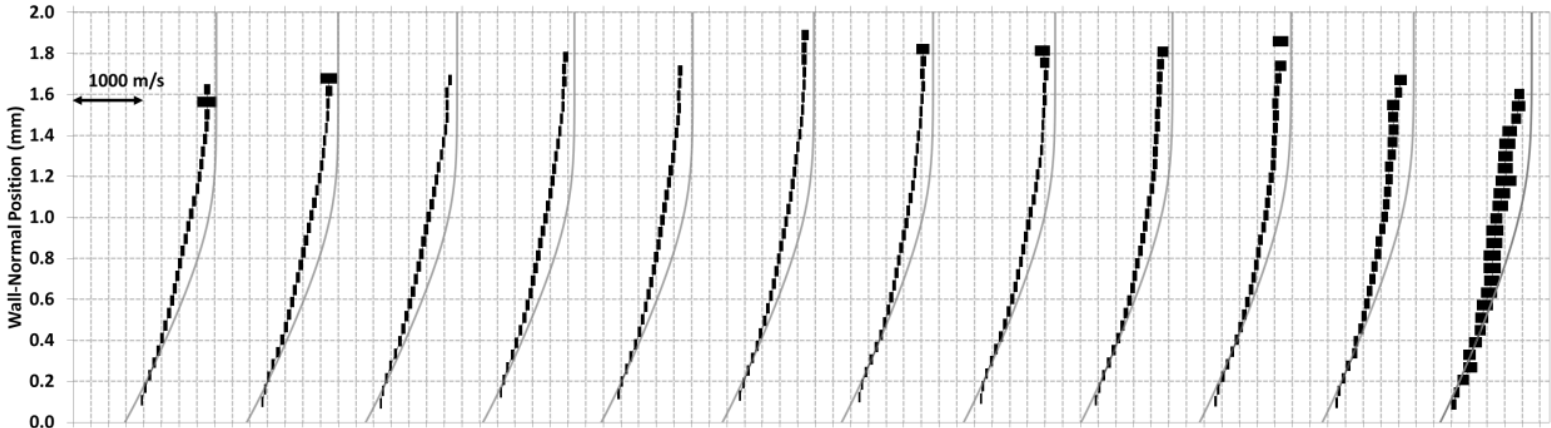

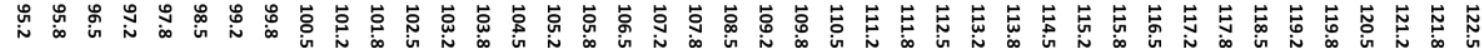

(c)

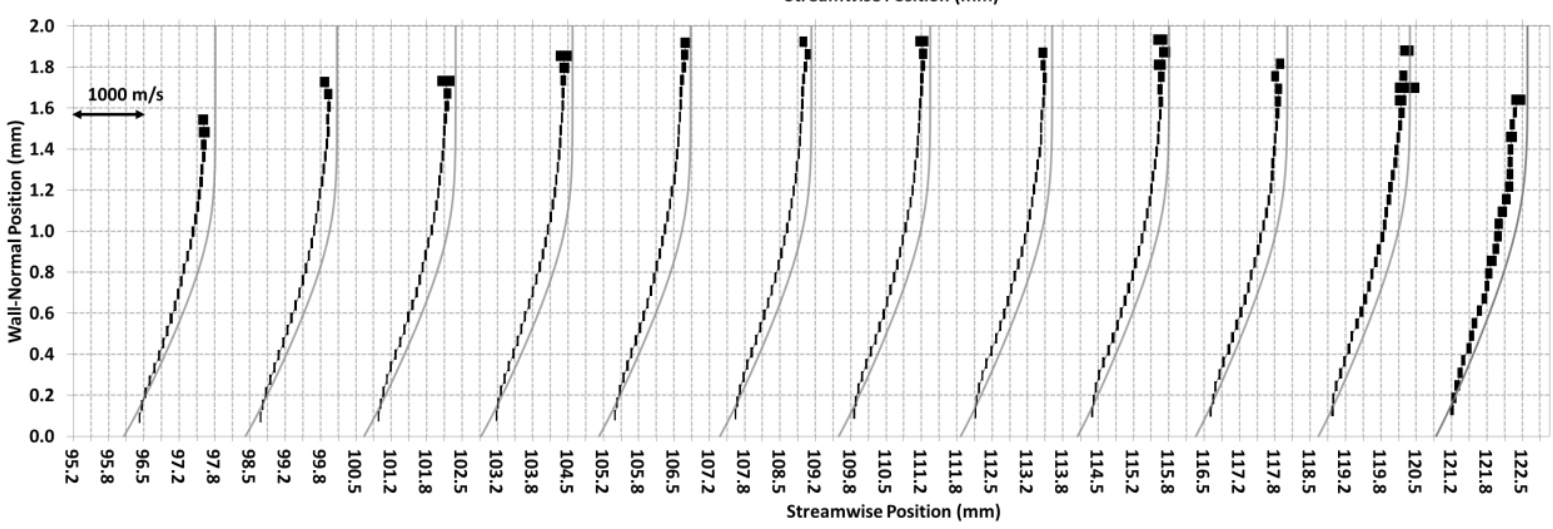

Figure 7. Side-view mean streamwise velocity $(\bar{U})$ profiles for a $1-\mathrm{mm}$ tall by 4 -mm wide cylinder $\left(\operatorname{Run} 14, \operatorname{Re}_{\infty}=3.3 \times 10^{6} \mathrm{~m}^{-1}\right)$ at four spanwise locations: (a) $z=0.0 \mathrm{~mm}, \dot{m}_{\text {Blowing }}=46.6 \mathrm{mg} / \mathrm{s}, k / \delta_{L}=0.86, R e_{k k}=1698$; (b) $z=-4.5 \mathrm{~mm}, \dot{m}_{B l o w i n g}=46.8 \mathrm{mg} / \mathrm{s}, k / \delta_{L}$ $=0.87, R e_{k k}=1798$; (c) $z=-6.0 \mathrm{~mm}, \dot{m}_{\text {Blowing }}=46.7 \mathrm{mg} / \mathrm{s}, k / \delta_{L}=0.88, R e_{k k}=1891 ;$ and $(\mathrm{d}) z=-7.5 \mathrm{~mm}, \dot{m}_{\text {Blowing }}=46.7 \mathrm{mg} / \mathrm{s}$, $k / \delta_{L}=0.90, \operatorname{Re}_{k k}=1999$. 


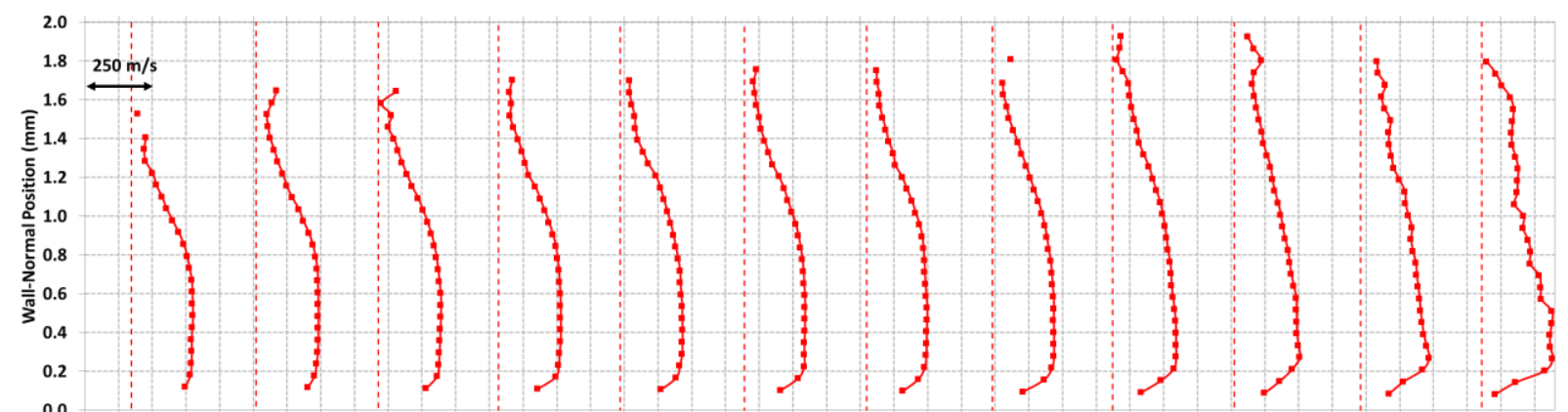

(a)

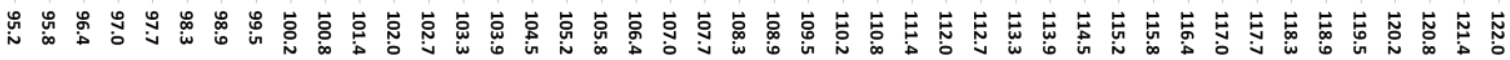

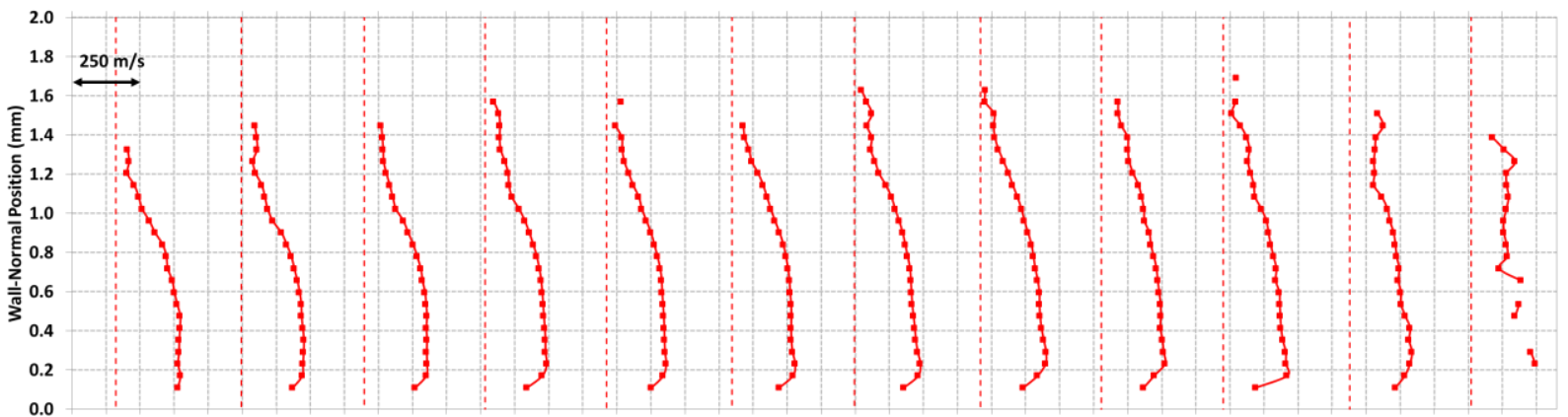

(b)

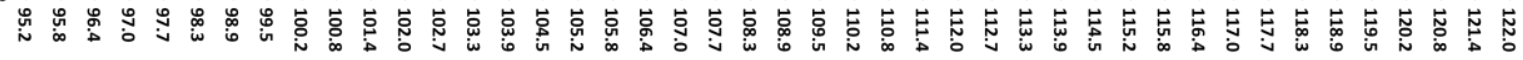

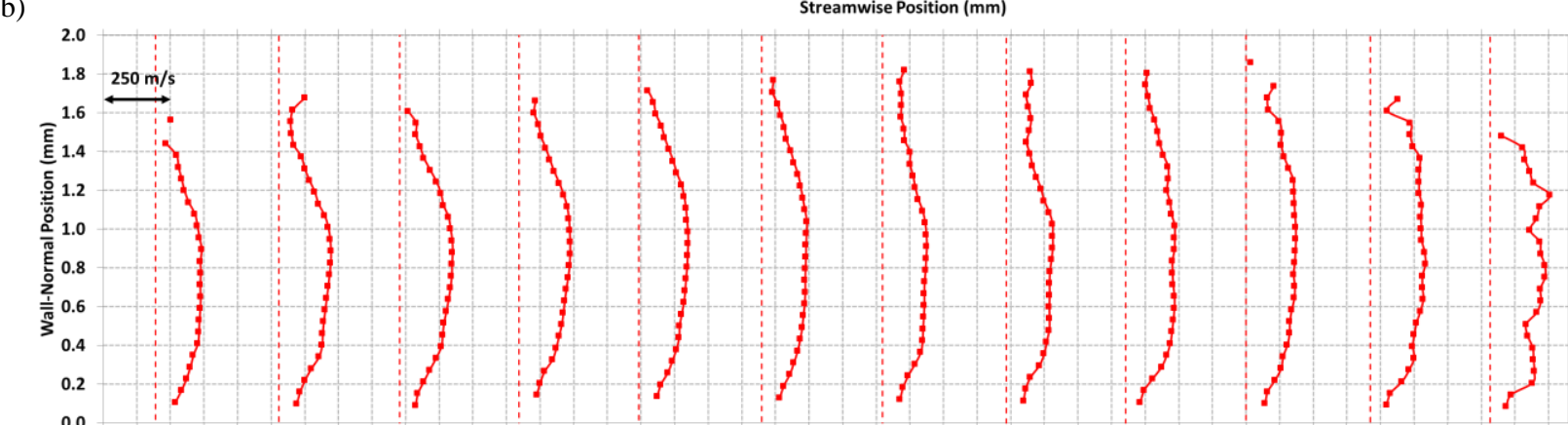

(c)

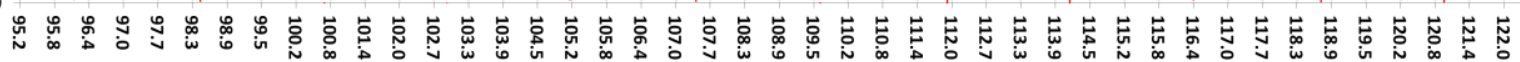

2.0

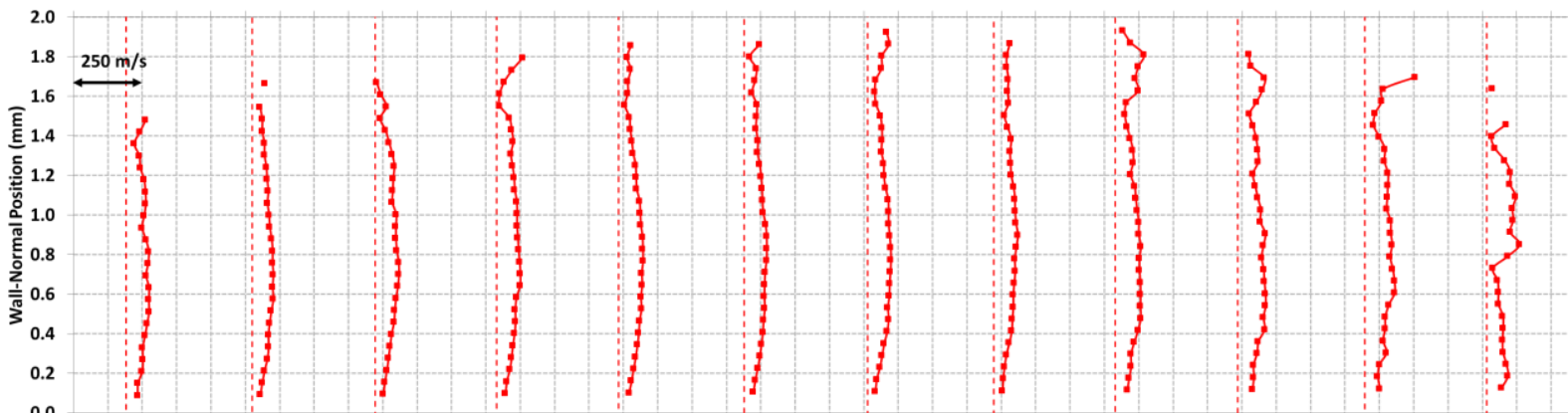

(d)

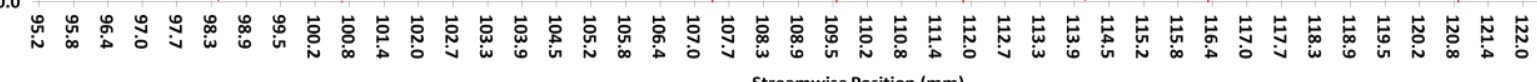

Figure 8. Side-view fluctuating streamwise velocity components $\left(U^{\prime}\right)$ profiles for a $1 \mathrm{~mm}$ tall by $4 \mathrm{~mm}$ wide cylinder (Run 14 , $\operatorname{Re}_{\infty}=3.3 \times 10^{6} \mathrm{~m}^{-1}$ ) at four spanwise locations: (a) $z=0.0 \mathrm{~mm}, \dot{m}_{\text {Blowing }}=46.6 \mathrm{mg} / \mathrm{s}, k / \delta_{L}=0.86, \operatorname{Re}_{k k}=1698$; (b) $z=-4.5 \mathrm{~mm}$, $\dot{m}_{\text {Blowing }}=46.8 \mathrm{mg} / \mathrm{s}, k / \delta_{L}=0.87, R e_{k k}=1798 ;(\mathrm{c}) z=-6.0 \mathrm{~mm}, \dot{m}_{\text {Blowing }}=46.7 \mathrm{mg} / \mathrm{s}, k / \delta_{L}=0.88, R e_{k k}=1891 ;$ and (d) $z=-7.5$ $\mathrm{mm}, \dot{m}_{\text {Blowing }}=46.7 \mathrm{mg} / \mathrm{s}, k / \delta_{L}=0.90, R e_{k k}=1999$. 
Figures 9 (a) - (c) show $\bar{U}$ profiles for trip heights of $k=0.53 \mathrm{~mm}, 1.0 \mathrm{~mm}$ [also shown in Fig. 7(b)], and 2.0 $\mathrm{mm}$, respectively, made at $z=-4.5 \mathrm{~mm}$. This is the same spanwise location at which the secondary streak, shown in Fig. 6(c), that emanated from the horseshoe vortex in front of the trip was observed for the $k=1.0-\mathrm{mm}$ trip. These figures correspond to Runs 16, 14, and 13 in Table 1, all at $R e_{\infty}=3.3 \times 10^{6} \mathrm{~m}^{-1}$.

For the $k=0.53$-mm trip height [Fig. 9(a)], the $\bar{U}$ profiles from left to right initially follow the computed laminar profiles much more closely than do the profiles for $k=1.0 \mathrm{~mm}$ and $2.0 \mathrm{~mm}$. Proceeding downstream, the profiles develop an increased velocity relative to the computed laminar profile below $y=0.8 \mathrm{~mm}$, much like the $k=1.0-\mathrm{mm}$ and $k=2.0-\mathrm{mm}$ cases. As previously noted, this behavior resembles that of a turbulent boundary layer near the wall. The $\bar{U}$ measurements in this case never extend beyond approximately $y=1.5 \mathrm{~mm}$ in the $+y$ direction.

For the $k=2.0-\mathrm{mm}$ trip case in Fig. 9(c), below approximately $y=1.6 \mathrm{~mm}$, the $\bar{U}$ profiles exhibit similar behavior to the $\bar{U}$ profiles measured in the $0.53-\mathrm{mm}$ and $1.0-\mathrm{mm}$ trip case. The profiles located at $x=104.0 \mathrm{~mm}$, $108.6 \mathrm{~mm}$, and $110.8 \mathrm{~mm}$ have several velocity measurements that extended beyond $y=1.6 \mathrm{~mm}$. The standard deviation of the raw delayed single-shot images in Fig. A35 of the appendix shows that these profiles in some instances extended higher above the plate surface than surrounding profiles. The raw single-shot images show that this behavior appears to occur much more frequently for profiles at $z=-5.5 \mathrm{~mm},-6.5 \mathrm{~mm}$, and $-7.5 \mathrm{~mm}$. Of particular interest are the measured $\bar{U}$ values near the upper portion of the profiles. Near the upper extent of these profiles, the measured $\bar{U}$ values are approximately equal to the estimated edge velocity, $U_{e}$. While the measurements of $\bar{U}=U_{e}$ near the upper edge of the boundary layers in this paper may be a result of flow distortion caused by the tripping element, this result appears to confirm that the edge velocity estimate using values from Table 2 is reasonable.

For comparison, Fig. 10 provides plan-view time-resolved flow visualization images for the $k=2$-mm trip case from Ref. 1, all taken with the laser sheet at $y=1.1 \mathrm{~mm}$. The time separation between the images shown is $1 \mu \mathrm{s}$. Figure 10(a) also shows the approximate location of the quartz window insert and MTV measurement region (denoted by the rectangle). When compared with the $k=1.0 \mathrm{~mm}$ flow visualization at approximately the same $y$ location $[y=1.0 \mathrm{~mm}$, Fig. 6(c)], two different features are observed. First, it appears that the gas seeded into the boundary layer is deflected by a greater distance in the spanwise direction for the $k=2.0-\mathrm{mm}$ trip case than in the $k$ $=1.0-\mathrm{mm}$ trip case. This is a result of the $2.0-\mathrm{mm}$ trip creating a larger flow blockage relative to the $1.0-\mathrm{mm}$ trip. Second, three distinct streamwise streaks are observed about the measurement region for the $k=2.0-\mathrm{mm}$ trip case. In the $k=1.0-\mathrm{mm}$ trip case, only two streaks were observed about the measurement region at this $y$ location.

Figures 11(a) - (c) show three $U^{\prime}$ profile measurements made at $z=-4.5 \mathrm{~mm}$ for trip heights of $k=0.53 \mathrm{~mm}, k=$ $1.0 \mathrm{~mm}$ [also shown in Fig. 8(b)], and $k=2.0 \mathrm{~mm}$, respectively. In Fig. 11(a), a peak in $U^{\prime}$ for $k=0.53 \mathrm{~mm}$ is apparent at approximately $y=0.2 \mathrm{~mm}$ to $0.4 \mathrm{~mm}$ for most of the profiles. All of the profiles in the $k=0.53$-mm case tend towards $U^{\prime}=0$ when moving in the $+y$ direction; that is, fluctuations are larger near the wall and decrease moving toward the upper edge of the boundary layer. For $k=1.0 \mathrm{~mm}$ in Fig. 11(b), the $U$ ' peak is broader, peaking at about the same location as the $\mathrm{k}=0.53$ case but extending farther out into the boundary layer. It should be noted that the measurements for $k=0.53 \mathrm{~mm}$ were acquired with $\Delta t_{P R O B E}=2 \mu \mathrm{s}$, while the measurements for $k=1.0 \mathrm{~mm}$ and $2.0 \mathrm{~mm}$ were acquired with $\triangle t_{P R O B E}=1 \mu \mathrm{s}$.

Nearly all of the profiles for the $k=2.0-\mathrm{mm}$ trip case in Fig. 11(c) have an identifiable $U^{\prime}$ peak occurring at approximately $y=0.2 \mathrm{~mm}$. For the profile at $x=110.8 \mathrm{~mm}$, the $U^{\prime}$ profile appears to have a secondary local maximum at approximately $y=2.0 \mathrm{~mm}$, although not as pronounced as that observed near the wall. The raw singleshot images for the $k=2.0$-mm trip case (Fig. A35) also exhibit a greater degree of variability between neighboring profiles in terms of both wall-normal and streamwise distortions. The flow visualization images for $k=2.0 \mathrm{~mm}$ in Fig. 10 show that, over the extent of the measurement region, the streamwise streaks appear to be breaking down.

Figures $12(\mathrm{a})-(\mathrm{d})$ show a comparison between $\bar{U}$ profiles obtained along the centerline $(z=0.0 \mathrm{~mm})$ of the model for no trip at $R e_{\infty}=3.3 \times 10^{6} \mathrm{~m}^{-1}$ [also shown in Fig. 5(a)], for the $k=0.53$-mm trip at $R e_{\infty}=2.4 \times 10^{6} \mathrm{~m}^{-1}$, for the $k=0.53$-mm trip at $R e_{\infty}=3.3 \times 10^{6} \mathrm{~m}^{-1}$, and for the $k=1.0-\mathrm{mm}$ trip at $R e_{\infty}=3.3 \times 10^{6} \mathrm{~m}^{-1}$, respectively. No profiles were obtained along the centerline for the $k=2.0-\mathrm{mm}$ trip, since little seeded gas convects into the centerline wake region for this case, as shown in Fig. 10.

For the $k=0.53-\mathrm{mm}$ trip cases with differing Reynolds numbers, qualitatively similar $\bar{U}$ behavior is observed. In both cases, an increased velocity relative to the computed laminar profile is observed up to approximately $y=1.0$ $\mathrm{mm}$ to $1.2 \mathrm{~mm}$. At this approximate position, all of the measured $\bar{U}$ profiles cross the computed laminar profile. However, the maximum velocity relative to the computed laminar profile for the higher $R e_{\infty}=3.3 \times 10^{6} \mathrm{~m}^{-1}$ case [Fig. $12(\mathrm{c})$ ] is relatively greater than that observed for the lower $R e_{\infty}=2.4 \times 10^{6} \mathrm{~m}^{-1}$ case [Fig. 12(b)]. Above $y=1.0 \mathrm{~mm}$ to $1.2 \mathrm{~mm}$, nearly all of the profiles exhibit a velocity deficit relative to the computed laminar profile. 
An interesting feature of the $\bar{U}$ profiles for the $k=1.0-\mathrm{mm}$ trip case in Fig. 12(d) is the existence of two inflection points in all of the profiles. These are not observed in the $k=0.53-\mathrm{mm}$ trip cases. The primary inflection point occurs at approximately the same location at which the measured $\bar{U}$ profiles cross the computed laminar profiles. A secondary inflection point occurs between $y=1.0 \mathrm{~mm}-2.0 \mathrm{~mm}$ with the position increasing in height with distance downstream. These inflection points are highlighted by red arrows for the profile at $x=102.8 \mathrm{~mm}$ in Fig. 12(d). This behavior is also observed, albeit intermittently, in some of the raw single-shot images presented in Fig. A20. Comparing the qualitative trends of these inflection points with those presented in Ref. 15, the secondary inflection point is possibly inviscidly unstable whereas the primary inflection point is unconditionally stable. These trends are also observed on profiles at other locations and conditions [such as in Fig. 9(c)].

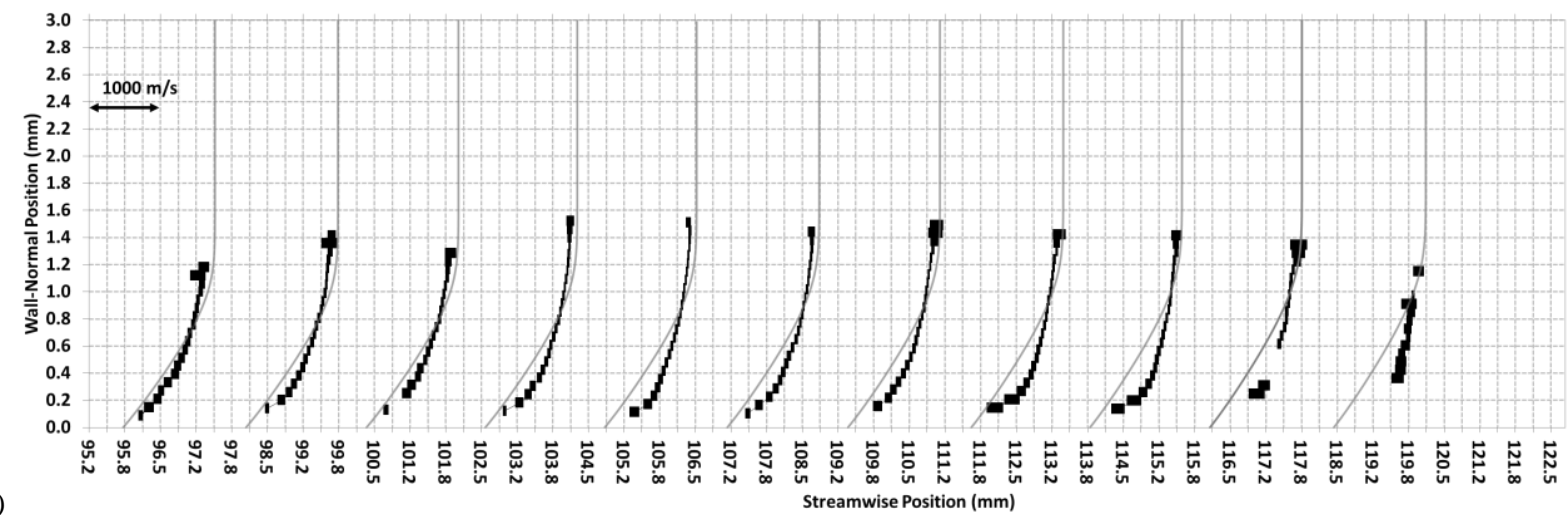

(a)

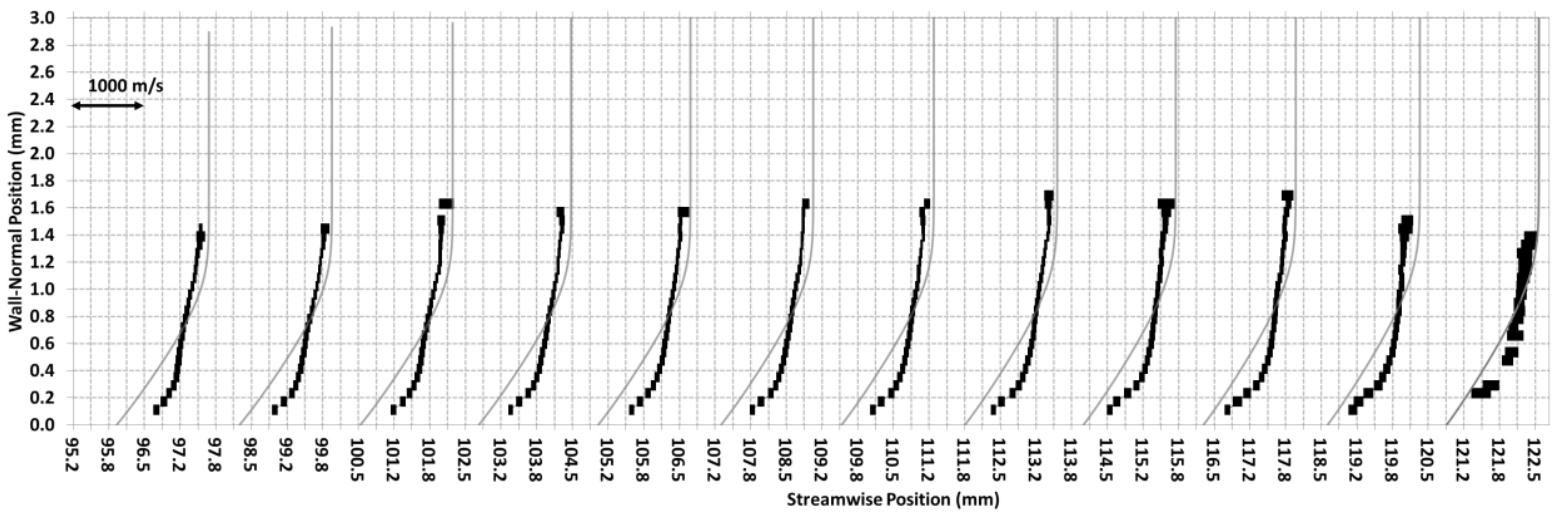

(b)

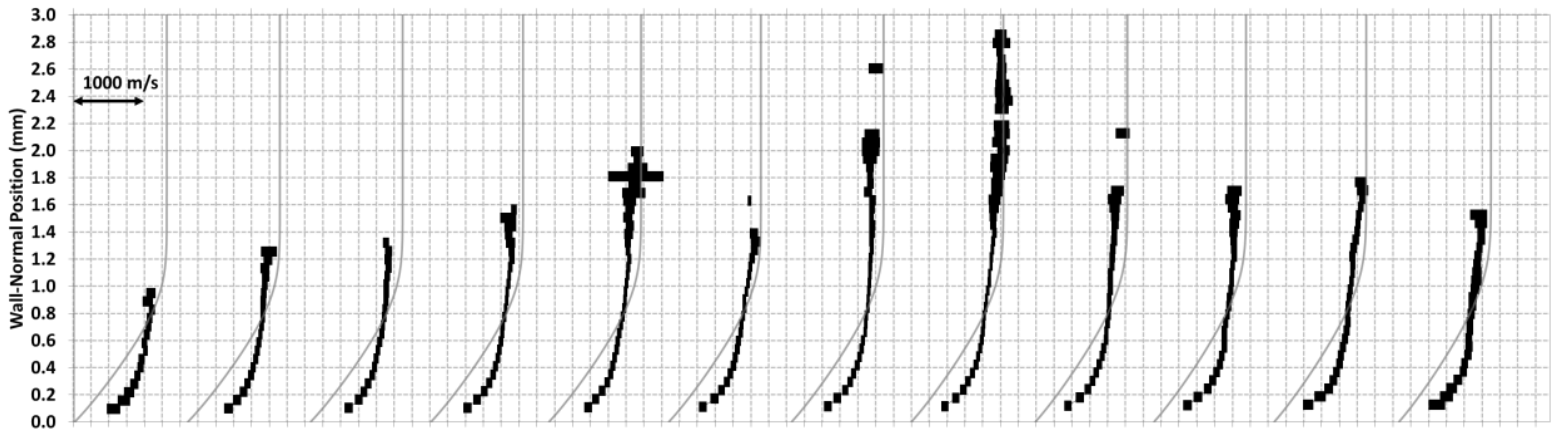

(c)

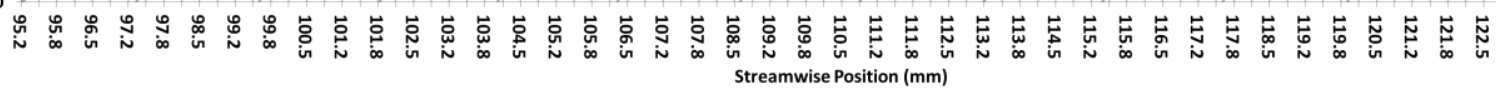

Figure 9. Side-view mean streamwise velocity $(\bar{U})$ profiles at $z=-4.5 \mathrm{~mm}$ : (a) Run 16 with $k=0.53$-mm trip, $k / \delta_{L}=0.47, R e_{k k}=$ 420; (b) Run 14 with $k=1.0$-mm trip, $k / \delta_{L}=0.87, R e_{k k}=1798$; and (c) Run 13 with $k=2.0$-mm trip, $k / \delta_{L}=1.86, R e_{k k}=5296 . R e_{\infty}=$ $3.3 \times 10^{6} \mathrm{~m}^{-1}$ for all runs. 

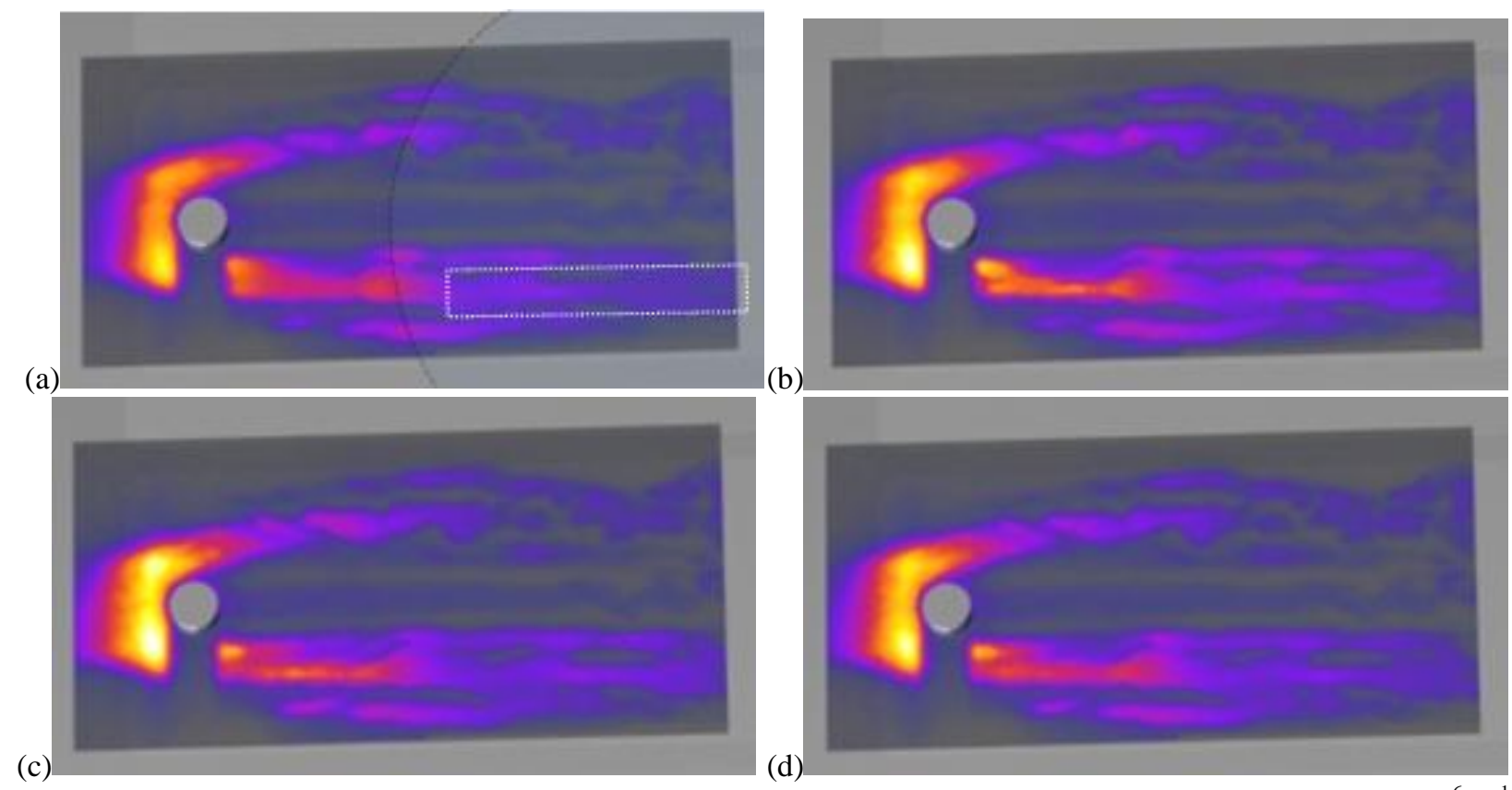

Figure 10. Plan-view flow visualization movie sequence for a $k=2 \mathrm{~mm}$ tall trip, NO $\dot{m}_{\text {Blowing }}=6.09 \mathrm{mg} / \mathrm{s}, R e_{\infty}=3.3 \times 10^{6} \mathrm{~m}^{-1}$. Laser sheet $1.1 \mathrm{~mm}$ above plate surface. MTV measurement region shown in (a). Images taken from Ref. 1.

Figures 13(a) - (d) show the centerline $(z=0.0 \mathrm{~mm}) U^{\prime}$ profiles corresponding to the same flow conditions as those presented in Figs. 12(a) - (d), respectively. The $U^{\prime}$ profiles for the $k=0.53-\mathrm{mm}$ trip case at $R e_{\infty}=2.4 \times 10^{6} \mathrm{~m}^{-1}$ [Fig. 13(b)] show a magnitude peak between $y=0.3 \mathrm{~mm}$ to $0.4 \mathrm{~mm}$, both closer to the surface and greater in magnitude than the peak fluctuations of the no-trip case in Fig. 13(a). At $R e_{\infty}=3.3 \times 10^{6} \mathrm{~m}^{-1}$ for the same trip height [Fig. 13(c)], the $U^{\prime}$ profiles exhibit peaks closer to the wall, ranging between $y=0.1 \mathrm{~mm}$ to $0.3 \mathrm{~mm}$. The peaks in Fig. 13(c) are less rounded than those at the lower $R e_{\infty}$ condition of Fig. 13(b). The magnitudes of the peaks are also, in general, greater than those observed at the lower $R e_{\infty}$ condition. Again, the $U^{\prime}$ profiles observed for the $k=1.0-$ mm case [Fig. 13(d)] are broader and extend farther out into the flow than the shorter trip cases.

\section{Discussion}

A possible reason was investigated for the fullness of the $\bar{U}$ profiles in some of the measurements presented in this paper, as mentioned in section III. Figure 14 shows a $\bar{U}$ profile measured at $z=-7.5 \mathrm{~mm}$ and $x=113.3 \mathrm{~mm}$ for the $k$ $=2.0-\mathrm{mm}$ trip case taken from Fig. A43(a). The profile is similar to the profile shown in Fig. 9(c) at $x=110.8 \mathrm{~mm}$, but was chosen because it was a particularly tall profile, with data points acquired nearly $4.8 \mathrm{~mm}$ above the plate surface. A laminar boundary layer profile computed at the same flow conditions and location is denoted by the solid gray line. For comparison, a turbulent profile was also computed using the Virginia Tech Compressible Turbulent Boundary Layer (CTBL) solver. ${ }^{\S \S}$ This profile is denoted by the dashed orange line. The horizontal solid red line denotes the laminar velocity boundary layer thickness $\left(\delta_{L}\right)$ at this $x$ location if no trip were present. For this calculation, the streamwise origin of the turbulent profile was set to be equal to the trip location, $x_{T}=75.4 \mathrm{~mm}$. While this comparison is meant to be qualitative in nature, a few interesting features associated with the measured $\bar{U}$ profile are observed. Near the wall, the $\bar{U}$ profile appears to closely follow the trend of the turbulent boundary layer profile. At approximately $y=0.2 \mathrm{~mm}$, the magnitude of the slope of $\bar{U}(d \bar{U} / d y)$ trends away from that of the computed turbulent profile. At $y=0.9 \mathrm{~mm}$, the measured $\bar{U}$ crosses the computed laminar profile. At approximately $y=\delta_{L}$, the magnitude of $d \bar{U} / d y$ is approximately zero. This behavior for $y \leq \delta_{L}$ appears to be indicative of the transition process. Between approximately $y=\delta_{L}$ and $y=2 \delta_{L}$, the measured $\bar{U}$ profile has a nearly constant velocity of $1100 \mathrm{~m} / \mathrm{s}$. This deficit relative to the laminar solution is likely a consequence of the wake of the tripping element. Above approximately $y=2 \delta_{L}, \bar{U}$ linearly approaches the edge velocity until approximately $y=4.6 \mathrm{~mm}$ where the computed edge velocity is measured experimentally.

\footnotetext{
${ }^{\S \S}$ Software available at http://www.engapplets.vt.edu/fluids/bls2/ [accessed December 1, 2012]
} 
The centerline $\bar{U}$ profiles in the wake of a cylindrical tripping element such as in Fig. 12(b) - (d) also exhibit augmented velocity near the wall. This is opposed to data acquired at lower Reynolds numbers but similar $k / \delta_{L}$ values, such as the measurements of $\bar{U}$ in Ref. 16, Fig. 1(c). In that paper, the profiles downstream of the trip appear to recover back to a laminar shape at downstream locations. Also in Ref. 16, the $\bar{U}$ profiles in Fig. 1(c) between the region immediately behind the tripping element at $x=81 \mathrm{~mm}$ and approximately $x=120 \mathrm{~mm}$ exhibit two inflection points similar to those shown in Fig. 12(d) in this paper, suggesting that the development of these inflection points is a laminar effect, unrelated to transition-to-turbulence. It should be noted that the measurements in Fig. 1(c) of Ref. 16 were acquired at different $\dot{m}_{\text {Blowing }}, M_{e}$, and $R e_{\infty}$ conditions. However, the measurements in this paper and in Ref. 16 provide the opportunity to make comparisons between $\bar{U}$ profile behaviors at several flow conditions and relate observations to either the laminar or transition-to-turbulence behavior of those profiles.

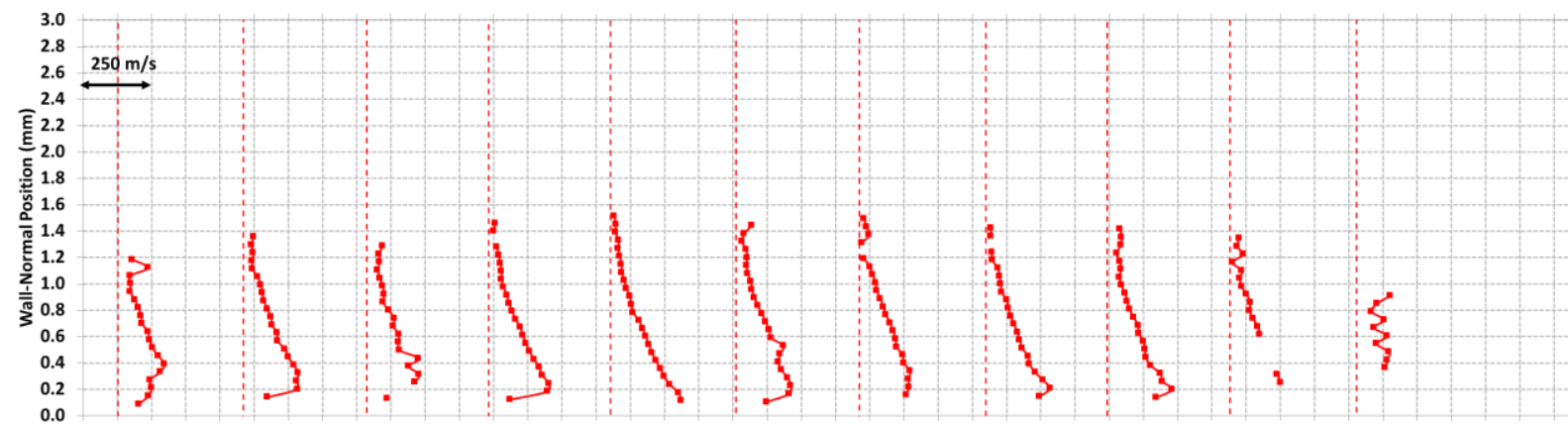

(a)
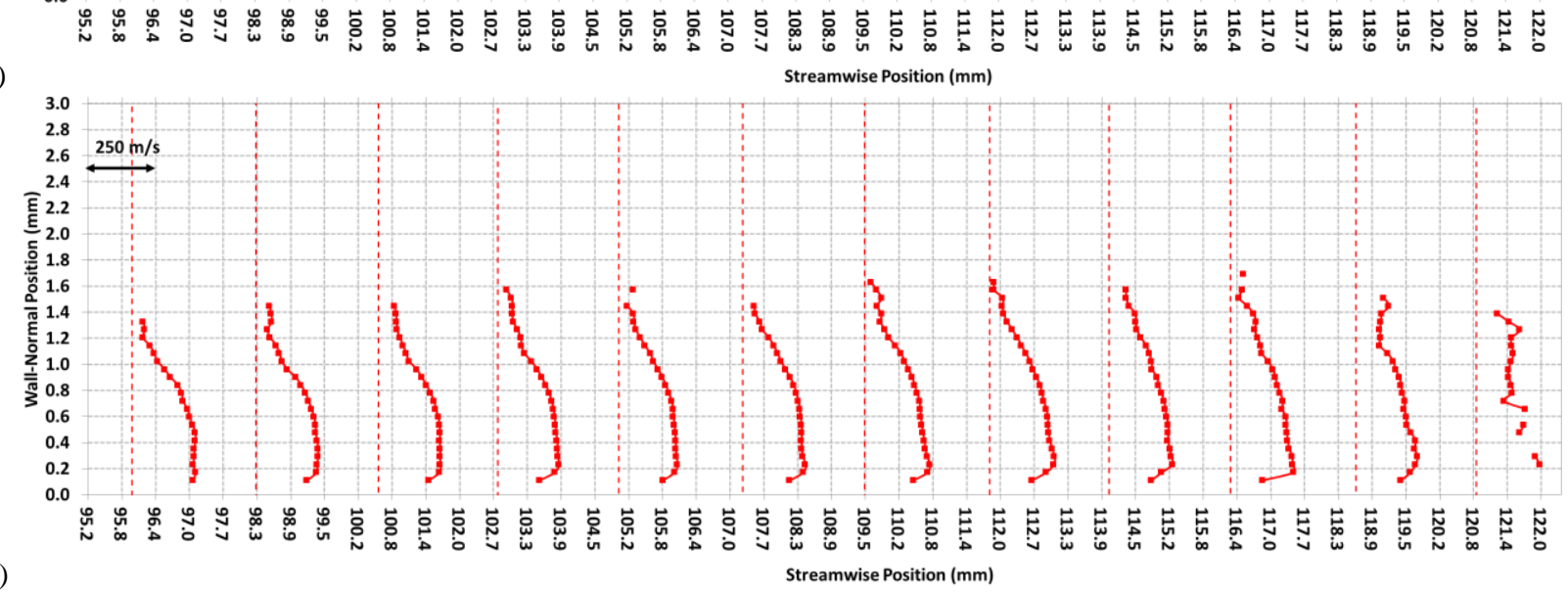

(b)

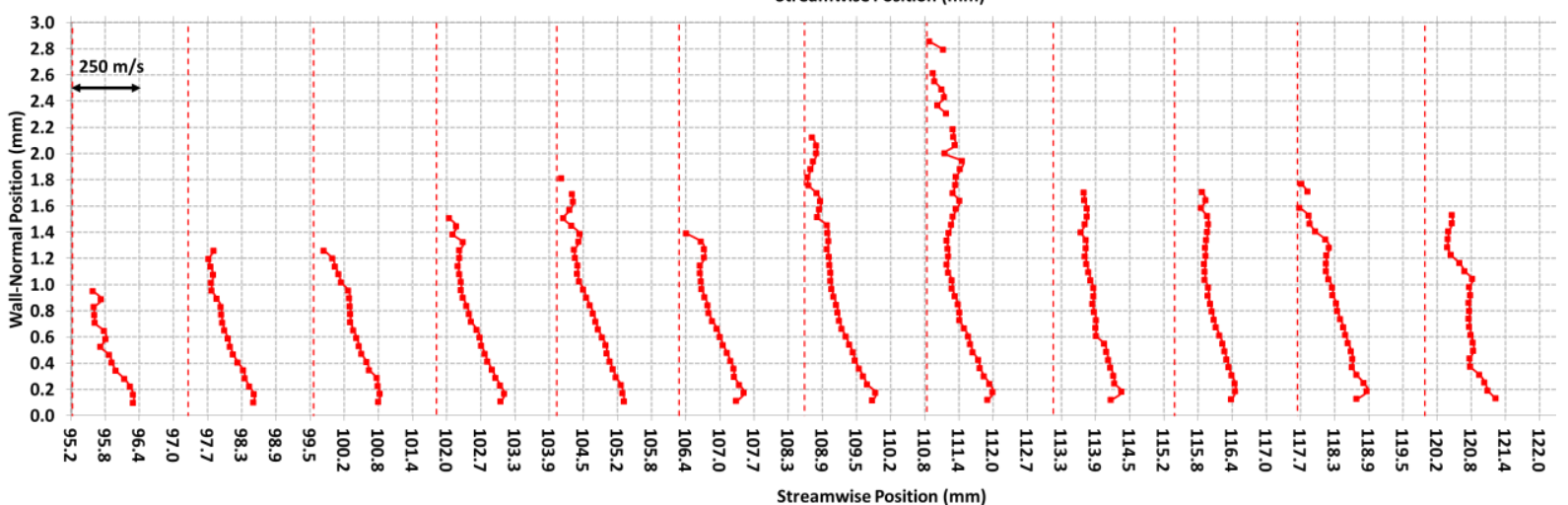

Figure 11. Side-view streamwise fluctuating velocity $\left(U^{\prime}\right)$ profiles at $z=-4.5 \mathrm{~mm}$ : (a) Run 16 with $k=0.53-\mathrm{mm}$ trip, $k / \delta_{L}=0.47$, $R e_{k k}=420$; (b) Run 14 with $k=1.0$-mm trip, $k / \delta_{L}=0.87, R e_{k k}=1798$; and (c) Run 13 with $k=2.0$-mm trip, $k / \delta_{L}=1.86, R e_{k k}=$ 5296. $R e_{\infty}=3.3 \times 10^{6} \mathrm{~m}^{-1}$ for all runs. 


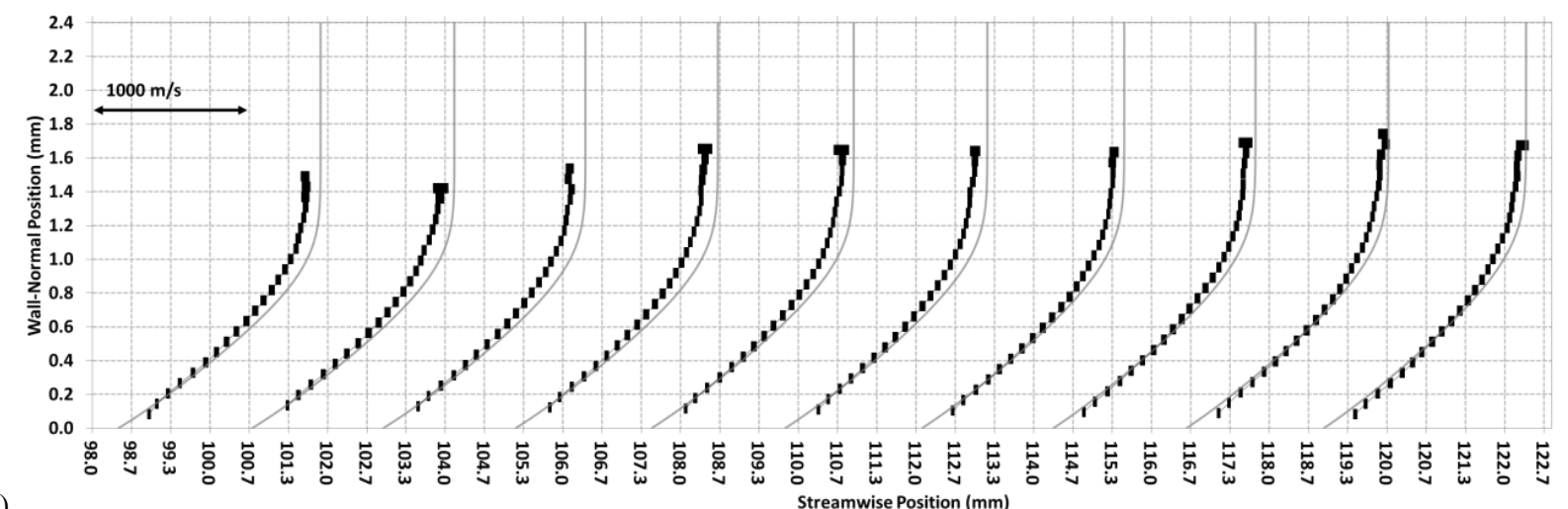

(a)

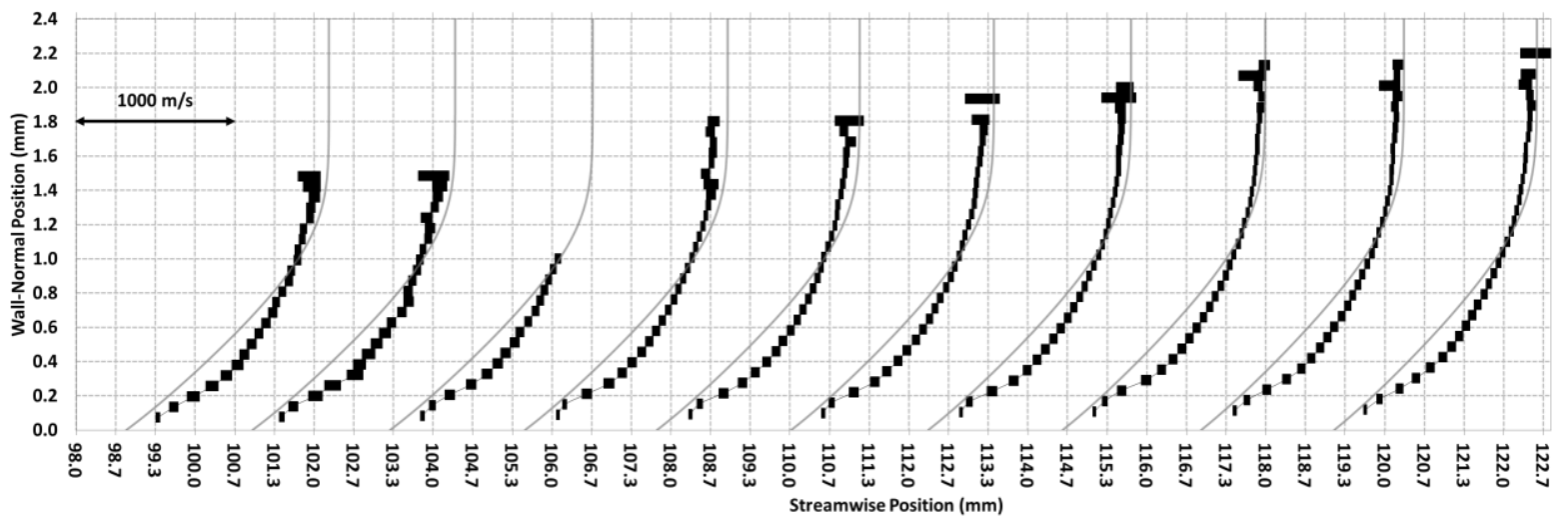

(b)

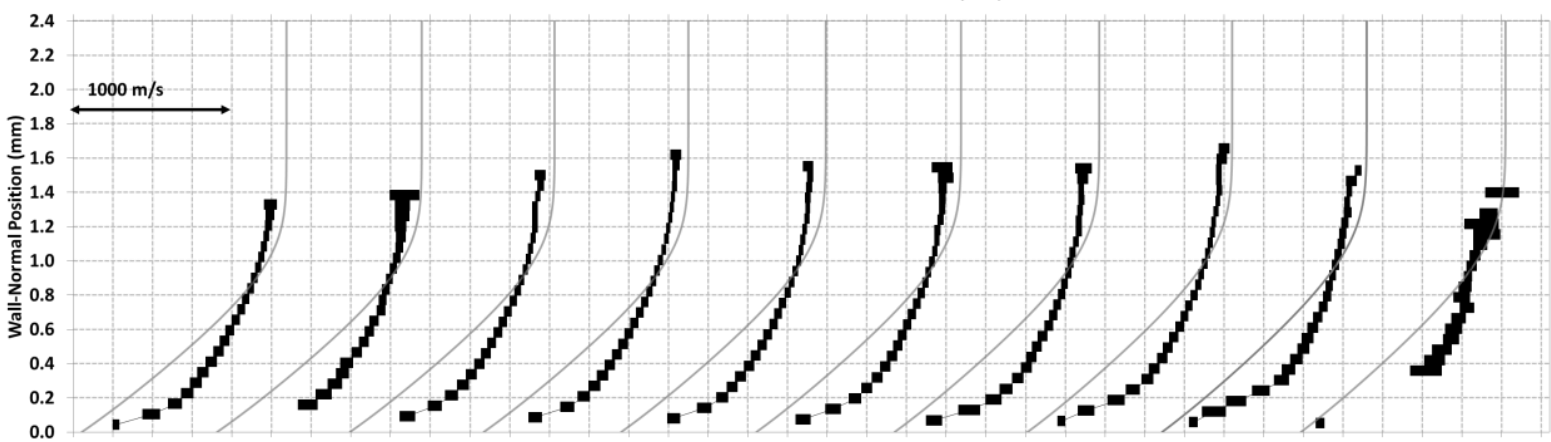

(c)

\&

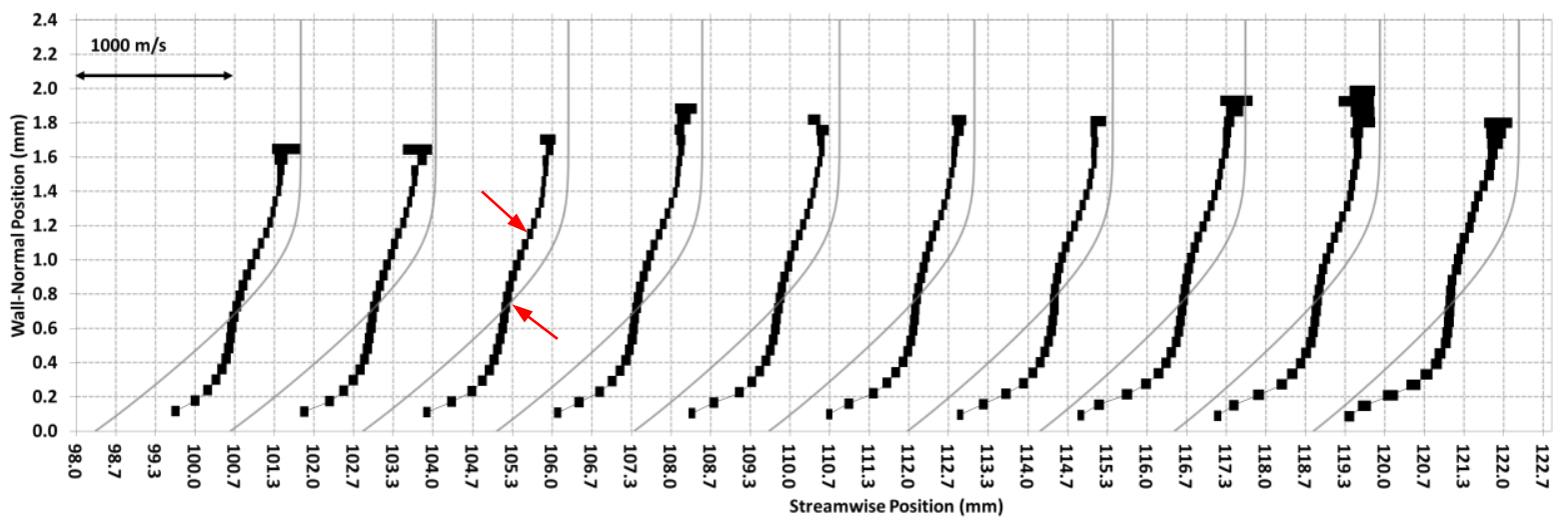

Figure 12. Side-view mean streamwise velocity $(\bar{U})$ profiles at $z=0.0 \mathrm{~mm}$ (centerline): (a) Run 12 with no trip; (b) Run 30 with $k=0.53$-mm trip, $k / \delta_{L}=0.41, R e_{k k}=293$; (c) Run 16 with $k=0.53$-mm trip, $k / \delta_{L}=0.47, R e_{k k}=393$; and (d) Run 14 with $k=1.0-$ mm trip, $k / \delta_{L}=0.86, R e_{k k}=1698$. Red arrows in (d) denote examples of inflection points. 


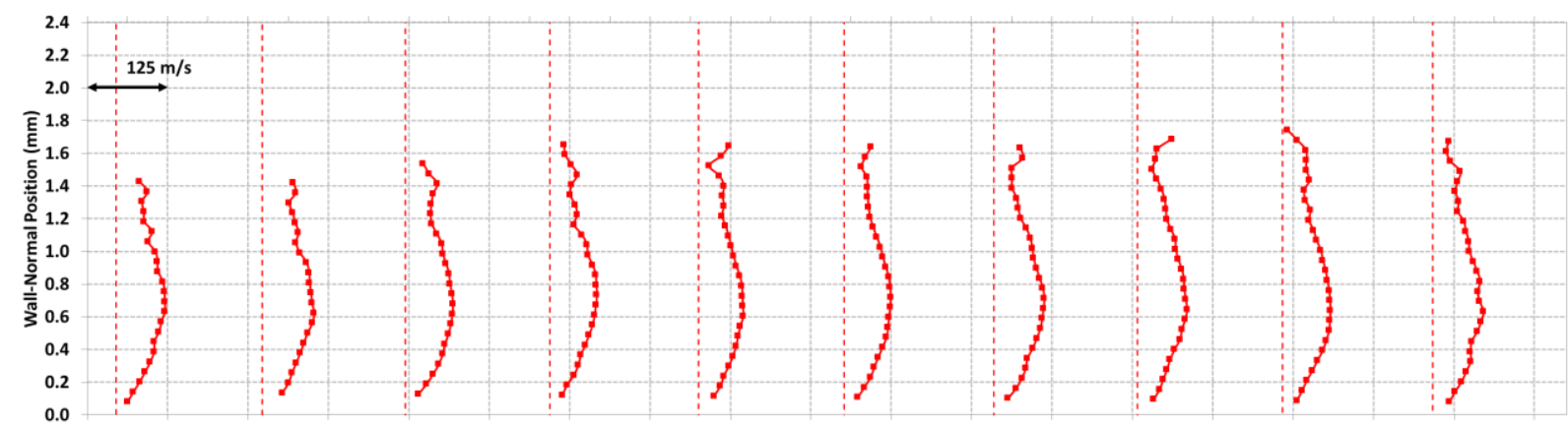

(a)
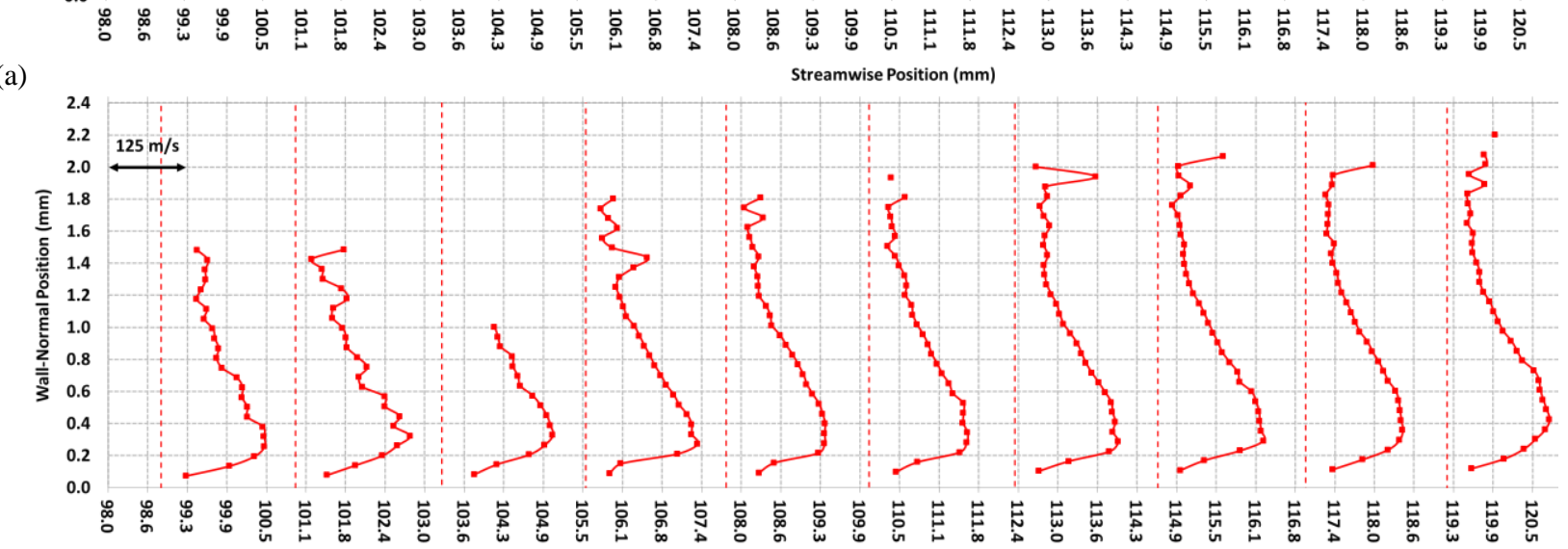

(b)

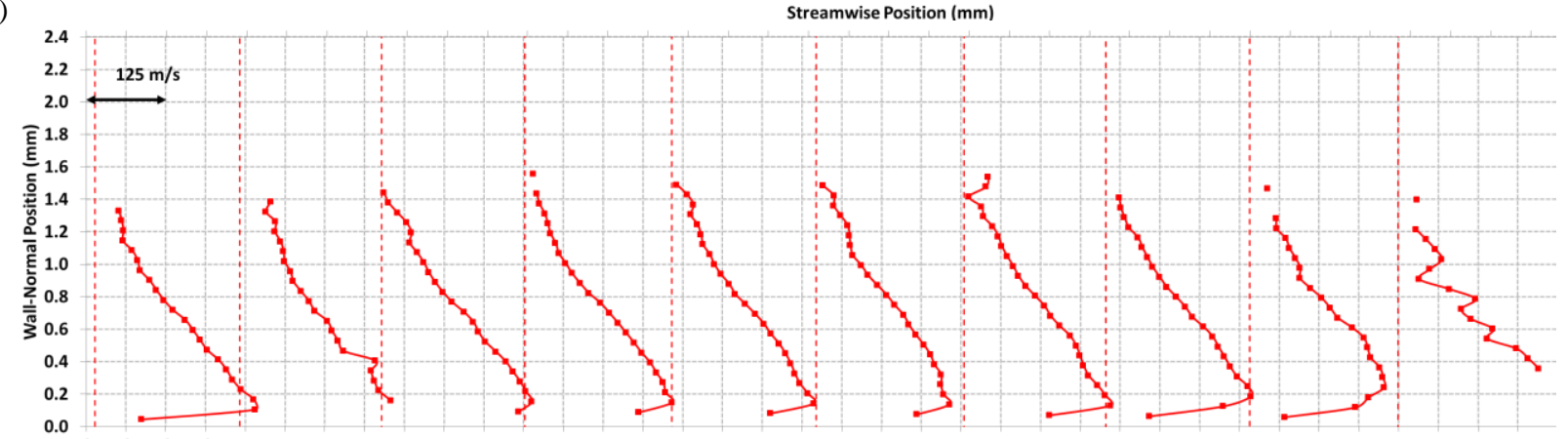

(c)

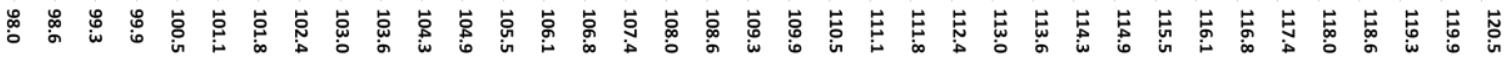

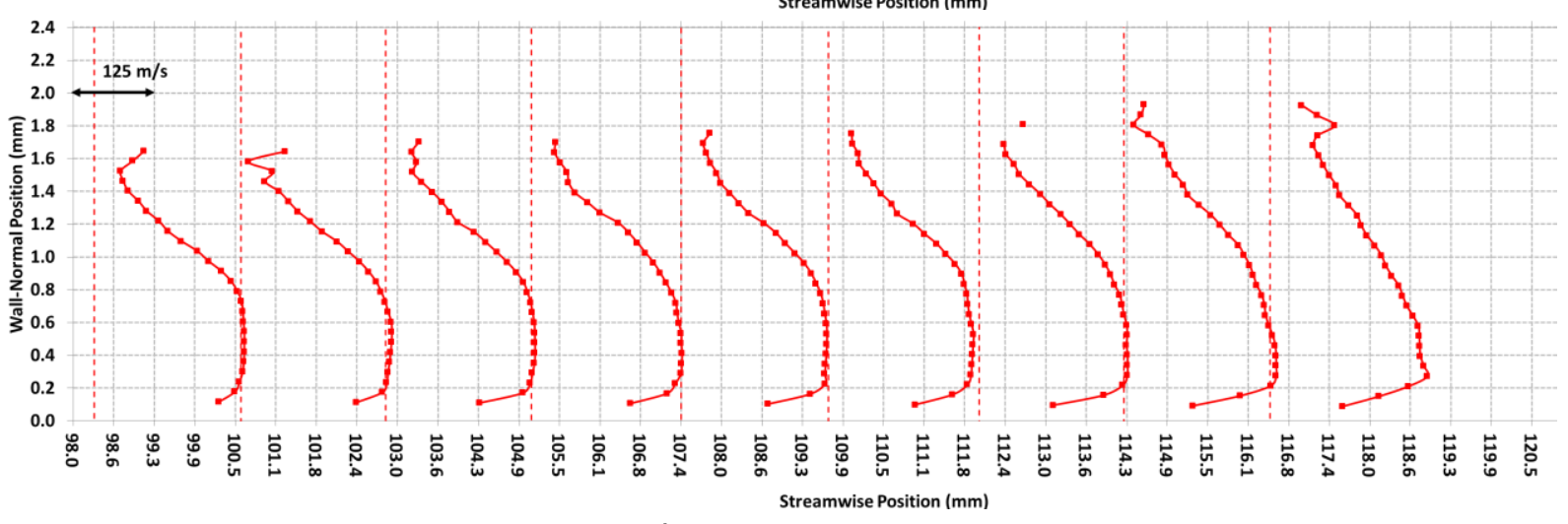

Figure 13. Side-view streamwise fluctuating velocity $\left(U^{\prime}\right)$ profiles at $z=0.0 \mathrm{~mm}$ (centerline): (a) Run 12 with no trip; (b) Run 30 with $k=0.53$-mm trip, $k / \delta_{L}=0.41, R e_{k k}=293$; (c) Run 16 with $k=0.53-\mathrm{mm}$ trip, $k / \delta_{L}=0.47, R_{k k}=393$; and (d) Run 14 with $k=$ 1.0-mm trip, $k / \delta_{L}=0.86, \operatorname{Re}_{k k}=1698$. 


\section{Conclusions}

This paper presents velocity data acquired in a hypersonic boundary layer undergoing laminar-to-turbulent transition. An $\mathrm{NO}_{2}$-to-NO photolysis molecular tagging velocimetry technique was used to make the measurements. The measurements were made in the wake of a cylindrical tripping element at several streamwise and spanwise locations. Three different trip heights were tested, $k=0.53 \mathrm{~mm}, 1.0 \mathrm{~mm}$, and $2.0 \mathrm{~mm}$. An analysis of the mean streamwise velocity $(\bar{U})$, fluctuating component of streamwise velocity $\left(U^{\prime}\right)$, and instantaneous streamwise velocity profiles was performed, relating the features of these profiles to the trip heights and Reynolds numbers tested. A comparison of the tripped profile data with both computed and measured no-trip laminar velocity profiles was also presented. Analysis showed that along the centerline of the model, the maximum measured fluctuating velocity component increased from approximately $\pm 75 \mathrm{~m} / \mathrm{s}$ in the no-trip case to $\pm 225 \mathrm{~m} / \mathrm{s}$ with a 0.53 - $\mathrm{mm}$ trip, and to $\pm 240 \mathrm{~m} / \mathrm{s}$ with a 1 - $\mathrm{mm}$ trip. Near the wall, some of the mean velocity profiles in the tripped flow cases also exhibited regions of increased velocity relative to the laminar boundary layer measurements and computations. The corresponding profiles of the fluctuating component of streamwise velocity exhibited increased magnitudes (i.e. stronger fluctuations) relative to the laminar boundary layer profile measurements. A measured mean velocity profile exhibiting relatively high velocity near the wall was compared with computed laminar and turbulent velocity profiles. Based on the analysis of these profiles and the comparison with the computed profiles, this increased velocity region relative to the laminar boundary layer measurements and computations was determined likely to be indicative of transition-to-turbulence.

\section{Acknowledgements}

We wish to acknowledge the contribution to this project from the NASA Langley Research Center 31-Inch Mach 10 Air Tunnel technicians and engineers, including Kevin Hollingsworth, Sheila Wright, Tony Robbins, Henry Fitzgerald, Johnny Ellis, Stan Mason, Doug Boggs, and Tim Berry. In addition, we would like to acknowledge Andrew Lutz of the University of Vermont, who assisted in the setup of the experiment. Dr. Johansen was supported by the Natural Sciences and Engineering Research Council of Canada (NSERC).

\section{References}

${ }^{1}$ Danehy, P.M., Ivey, C.B., Inman, J.A., Bathel, B.F., Jones, S.B., McCrea, A.C., Jiang, N., Webster, M., Lempert, W., Miller, J., and Meyer, T., "High-Speed PLIF Imaging of Hypersonic Transition over Discrete Cylindrical Roughness," AIAA Paper 2010-703, $48^{\text {th }}$ AIAA Aerospace Sciences Meeting, January $4-7,2010$, Orlando, FL.

${ }^{2}$ Micol, J.R., "Langley Aerothermodynamic Facilities Complex: Enhancements and Testing Capabilities," AIAA 1998-0147, 36th AIAA Aerospace Sciences Meeting, January 12-15, 1998, Reno, Nevada.

${ }^{3}$ Orlemann, C., Schulz, C., and Wolfrum, J., "NO-flow tagging by photodissociation of NO2.A new approach for measuring small-scale flow structures," Chem. Phys. Lett., 307, pp. 15-20, 1999.

${ }^{4}$ Shinji, N., Kasahara, M., Tsue, M., and Kono, M., "Velocity Measurements of Reactive and Non-reactive Flows by NO-LIF Method Using $\mathrm{NO}_{2}$ Photodissociation,” Heat Transfer - Asian Research, 34 (1), pp. 40-52, 2005. doi: $10.1002 / \mathrm{htj} .20038$

${ }^{5}$ Hsu, A.G., Srinivasan, R., Bowersox, R.D.W., and North, S.W., "Two-component molecular tagging velocimetry utilizing NO fluorescence lifetime and NO2 photodissociation techniques in an underexpanded jet flowfield," Applied Optics, 48 (22), pp. 4414-4423, August, 2009.

${ }^{6}$ Hsu, A.G., Srinivasan, R., Bowersox, R.D.W, and North, S.W., “Molecular Tagging Using Vibrationally Excited Nitric Oxide in an Underexpanded Jet Flowfield,” AIAA Journal, 47 (11), pp. 2597-2604, November, 2009.

doi: $10.2514 / 1.47716$

American Institute of Aeronautics and Astronautics 
7 Jiang, N., Nishihara, M., and Lempert, W.R., "500 kHz $\mathrm{NO}_{2}$ Molecular Tagging Velocimetry in a Mach 5 Wind Tunnel," AIAA 2010-4348, $27^{\text {th }}$ AIAA Aerodynamic Measurement Technology and Ground Testing Conference, Chicago, IL, June 28 - July $1,2010$.

${ }^{8}$ Bathel, B.F., Johansen, C.T., Danehy, P.M., Inman, J.A., Jones, S.B., and Goyne, C.P., "Hypersonic Boundary Layer Transition Measurements Using $\mathrm{NO}_{2} \rightarrow \mathrm{NO}$ Photo-dissociation Tagging Velocimetry," AIAA Paper 2011-3246, 41 ${ }^{\text {st }}$ AIAA Fluid Dynamics Conference and Exhibit, June 27-30, 2011, Honolulu, HI.

${ }^{9}$ Bathel, B.F., Danehy, P.M., Johansen, C.T., Jones, S.B., and Goyne, C.P., "Hypersonic Boundary Layer Measurements with Variable Blowing Rates Using Molecular Tagging Velocimetry," AIAA Paper 2012-2886, $28^{\text {th }}$ AIAA Aerodynamic Measurement Technology, Ground Testing, and Flight Testing Conference, June 25-28, 2012, New Orleans, LA.

${ }^{10}$ Bathel, B.F., Johansen, C.T., Inman, J.A., Jones, S.B., and Danehy, P.M., "Application of Fluorescence-Based Velocimetry Techniques to Study High-Speed Compressible Flows," To be presented at the $51^{\text {st }}$ AIAA Aerospace Sciences Meeting, January 7-10, 2013, Grapevine, TX.

${ }_{11}$ Anderson, J.D., Hypersonic and High-Temperature Gas Dynamics, 2nd ed., AIAA, Reston, VA, 2006, pp. 261-374.

${ }^{12}$ Hollis, B.R., "Real-Gas Flow Properties of NASA Langley Research Center Aerothermodynamics Facilities Complex Wind Tunnels," NASA Contractor Report 4755, September, 1996.

${ }^{13}$ Ramsey, M.C. and Pitz, R.W., "Template matching for improved accuracy in molecular tagging velocimetry," Experiments in Fluids, 6, May, 2011. doi: 10.1007/s00348-011-1098-y

${ }^{14}$ Johansen, C.T. and Danehy, P.M., "Numerical investigation of PLIF gas seeding for hypersonic boundary layer flows," AIAA 2012-1057, 50 ${ }^{\text {th }}$ AIAA Aerospace Sciences Meeting, January 9-12, 2012, Nashville, TN.

${ }^{15}$ White, F.M., Viscous Fluid Flow, 2nd ed., McGraw-Hill, New York, NY, 1991, pp. 345-348.

${ }^{16}$ Bathel, B.F., Danehy, P.M., Inman, J.A., Watkins, A.N., Jones, S.B., Lipford, W.E., Goodman, K.Z., Ivey, C.B., and Goyne, C.P., "Hypersonic Laminar Boundary Layer Velocimetry with Discrete Roughness on a Flat Plate," AIAA Paper 2010-4998, 40th Fluid Dynamics Conference and Exhibit, Chicago, IL, June 28 - July 1, 2010. 


\section{Appendix}

The table below lists the flow conditions associated with each of the figure types described in section III.1. The figures are organized first according to trip height (smallest to largest), $k$, then by freestream Reynolds number, $R e_{\infty}$, and then spanwise measurement location, $z$. For each $z$ location (with $k$ and $R e_{\infty}$ constant), three separate figures are provided. The first figure includes the measured mean streamwise velocity profiles, fluctuating streamwise velocity component profiles, and sample single-shot streamwise velocity profiles (denoted $\bar{U}, U^{\prime}$, and $S S$ profiles in the table, respectively). The second figure shows an average of the zero-delay and delay images, followed by seven singleshot images, and finally a standard deviation of the delay images (denoted Avg., SS, and Std. Dev. Images in the table, respectively). The third figure shows three single-shot velocity profiles with corresponding measurement uncertainty (denoted SS Uncertainty in the table).

\begin{tabular}{|c|c|c|c|c|c|c|c|c|c|c|c|}
\hline Run & Figure & Data Type & $\operatorname{Re}_{\infty}\left(m^{-1}\right)$ & $\mathrm{P}_{\mathrm{w}}(\mathrm{kPa})$ & $\mathrm{T}_{\mathrm{w}}(\mathrm{K})$ & $\Delta \mathrm{t}_{\mathrm{PROBE}}(\mu \mathrm{s})$ & $\dot{\mathrm{m}}_{\text {Blowing }}(\mathrm{mg} / \mathrm{s})$ & $\mathrm{k}(\mathrm{mm})$ & $\mathrm{k} / \delta$ & $\mathrm{Re}_{\mathrm{kk}}$ & $\mathrm{z}(\mathrm{mm})$ \\
\hline \begin{tabular}{|c|}
12 \\
\end{tabular} & $\mathrm{~A} 1$ & $\bar{U}, U^{\prime}$, and $S S$ Profiles & $3.3 \times 10^{6}$ & 2.77 & 340 & 1 & 62.4 & 0 & 0 & 0 & 0.0 \\
\hline 12 & A2 & Avg., SS, and Std. Dev. Images & $3.3 \times 10^{6}$ & 2.77 & 340 & 1 & 62.4 & 0 & 0 & 0 & 0.0 \\
\hline 12 & A3 & SS Uncertainty Profiles & $3.3 \times 10^{6}$ & 2.77 & 340 & 1 & 62.4 & 0 & 0 & 0 & 0.0 \\
\hline 30 & A4 & $\bar{U}, U^{\prime}$, and $S S$ Profiles & $2.4 \times 10^{6}$ & 2.08 & 379 & 2 & 22.9 & 0.53 & 0.41 & 293 & 0.0 \\
\hline 30 & A5 & $A v g ., S S$, and $S t d$. Dev. Images & $2.4 \times 10^{6}$ & 2.08 & 379 & 2 & 22.9 & 0.53 & 0.41 & 293 & 0.0 \\
\hline 30 & A6 & SS Uncertainty Profiles & $2.4 \times 10^{6}$ & 2.08 & 379 & 2 & 22.9 & 0.53 & 0.41 & 293 & 0.0 \\
\hline 30 & A7 & $\bar{U}, U^{\prime}$, and $S S$ Profiles & $2.4 \times 10^{6}$ & 2.07 & 365 & 2 & 22.5 & 0.53 & 0.41 & 265 & 4.5 \\
\hline 30 & A8 & $A v g ., S S$, and $S t d$. Dev. Images & $2.4 \times 10^{6}$ & 2.07 & 365 & 2 & 22.5 & 0.53 & 0.41 & 265 & 4.5 \\
\hline 30 & A9 & SS Uncertainty Profiles & $2.4 \times 10^{6}$ & 2.07 & 365 & 2 & 22.5 & 0.53 & 0.41 & 265 & 4.5 \\
\hline 30 & A10 & $\bar{U}, U^{\prime}$, and $S S$ Profiles & $2.4 \times 10^{6}$ & 2.06 & 350 & 2 & 22.7 & 0.53 & 0.41 & 284 & 6.0 \\
\hline 30 & A11 & Avg., SS, and $S t d$. Dev. Images & $2.4 \times 10^{6}$ & 2.06 & 350 & 2 & 22.7 & 0.53 & 0.41 & 284 & 6.0 \\
\hline 30 & A12 & SS Uncertainty Profiles & $2.4 \times 10^{6}$ & 2.06 & 350 & 2 & 22.7 & 0.53 & 0.41 & 284 & 6.0 \\
\hline 16 & A13 & $\bar{U}, U^{\prime}$, and $S S$ Profiles & $3.3 \times 10^{6}$ & 2.91 & 395 & 2 & 30.5 & 0.53 & 0.47 & 393 & 0.0 \\
\hline 16 & A14 & $A v g ., S S$, and $S t d$. Dev. Images & $3.3 \times 10^{6}$ & 2.91 & 395 & 2 & 30.5 & 0.53 & 0.47 & 393 & 0.0 \\
\hline 16 & A15 & SS Uncertainty Profiles & $3.3 \times 10^{6}$ & 2.91 & 395 & 2 & 30.5 & 0.53 & 0.47 & 393 & 0.0 \\
\hline 16 & A16 & $\bar{U}, U^{\prime}$, and $S S$ Profiles & $3.3 \times 10^{6}$ & 2.89 & 379 & 2 & 30.4 & 0.53 & 0.47 & 420 & -4.5 \\
\hline 16 & A17 & $A v g ., S S$, and Std. Dev. Images & $3.3 \times 10^{6}$ & 2.89 & 379 & 2 & 30.4 & 0.53 & 0.47 & 420 & -4.5 \\
\hline 16 & A18 & SS Uncertainty Profiles & $3.3 \times 10^{6}$ & 2.89 & 379 & 2 & 30.4 & 0.53 & 0.47 & 420 & -4.5 \\
\hline 14 & A19 & $\bar{U}, U^{\prime}$, and $S S$ Profiles & $3.3 \times 10^{6}$ & 2.94 & 419 & 1 & 46.6 & 1.00 & 0.86 & 1698 & 0.0 \\
\hline 14 & $\mathrm{~A} 20$ & $A v g ., S S$, and $S t d$. Dev. Images & $3.3 \times 10^{6}$ & 2.94 & 419 & 1 & 46.6 & 1.00 & 0.86 & 1698 & 0.0 \\
\hline 14 & $\mathrm{~A} 21$ & SS Uncertainty Profiles & $3.3 \times 10^{6}$ & 2.94 & 419 & 1 & 46.6 & 1.00 & 0.86 & 1698 & 0.0 \\
\hline 14 & A22 & $\bar{U}, U^{\prime}$, and $S S$ Profiles & $3.3 \times 10^{6}$ & 2.92 & 401 & 1 & 46.8 & 1.00 & 0.87 & 1798 & -4.5 \\
\hline 14 & $\mathrm{~A} 23$ & Avg., SS, and Std. Dev. Images & $3.3 \times 10^{6}$ & 2.92 & 401 & 1 & 46.8 & 1.00 & 0.87 & 1798 & -4.5 \\
\hline 14 & A24 & SS Uncertainty Profiles & $3.3 \times 10^{6}$ & 2.92 & 401 & 1 & 46.8 & 1.00 & 0.87 & 1798 & -4.5 \\
\hline 14 & A25 & $\bar{U}, U^{\prime}$, and $S S$ Profiles & $3.3 \times 10^{6}$ & 2.90 & 386 & 1 & 46.7 & 1.00 & 0.88 & 1891 & -6.0 \\
\hline 14 & A26 & $A v g ., S S$, and $S t d$. Dev. Images & $3.3 \times 10^{6}$ & 2.90 & 386 & 1 & 46.7 & 1.00 & 0.88 & 1891 & -6.0 \\
\hline 14 & A27 & SS Uncertainty Profiles & $3.3 \times 10^{6}$ & 2.90 & 386 & 1 & 46.7 & 1.00 & 0.88 & 1891 & -6.0 \\
\hline 14 & A28 & $\bar{U}, U^{\prime}$, and $S S$ Profiles & $3.3 \times 10^{6}$ & 2.89 & 369 & 1 & 46.7 & 1.00 & 0.90 & 1999 & -7.5 \\
\hline 14 & $\mathrm{~A} 29$ & Avg., SS, and Std. Dev. Images & $3.3 \times 10^{6}$ & 2.89 & 369 & 1 & 46.7 & 1.00 & 0.90 & 1999 & -7.5 \\
\hline 14 & $\mathrm{~A} 30$ & SS Uncertainty Profiles & $3.3 \times 10^{6}$ & 2.89 & 369 & 1 & 46.7 & 1.00 & 0.90 & 1999 & -7.5 \\
\hline 13 & A31 & $\bar{U}, U^{\prime}$, and $S S$ Profiles & $3.3 \times 10^{6}$ & 2.87 & 310 & 1 & 30.0 & 2.00 & 1.89 & 5535 & -3.5 \\
\hline 13 & $\mathrm{~A} 32$ & Avg., SS, and Std. Dev. Images & $3.3 \times 10^{6}$ & 2.87 & 310 & 1 & 30.0 & 2.00 & 1.89 & 5535 & -3.5 \\
\hline 13 & $\mathrm{~A} 33$ & SS Uncertainty Profiles & $3.3 \times 10^{6}$ & 2.87 & 310 & 1 & 30.0 & 2.00 & 1.89 & 5535 & -3.5 \\
\hline 13 & $\mathrm{~A} 34$ & $\bar{U}, U^{\prime}$, and $S S$ Profiles & $3.3 \times 10^{6}$ & 2.86 & 329 & 1 & 30.3 & 2.00 & 1.86 & 5296 & -4.5 \\
\hline 13 & A35 & Avg., $S S$, and Std. Dev. Images & $3.3 \times 10^{6}$ & 2.86 & 329 & 1 & 30.3 & 2.00 & 1.86 & 5296 & -4.5 \\
\hline 13 & $\mathrm{~A} 36$ & SS Uncertainty Profiles & $3.3 \times 10^{6}$ & 2.86 & 329 & 1 & 30.3 & 2.00 & 1.86 & 5296 & -4.5 \\
\hline 13 & A37 & $\bar{U}, U^{\prime}$, and $S S$ Profiles & $3.3 \times 10^{6}$ & 2.75 & 348 & 1 & 30.6 & 2.00 & 1.83 & 5072 & -5.5 \\
\hline 13 & A38 & Avg., SS, and Std. Dev. Images & $3.3 \times 10^{6}$ & 2.75 & 348 & 1 & 30.6 & 2.00 & 1.83 & 5072 & -5.5 \\
\hline 13 & A39 & SS Uncertainty Profiles & $3.3 \times 10^{6}$ & 2.75 & 348 & 1 & 30.6 & 2.00 & 1.83 & 5072 & -5.5 \\
\hline 13 & $\mathrm{~A} 40$ & $\bar{U}, U^{\prime}$, and $S S$ Profiles & $3.3 \times 10^{6}$ & 2.89 & 367 & 1 & 30.6 & 2.00 & 1.80 & 4881 & -6.5 \\
\hline 13 & $\mathrm{~A} 41$ & Avg., $S S$, and $S t d$. Dev. Images & $3.3 \times 10^{6}$ & 2.89 & 367 & 1 & 30.6 & 2.00 & 1.80 & 4881 & -6.5 \\
\hline 13 & $\mathrm{~A} 42$ & SS Uncertainty Profiles & $3.3 \times 10^{6}$ & 2.89 & 367 & 1 & 30.6 & 2.00 & 1.80 & 4881 & -6.5 \\
\hline 13 & $\mathrm{~A} 43$ & $\bar{U}, U^{\prime}$, and $S S$ Profiles & $3.3 \times 10^{6}$ & 2.91 & 391 & 1 & 30.6 & 2.00 & 1.76 & 4665 & -7.5 \\
\hline 13 & A44 & $A v g ., S S$, and $S t d . D e v$. Images & $3.3 \times 10^{6}$ & 2.91 & 391 & 1 & 30.6 & 2.00 & 1.76 & 4665 & -7.5 \\
\hline 13 & $\mathrm{~A} 45$ & SS Uncertainty Profiles & $3.3 \times 10^{6}$ & 2.91 & 391 & 1 & 30.6 & 2.00 & 1.76 & 4665 & -7.5 \\
\hline
\end{tabular}




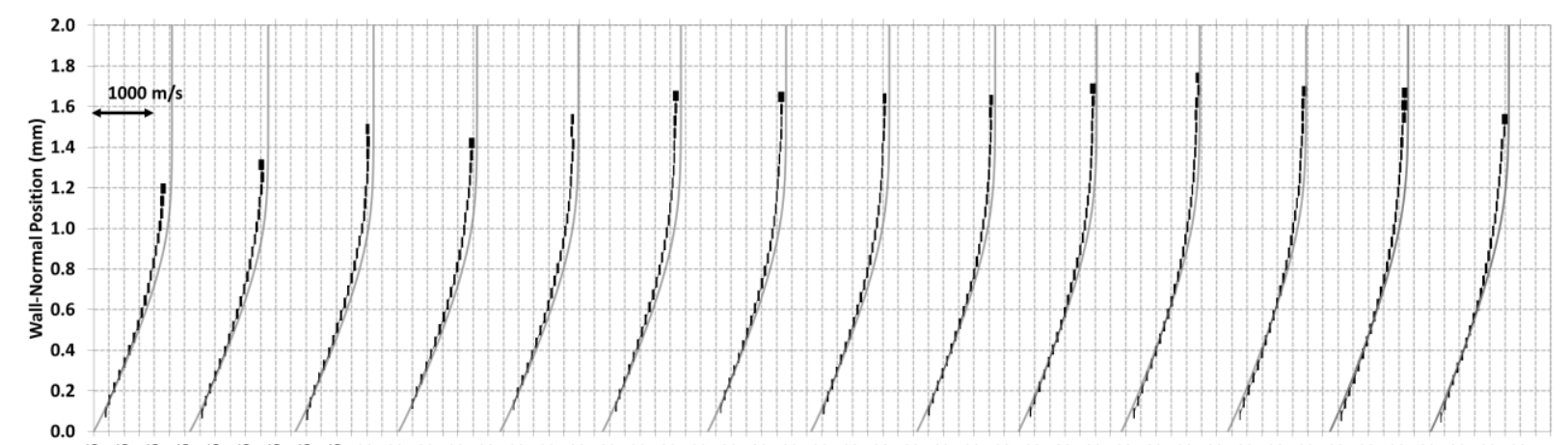

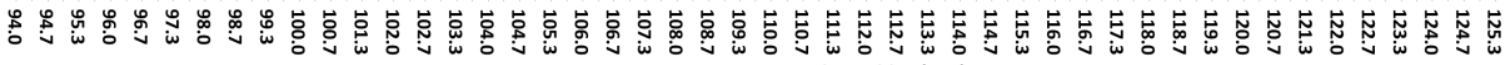

(a)

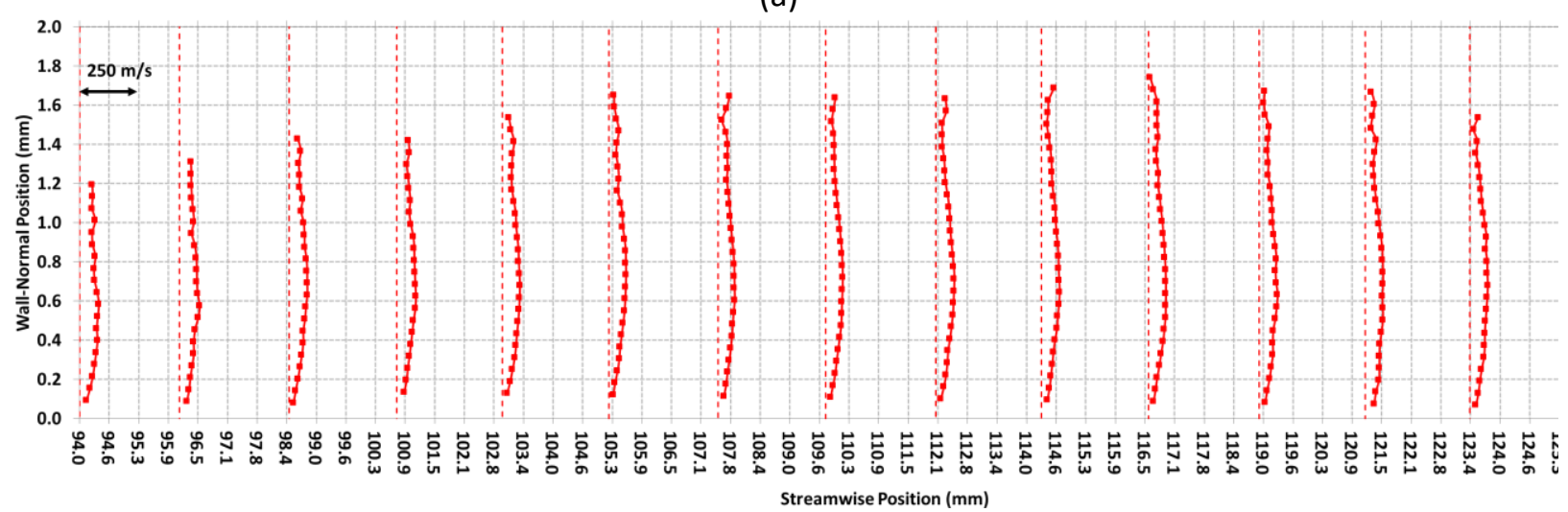

(b)

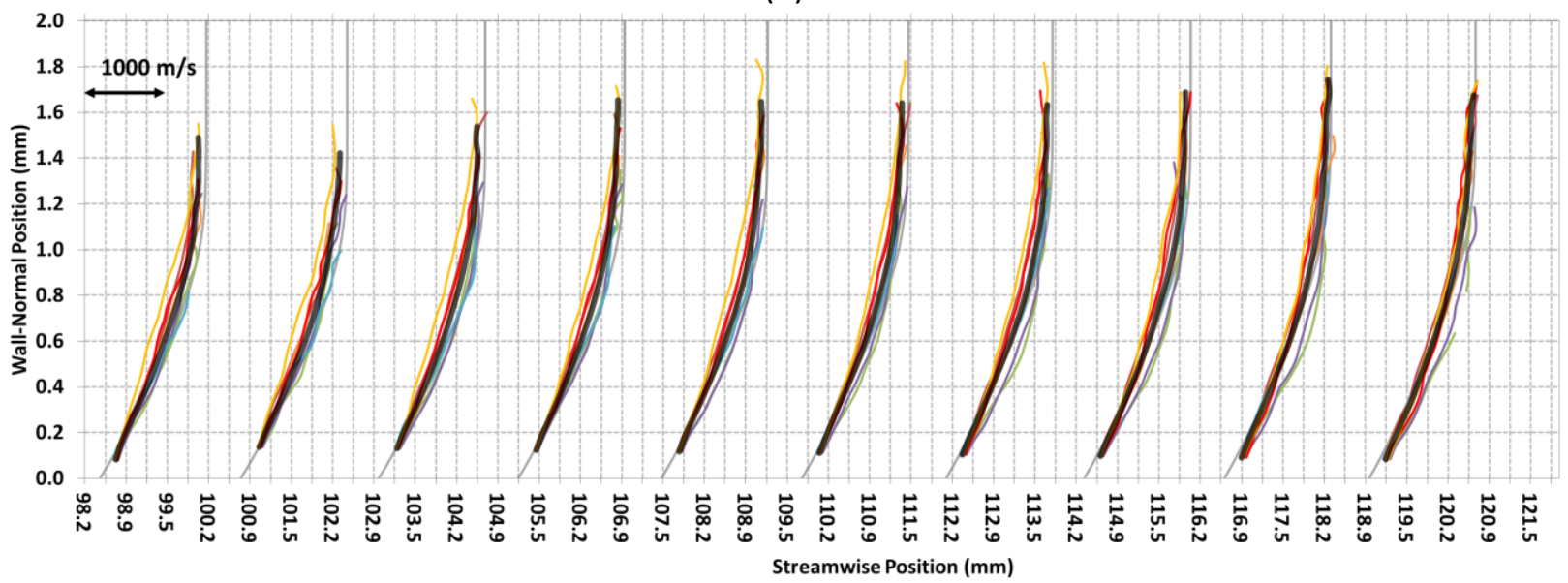

(c)

Figure A1. Run 12 (a) mean, (b) fluctuating, and (c) single-shot velocity profiles. $k / \delta_{L}=0.0, R_{k k}=0$. Profiles taken along centerline. 


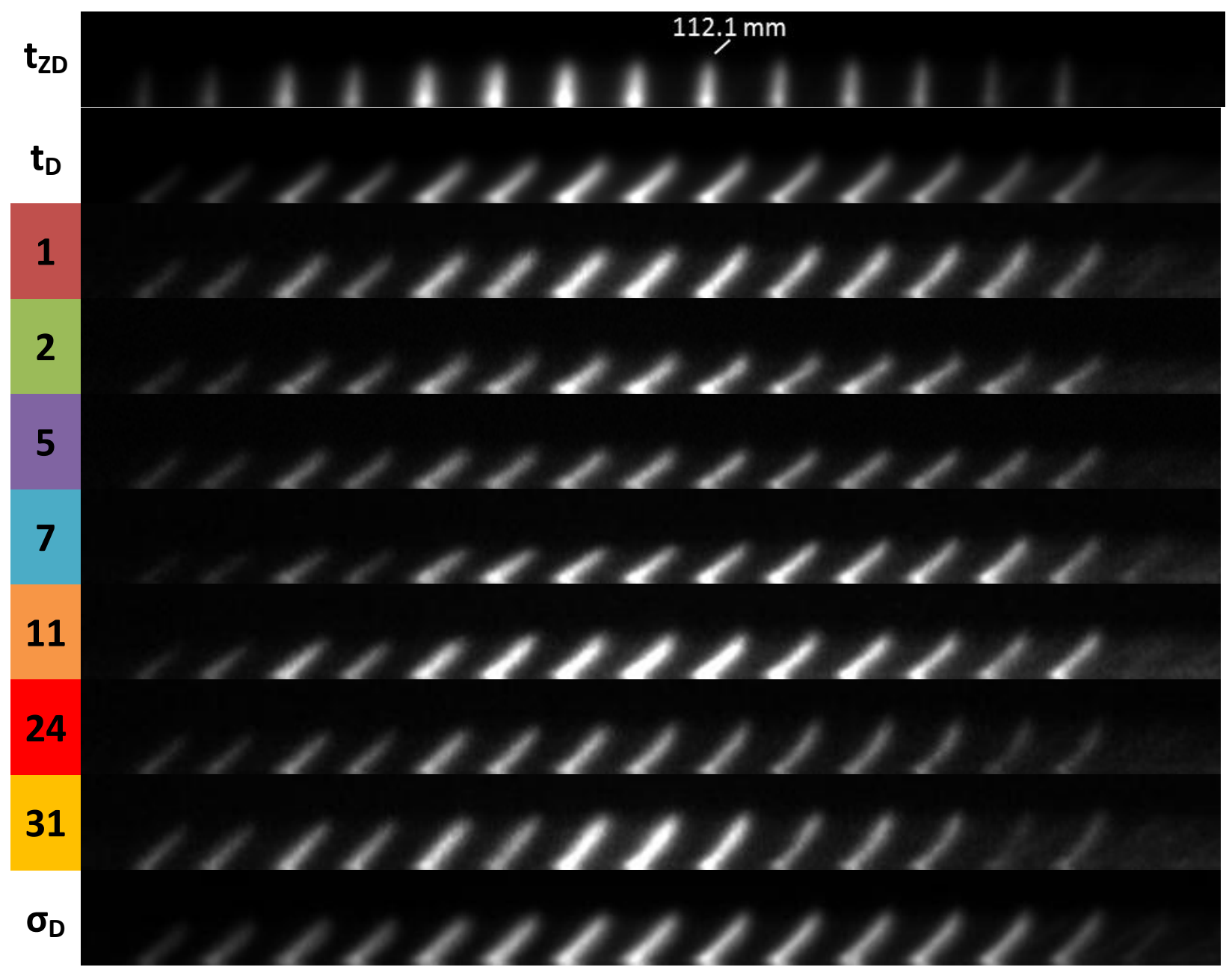

Figure A2. Run 12 (top) 87-shot average zero-delay image $\left(t_{\mathrm{zD}}\right)$, 87-shot average delayed image $\left(\mathrm{t}_{\mathrm{D}}\right)$, single-shot delayed images, and (bottom) 87-shot standard deviation of delayed images $\left(\sigma_{D}\right)$. Images taken along centerline. 


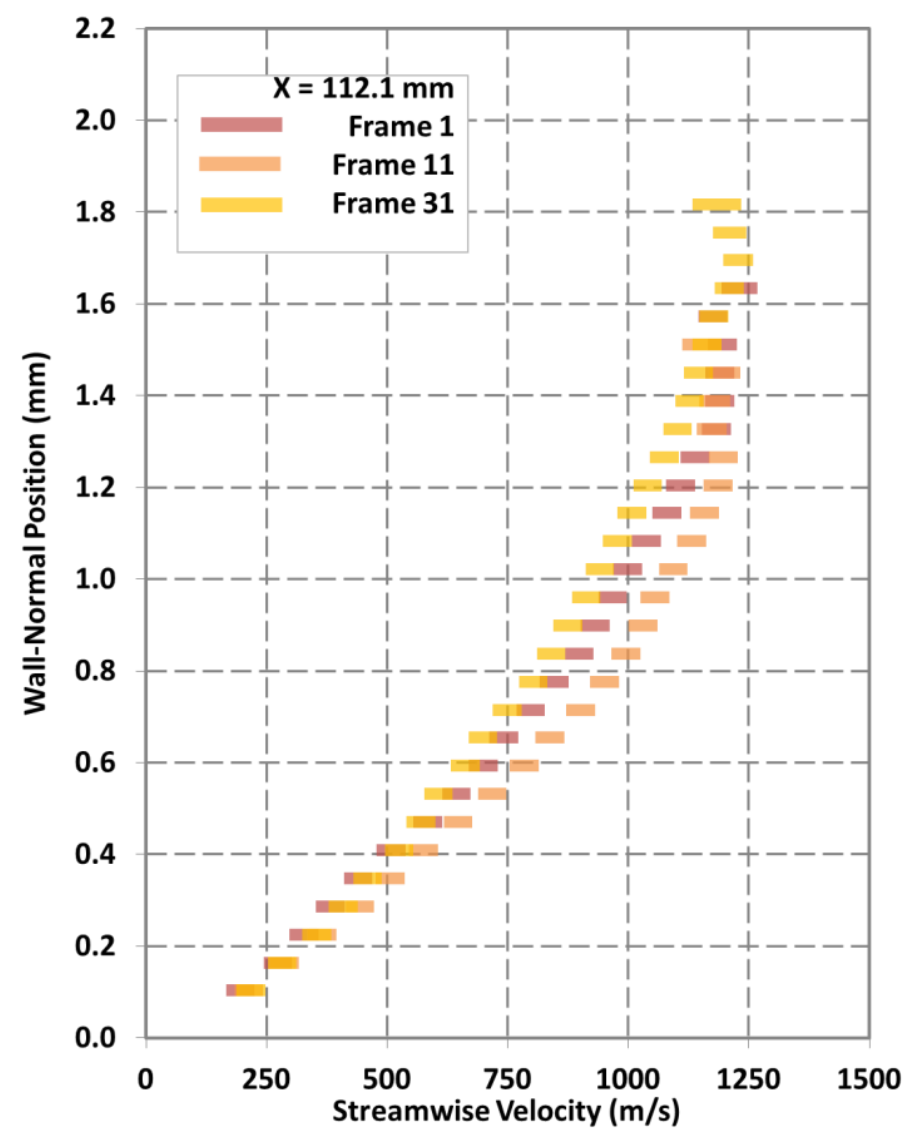

Figure A3. Run 12 single-shot velocity profiles at $112.1 \mathrm{~mm}$ downstream of leading edge along centerline. 


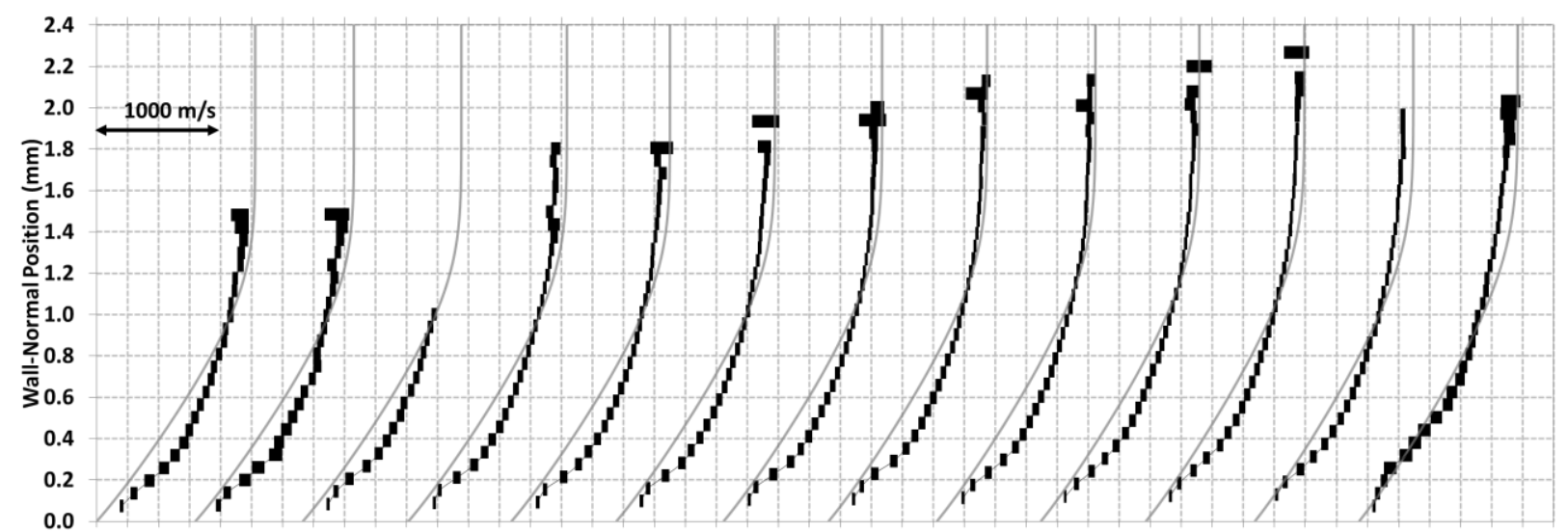

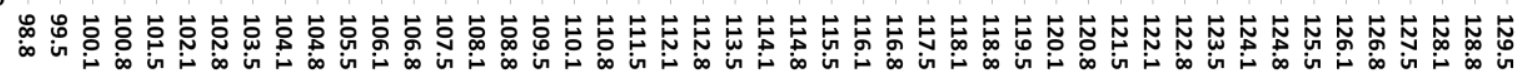

Streamwise Position (mm)

(a)

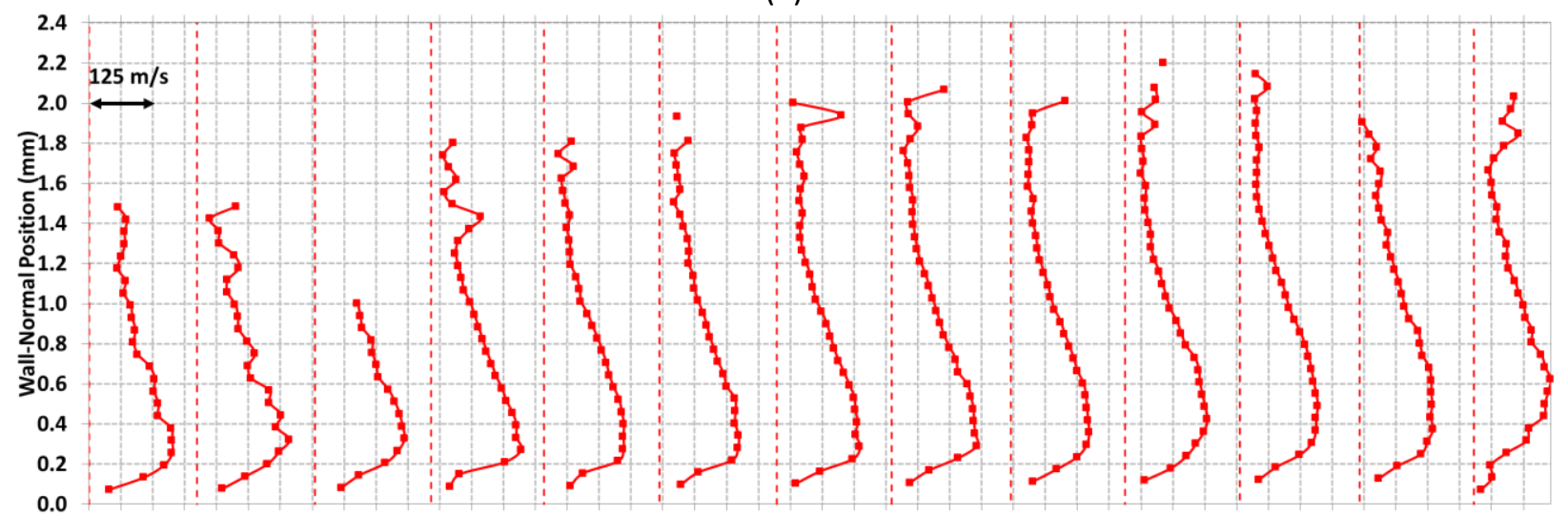

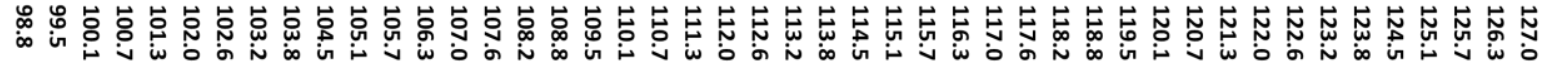

Streamwise Position ( $\mathrm{mm}$ )

(b)

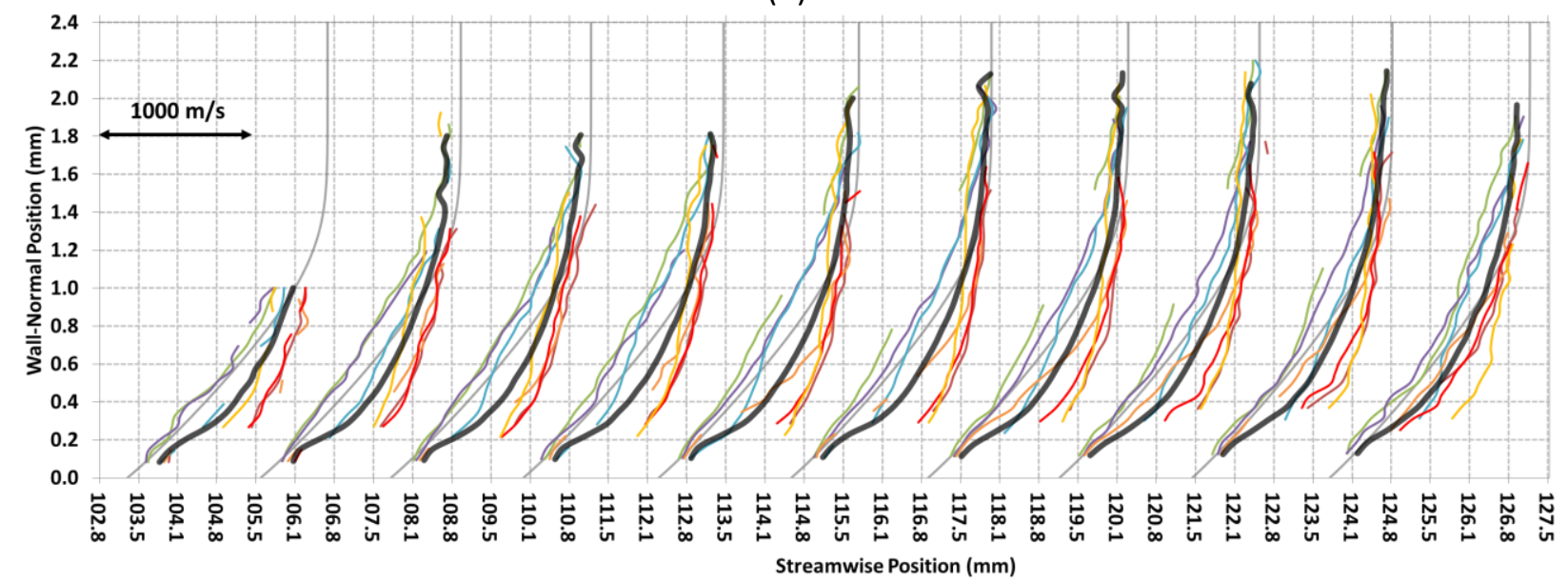

(c)

Figure A4. Run 30 (a) mean, (b) fluctuating, and (c) single-shot velocity profiles. $k / \delta_{L}=0.41, R_{k k}=293$. Profiles taken along centerline. 


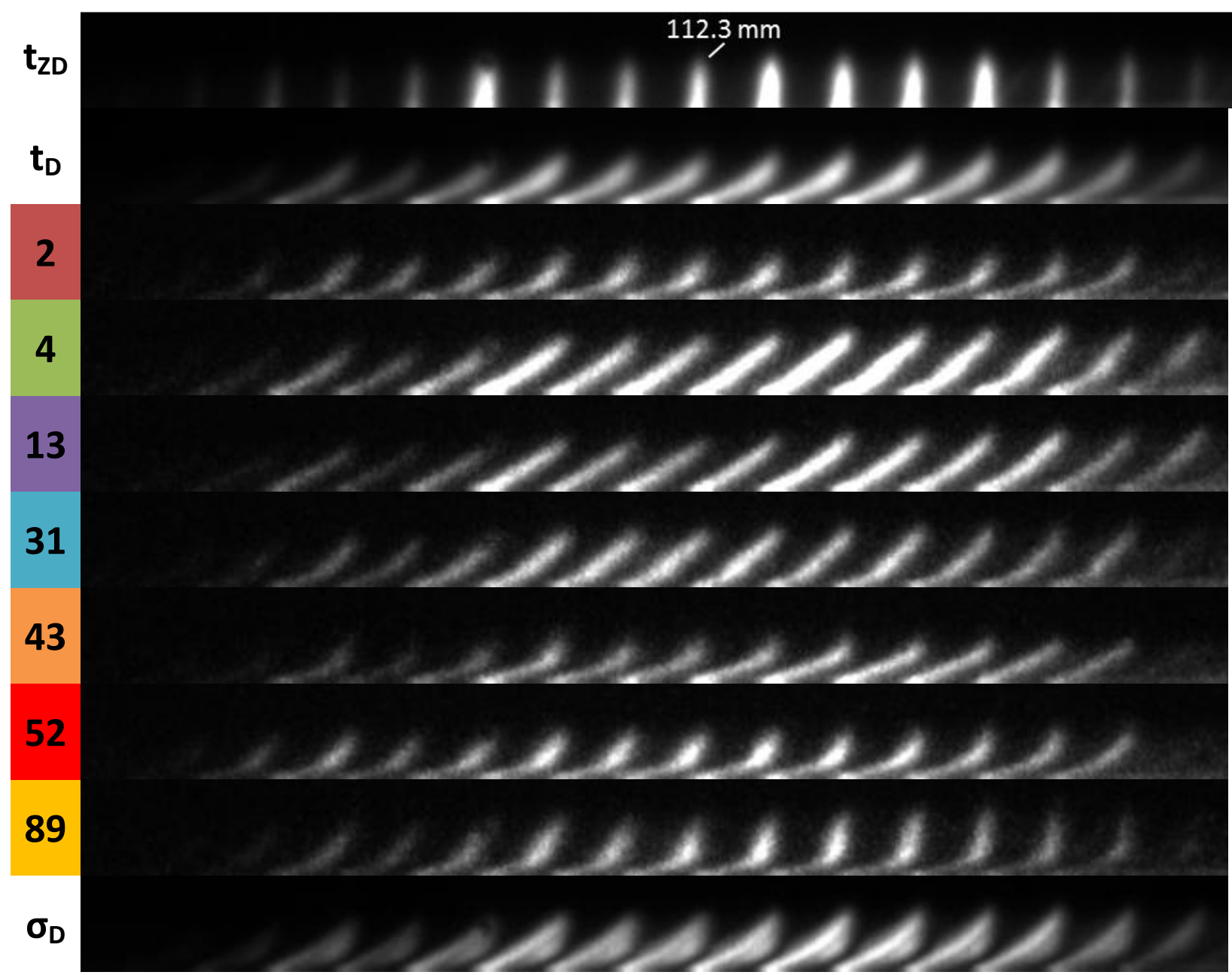

Figure A5. Run 30 (top) 151-shot average zero-delay image $\left(t_{2 \mathrm{D}}\right)$, 151-shot average delay image $\left(t_{\mathrm{D}}\right)$, single-shot delayed images, and (bottom) 151-shot standard deviation of delayed images $\left(\sigma_{D}\right)$. Images taken on centerline. 


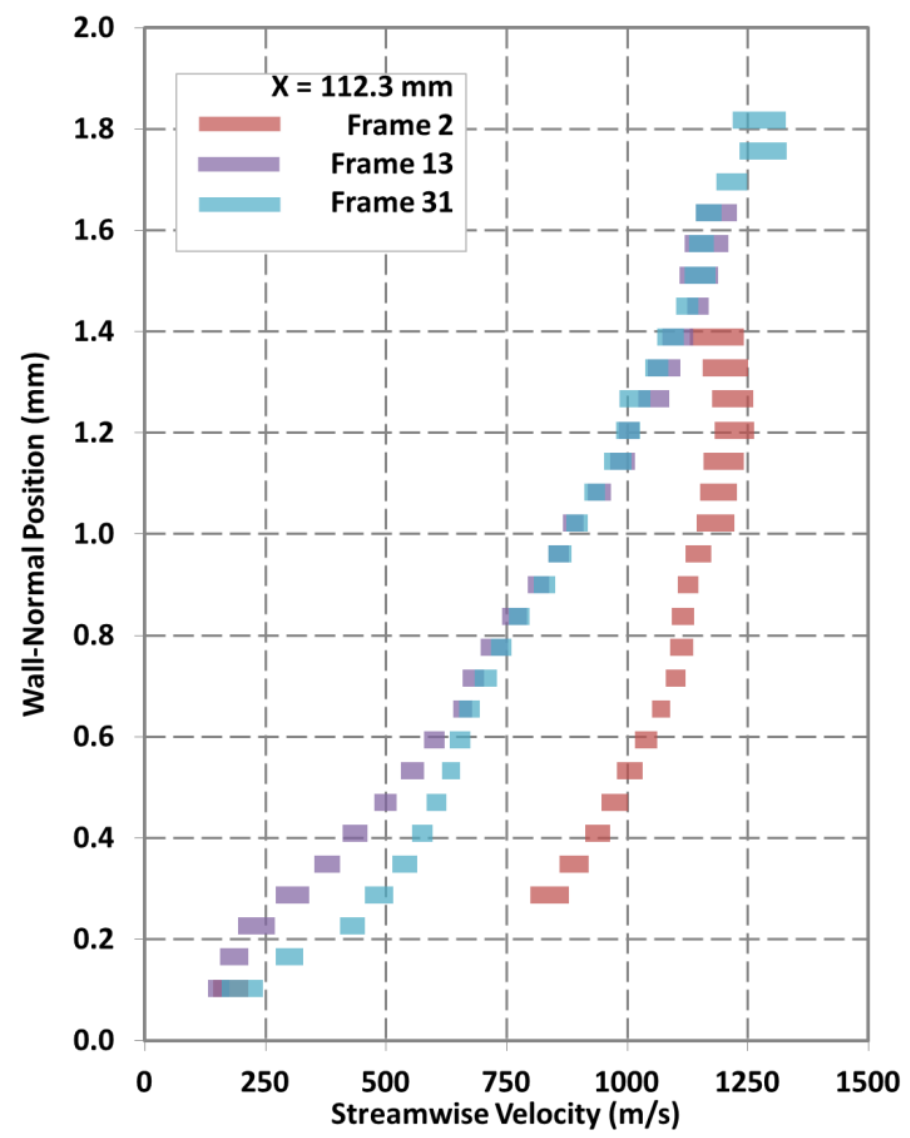

Figure A6. Run 30 single-shot velocity profiles at $112.3 \mathrm{~mm}$ downstream of leading edge along centerline. 


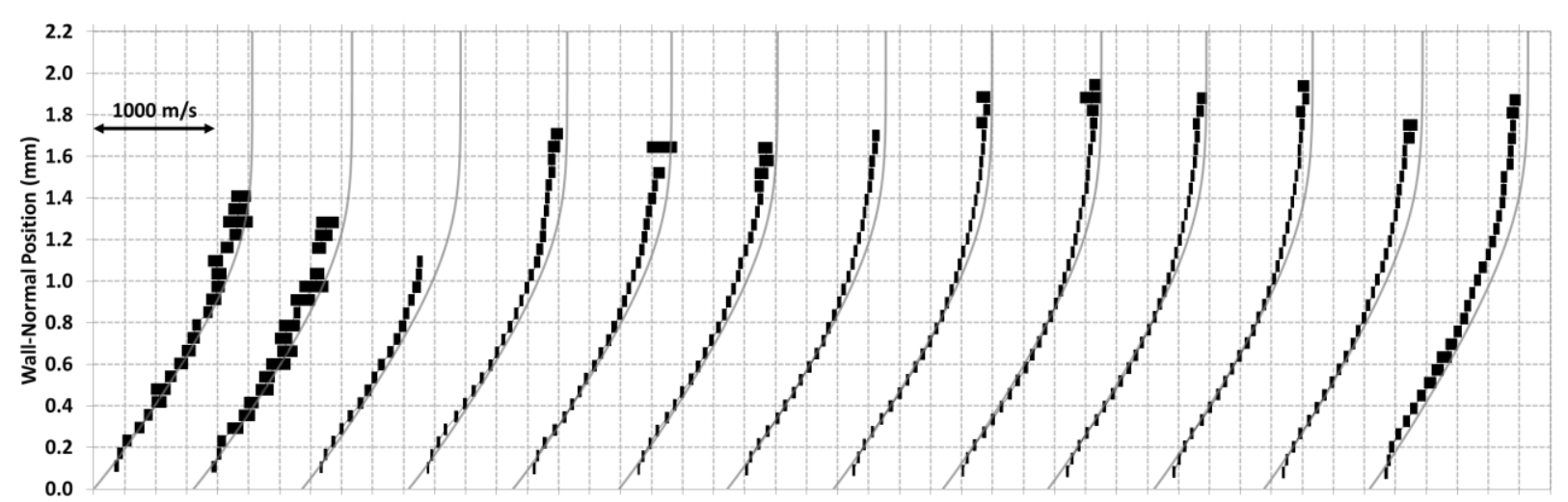

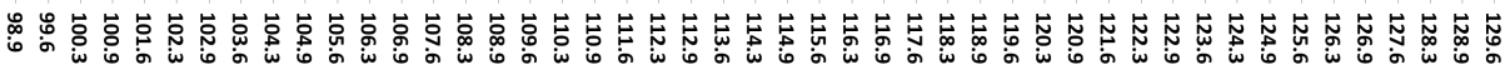

Streamwise Position (mm)

(a)

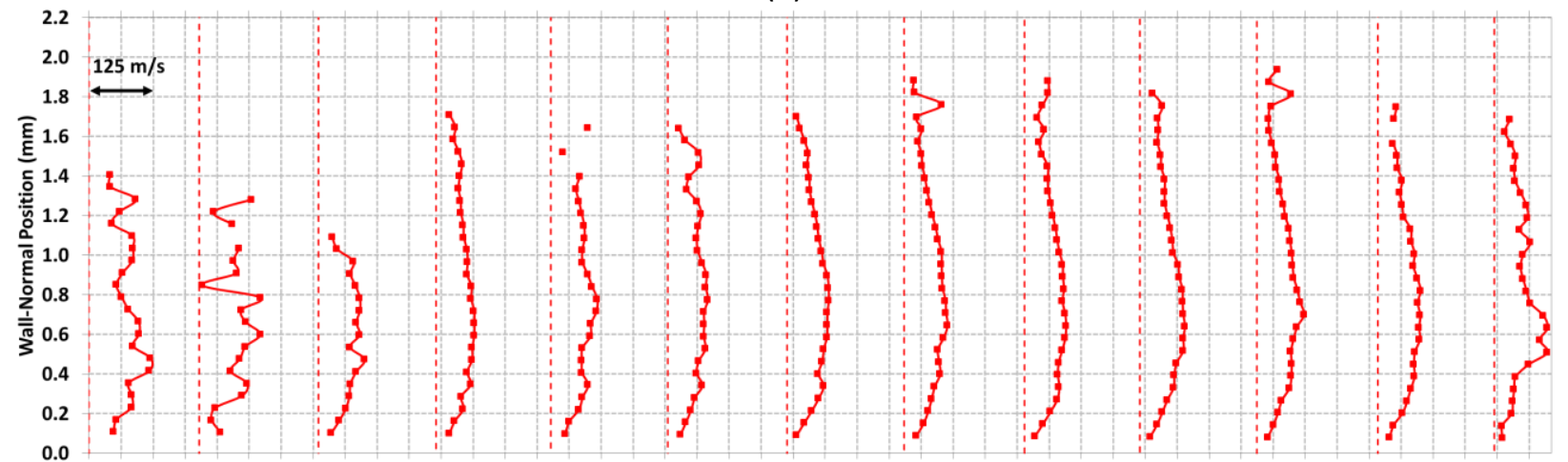

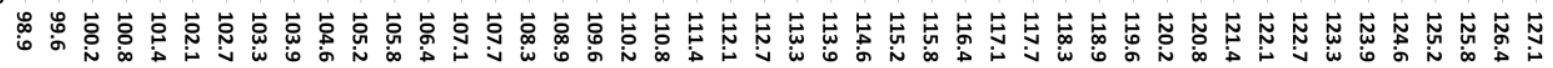

Streamwise Position ( $\mathrm{mm}$ )

(b)

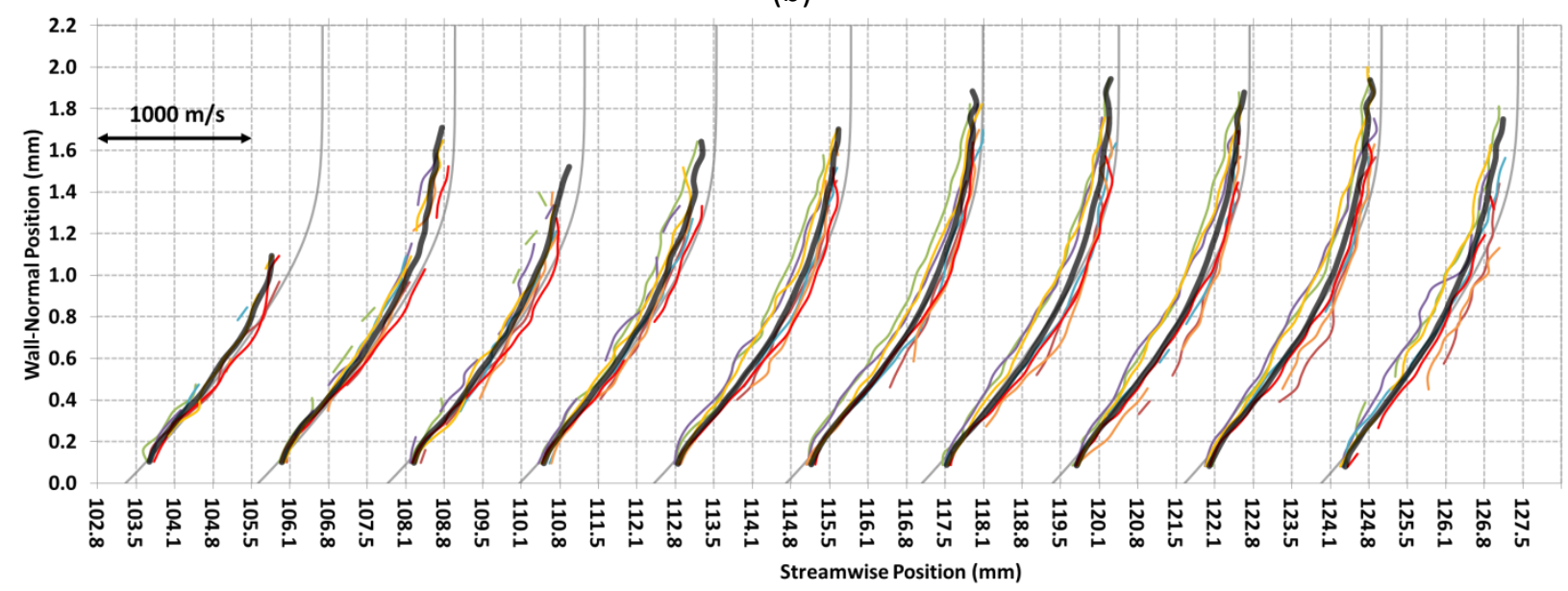

(c)

Figure A7. Run 30 (a) Mean, (b) fluctuating, and (c) single-shot velocity profiles. $k / \delta_{L}=0.41, R_{k k}=265$. Profiles taken $z=+4.5 \mathrm{~mm}$ off of centerline. 


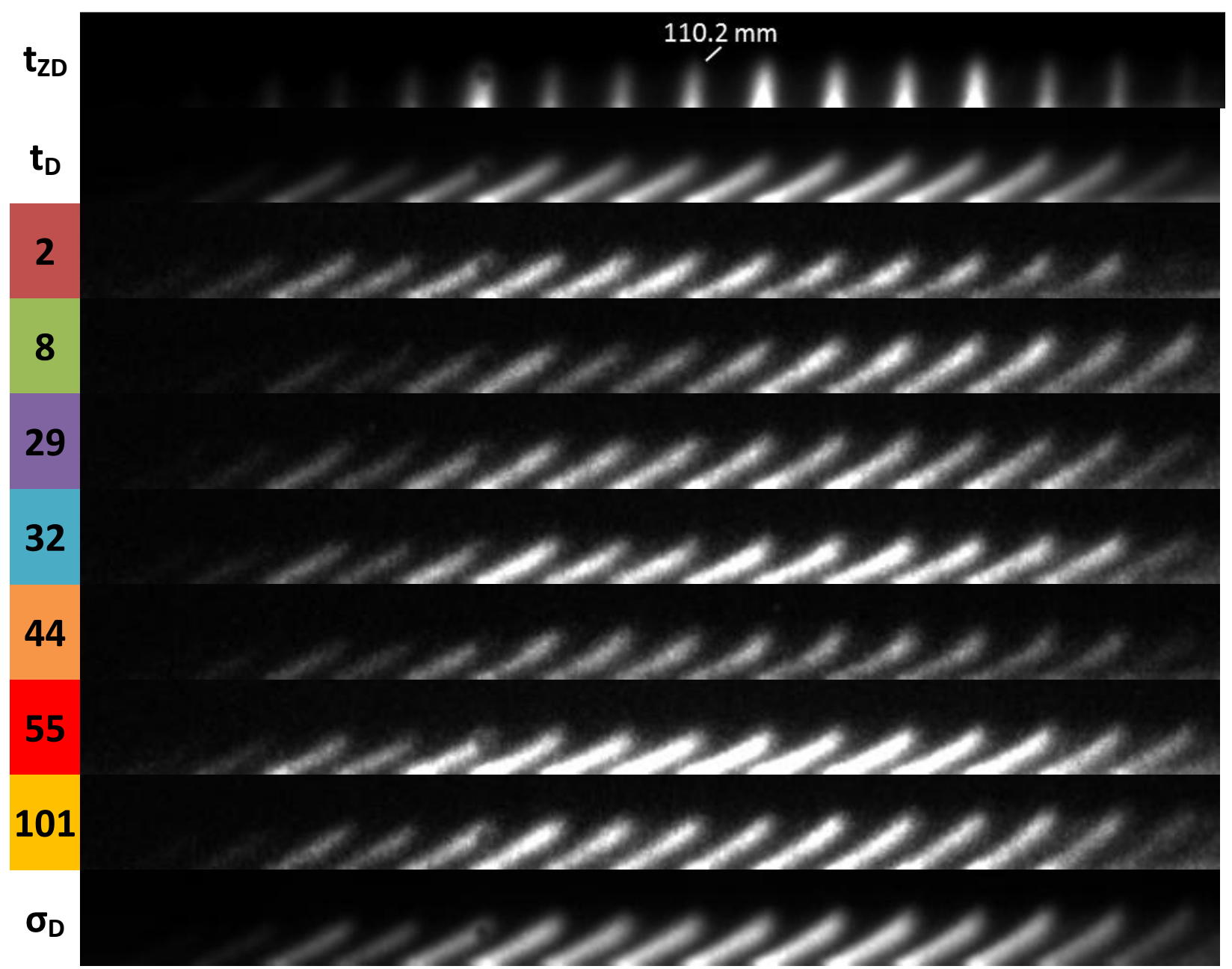

Figure A8. Run 30 (top) 149-shot average zero-delay image $\left(t_{\mathrm{ZD}}\right)$, 149-shot average delay image $\left(t_{\mathrm{D}}\right)$, single-shot delayed images, and (bottom) 149-shot standard deviation of delayed images $\left(\sigma_{D}\right)$. Images taken at $z=+4.5 \mathrm{~mm}$ off of centerline. 


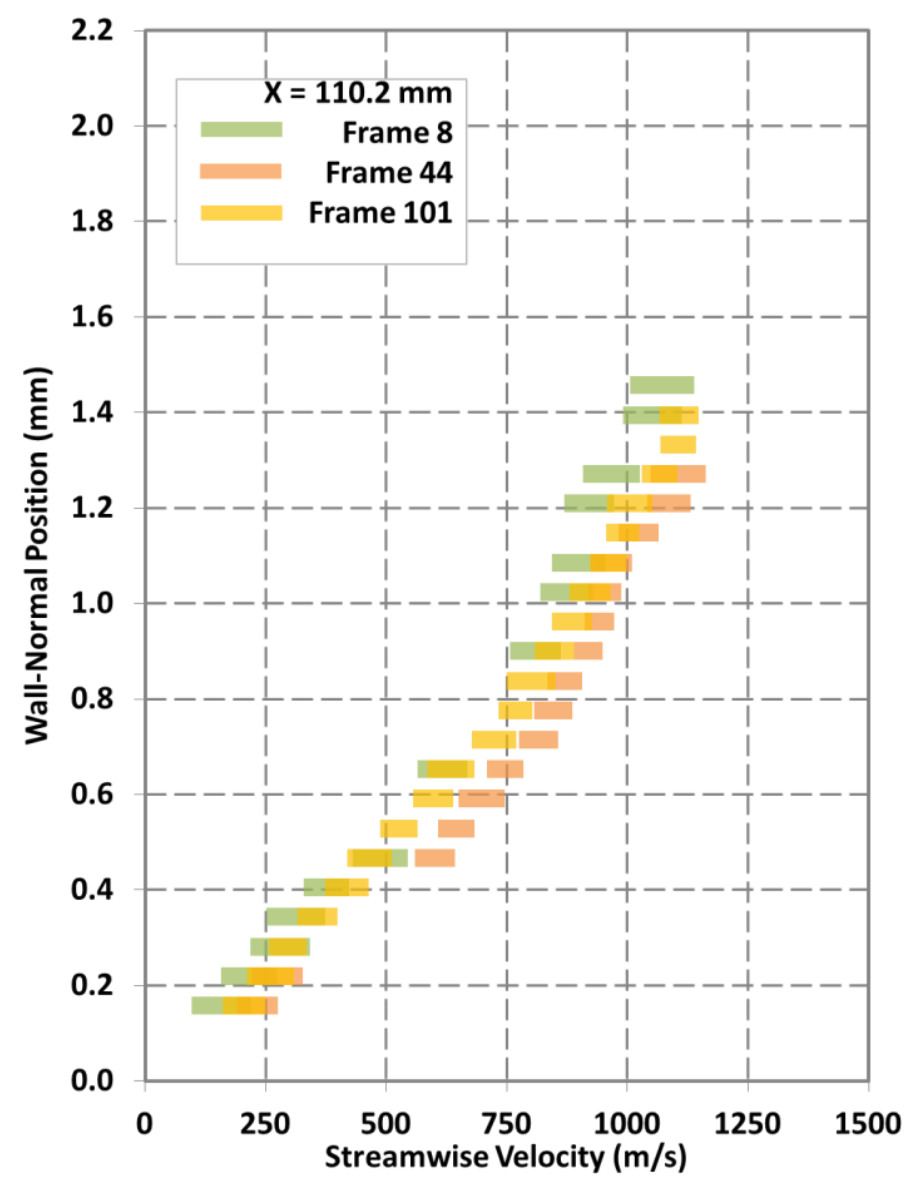

Figure A9. Run 30 single-shot velocity profiles at $110.2 \mathrm{~mm}$ downstream of leading edge, $z=+4.5 \mathrm{~mm}$ off of centerline. 


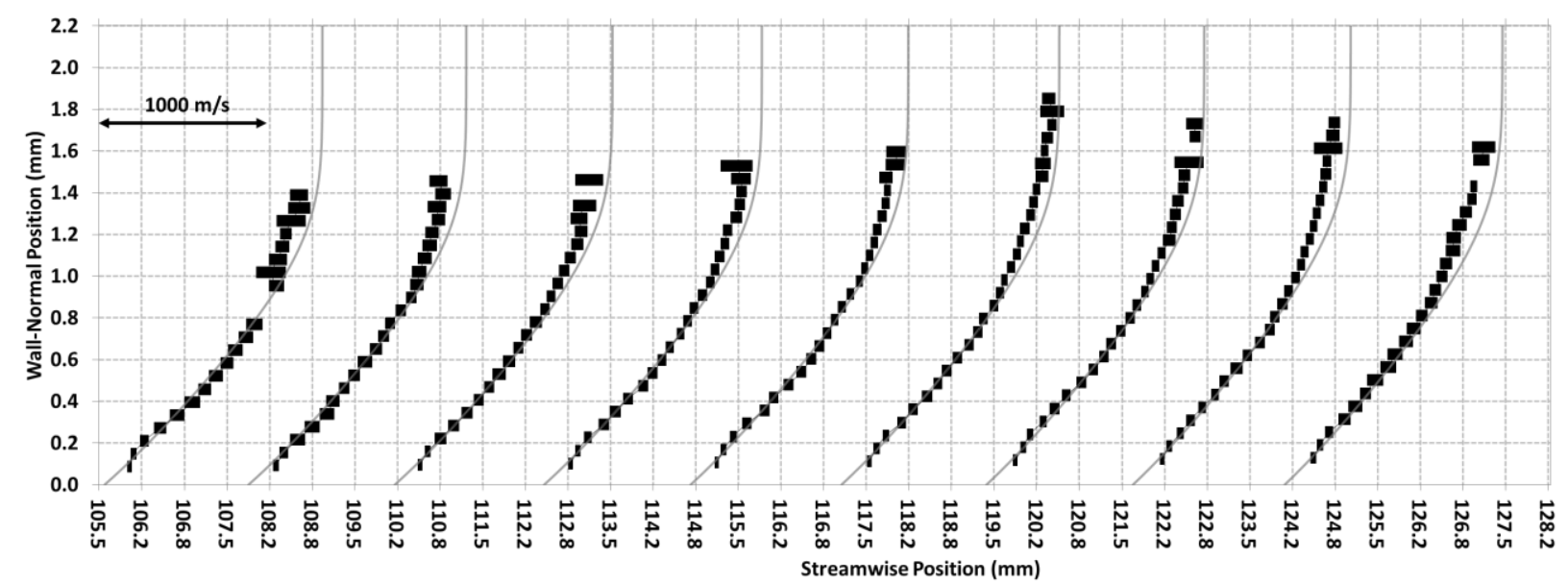

(a)

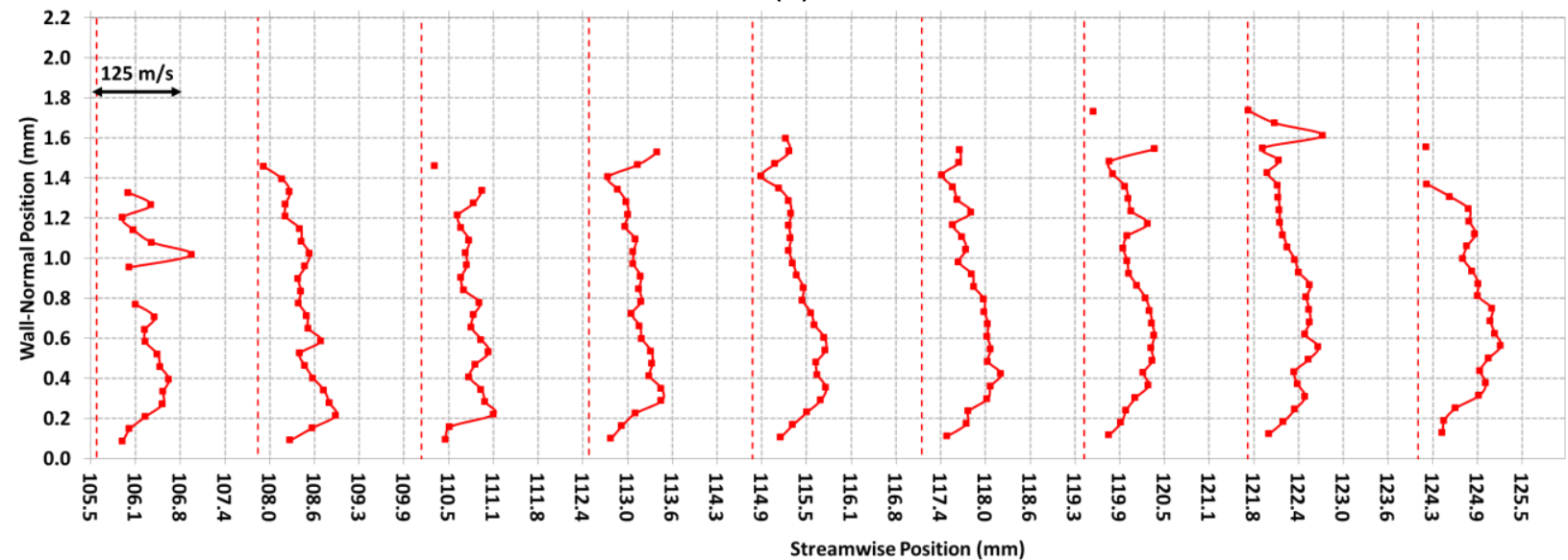

(b)

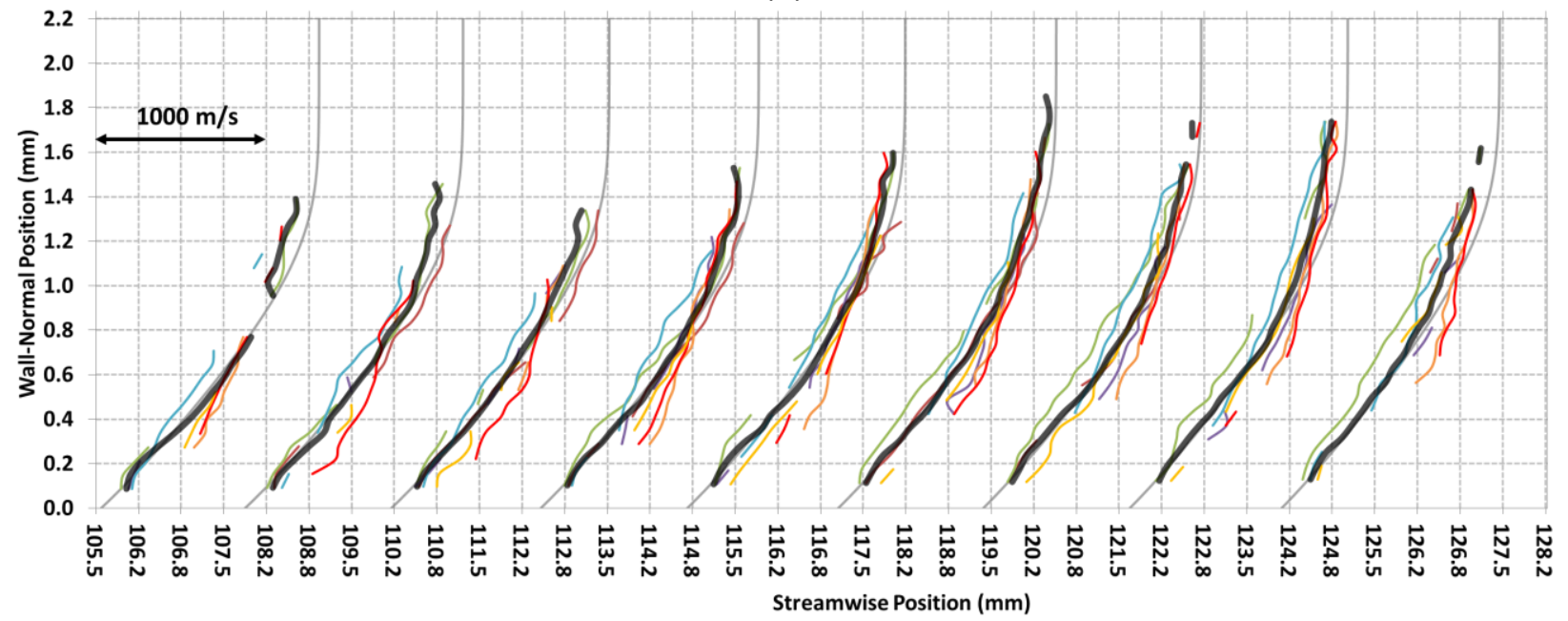

(c)

Figure A10. Run 30 (a) mean, (b) fluctuating, and (c) single-shot velocity profiles. $k / \delta_{L}=0.41, R e_{k k}=284$. Profiles taken $z=+6.0 \mathrm{~mm}$ off of centerline. 


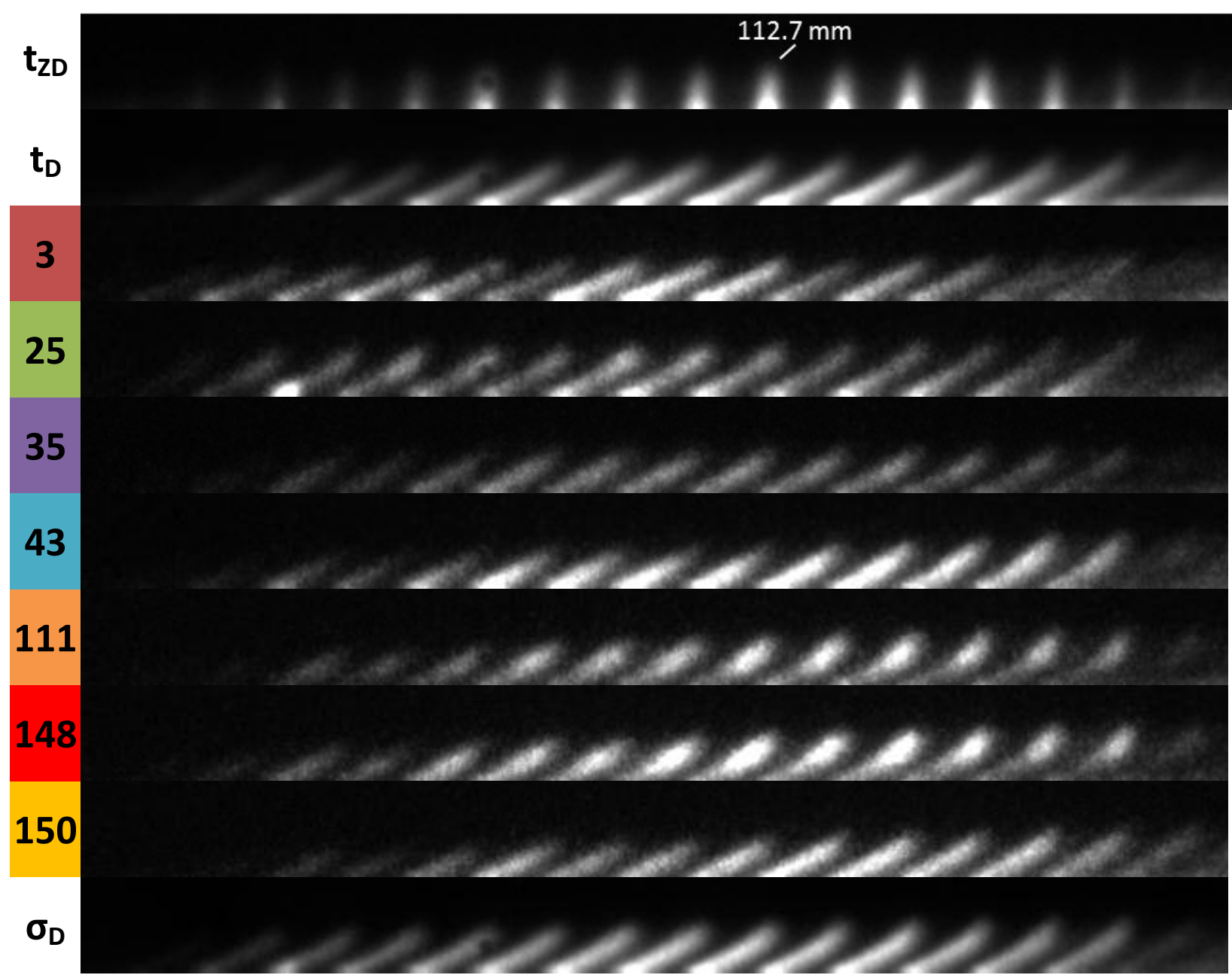

Figure A11. Run 30 (top) 150-shot average zero-delay image $\left(t_{z D}\right), 150$-shot average delay image $\left(t_{D}\right)$, single-shot delayed images, and (bottom) 150-shot standard deviation of delayed images $\left(\sigma_{\mathrm{D}}\right)$. Images taken $z=+6.0 \mathrm{~mm}$ off of centerline. 


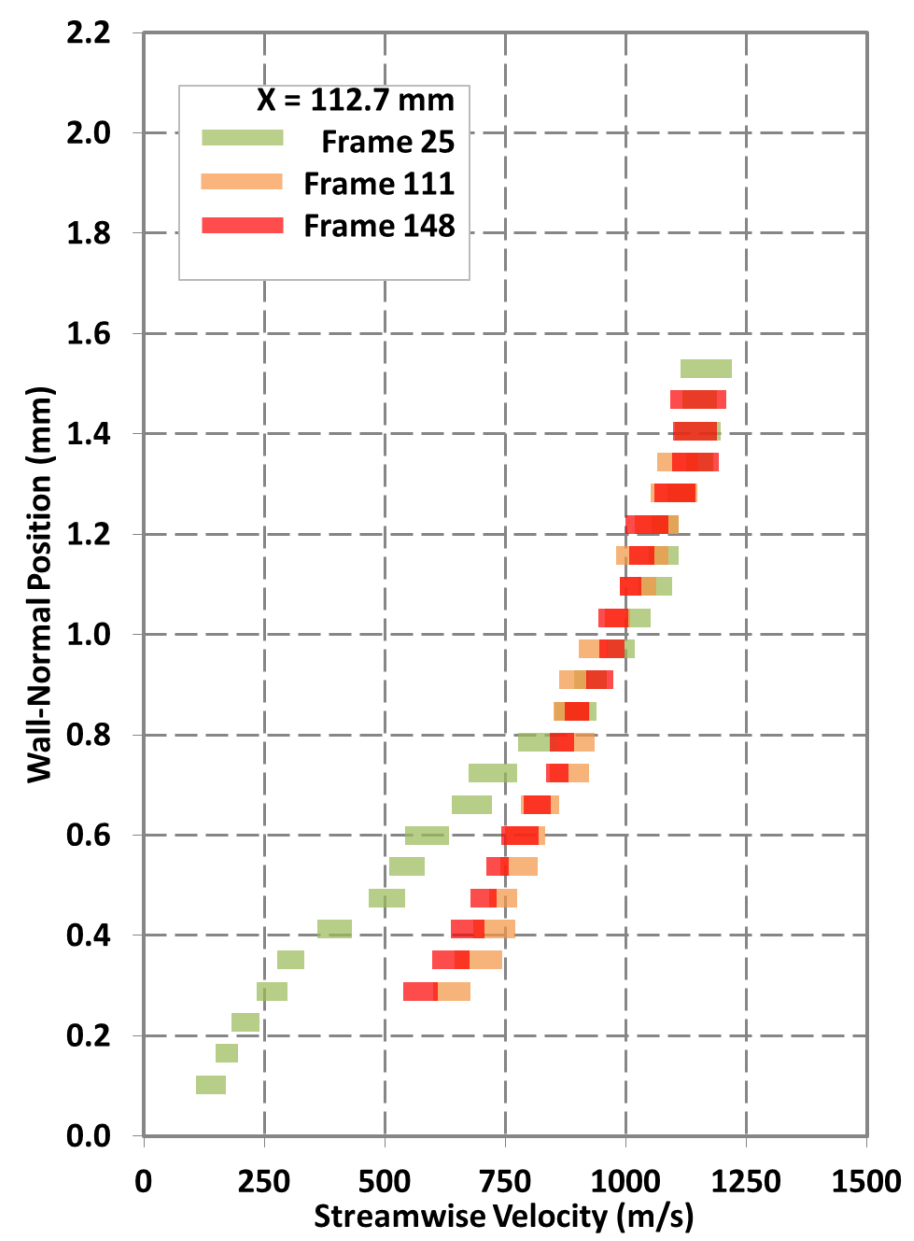

Figure A12. Run 30 single-shot velocity profiles at $112.7 \mathrm{~mm}$ downstream of leading edge, $z=+6.0 \mathrm{~mm}$ off of centerline. 


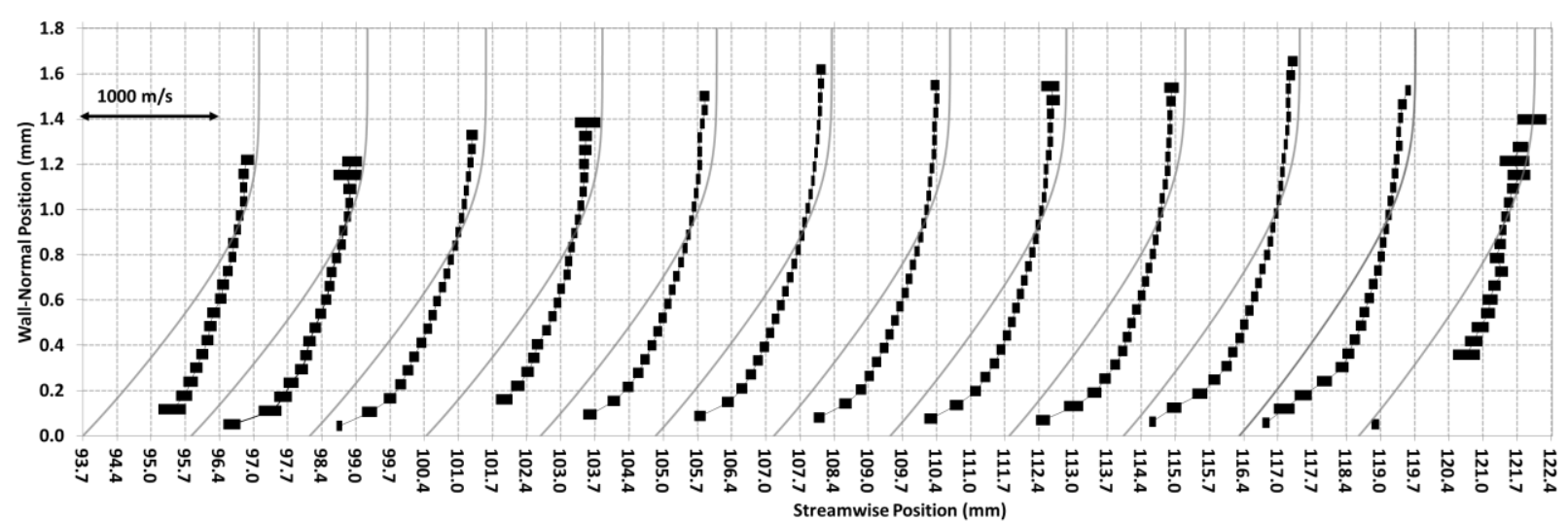

(a)

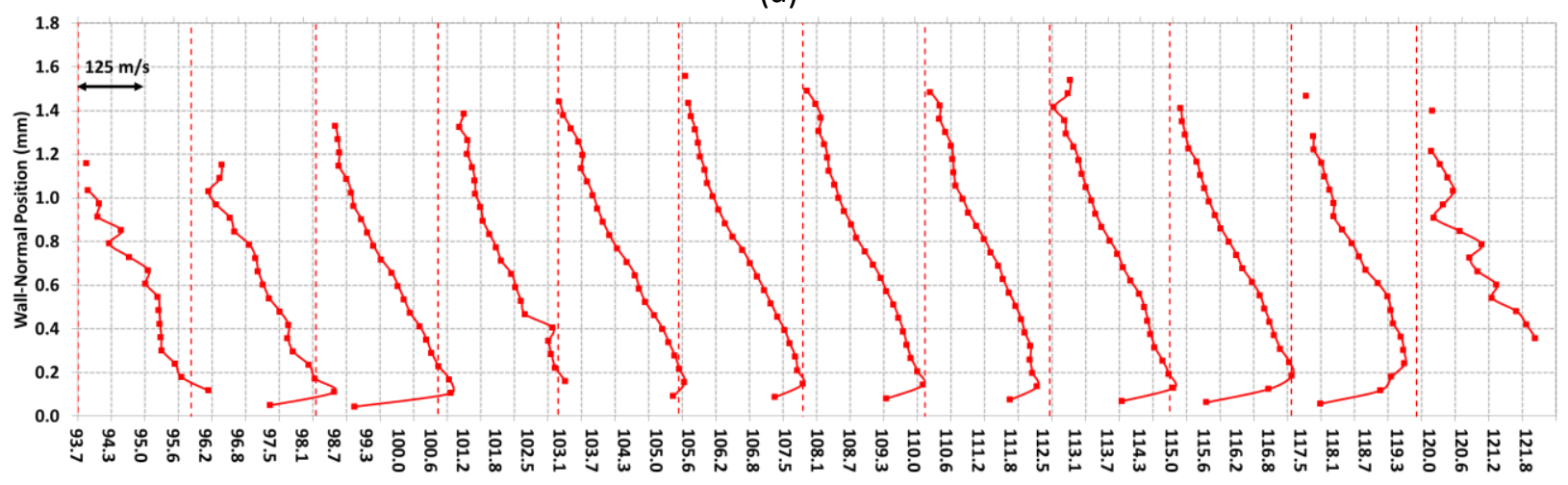

Streamwise Position $(\mathrm{mm})$

(b)

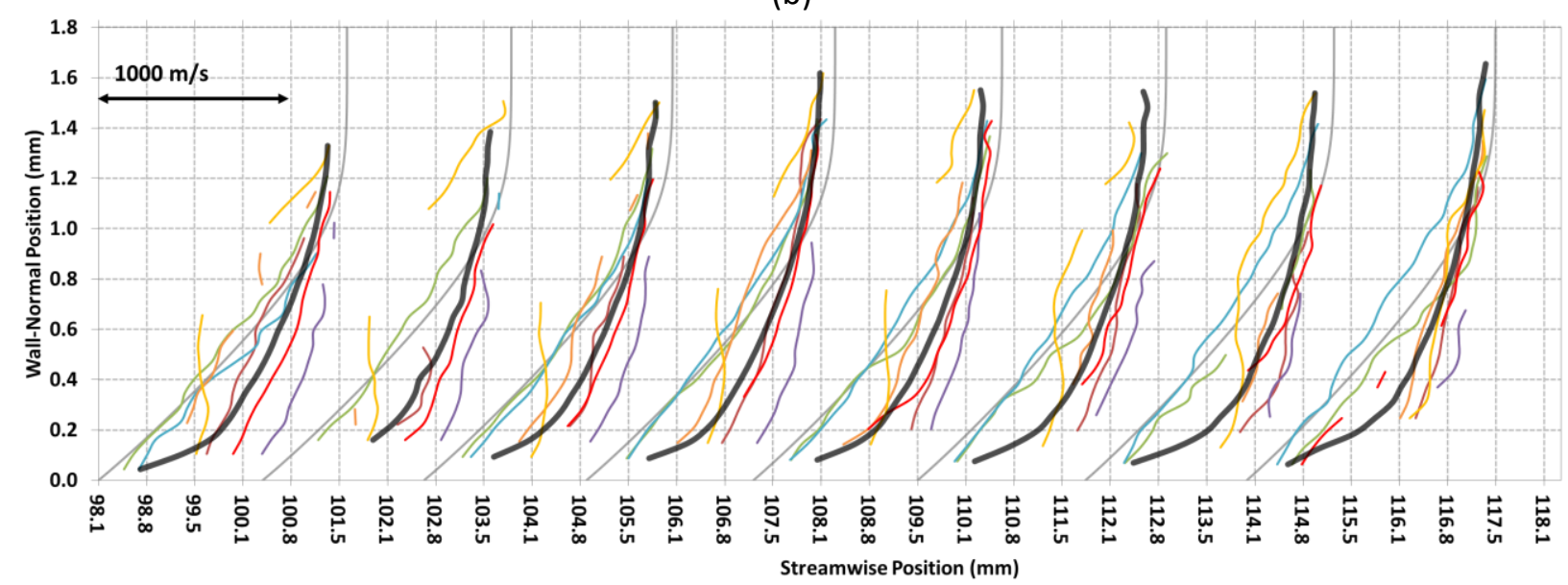

(c)

Figure A13. Run 16 (a) mean, (b) fluctuating, and (c) single-shot velocity profiles. $k / \delta_{L}=0.47, R_{k k}=393$. Profiles taken along centerline. 


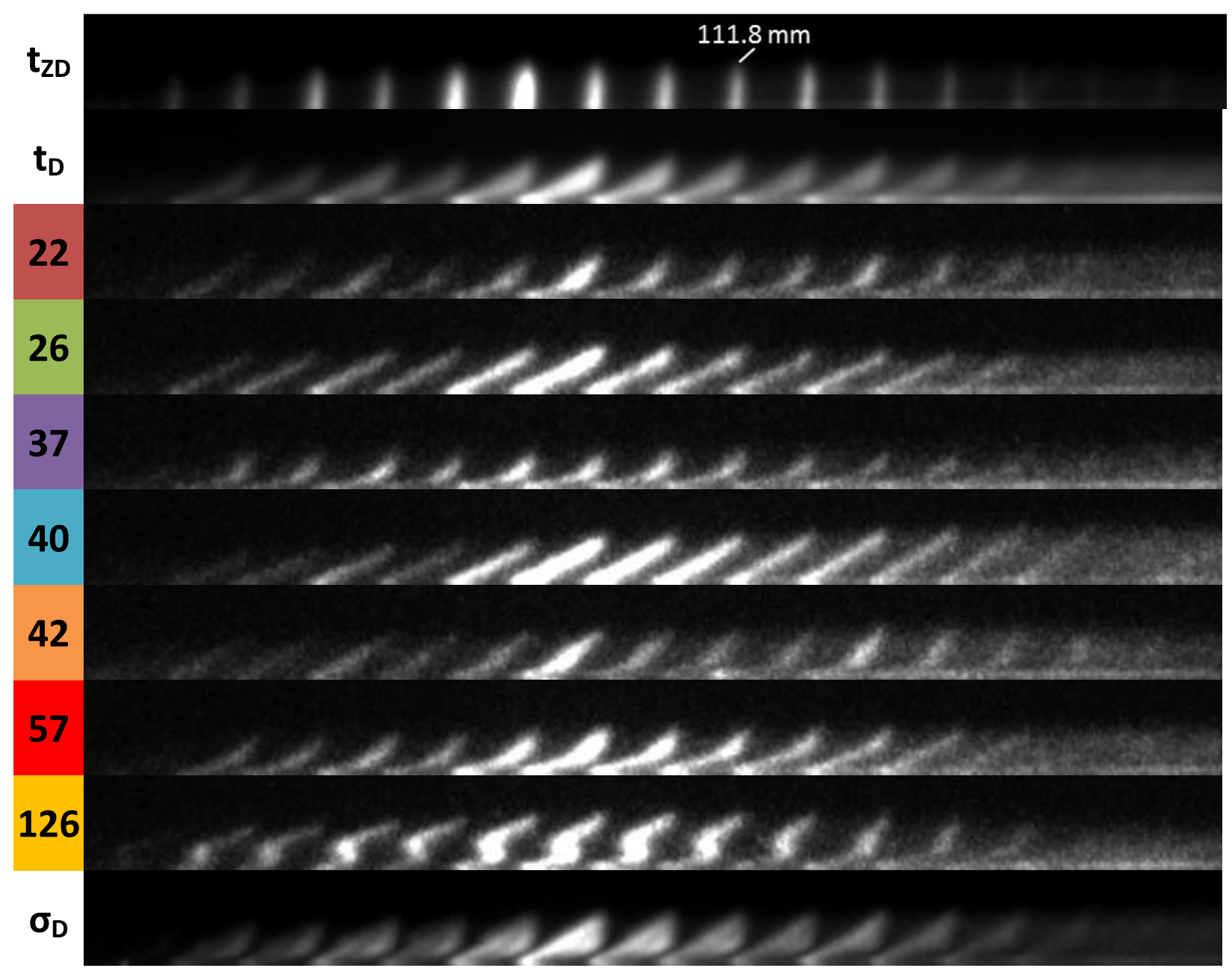

Figure A14. Run 16 (top) 155-shot average zero-delay image $\left(t_{z D}\right)$, 155-shot average delay image $\left(t_{D}\right)$, single-shot delayed images, and (bottom) 155-shot standard deviation of delayed images $\left(\sigma_{D}\right)$. Images taken along centerline. 


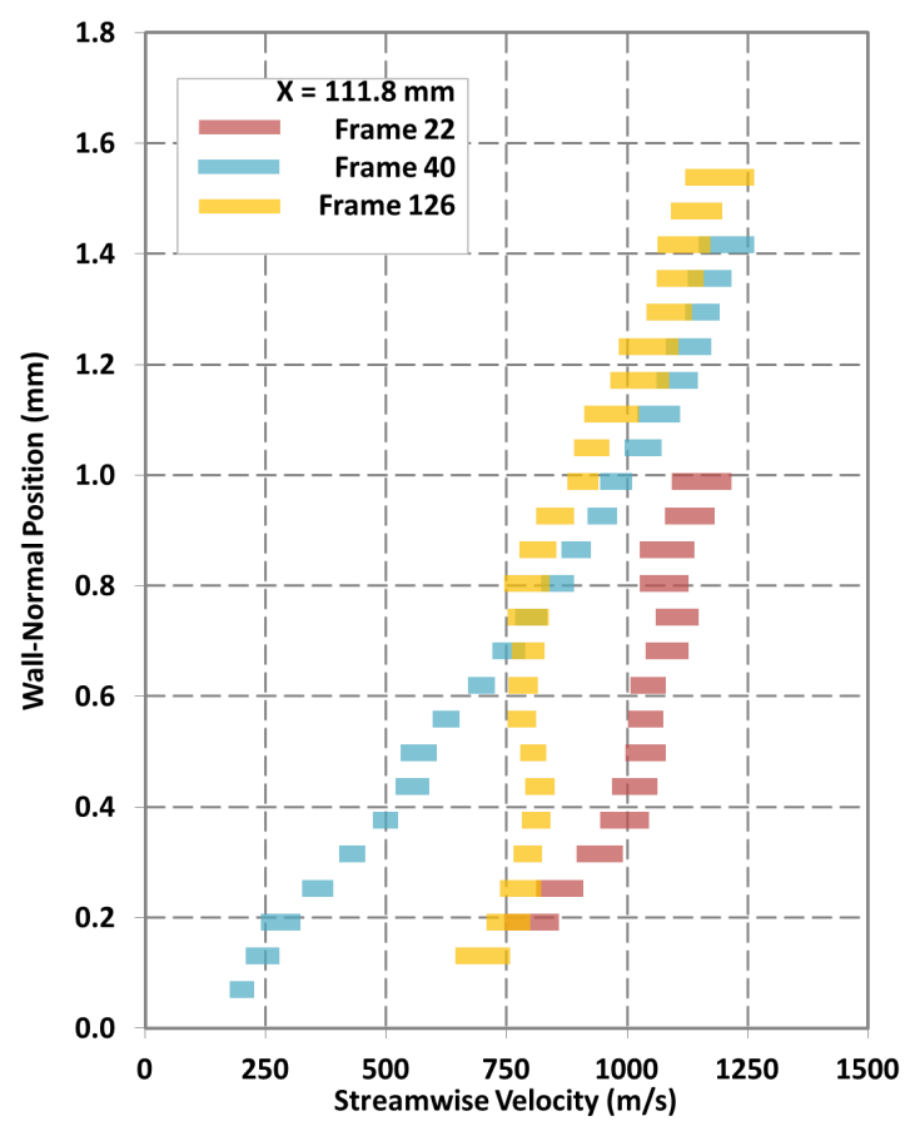

Figure A15. Run 16 single-shot velocity profiles at $111.8 \mathrm{~mm}$ downstream of leading edge, along centerline. 


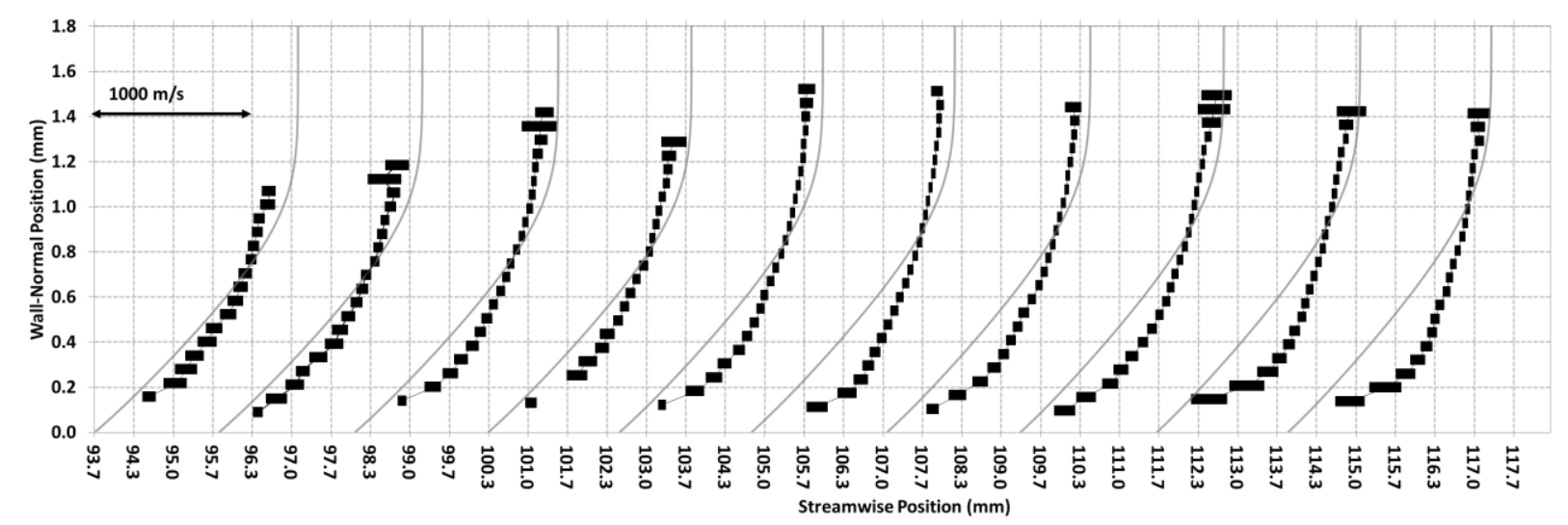

(a)

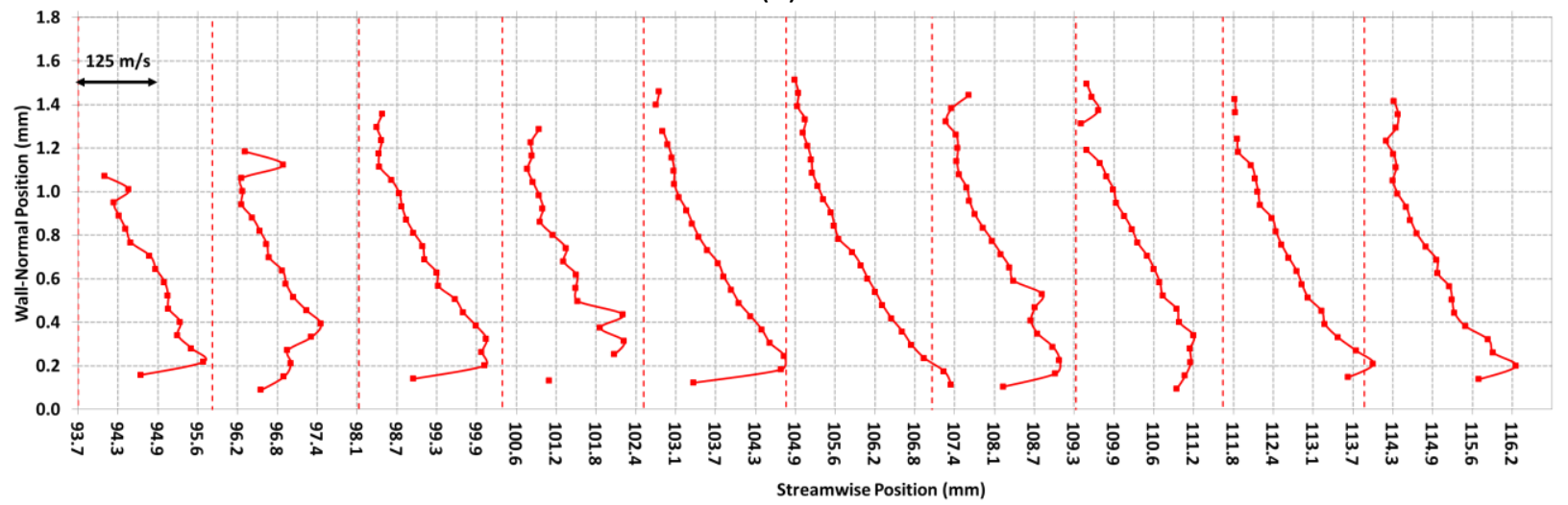

(b)

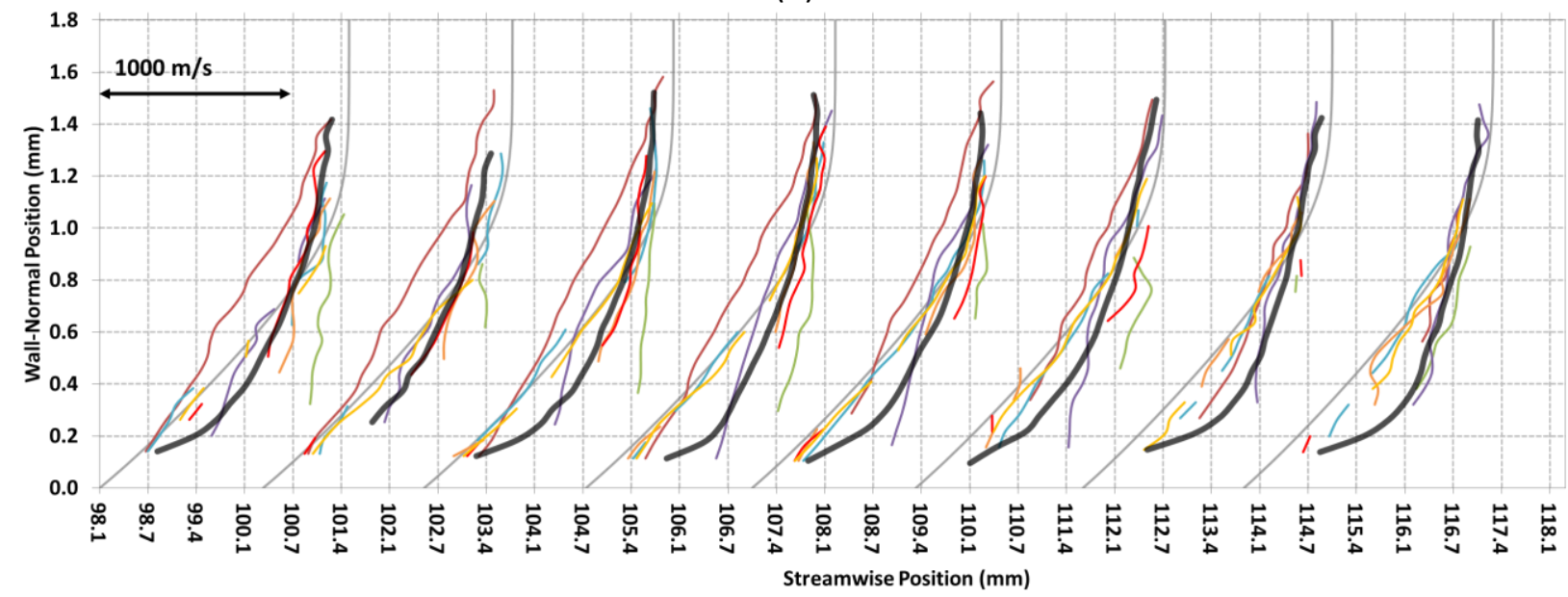

(c)

Figure A16. Run 16 (a) mean, (b) fluctuating, and (c) single-shot velocity profiles. $k / \delta_{L}=0.47, R_{k k}=420$. Profiles taken at $z=-4.5 \mathrm{~mm}$ off of centerline. 


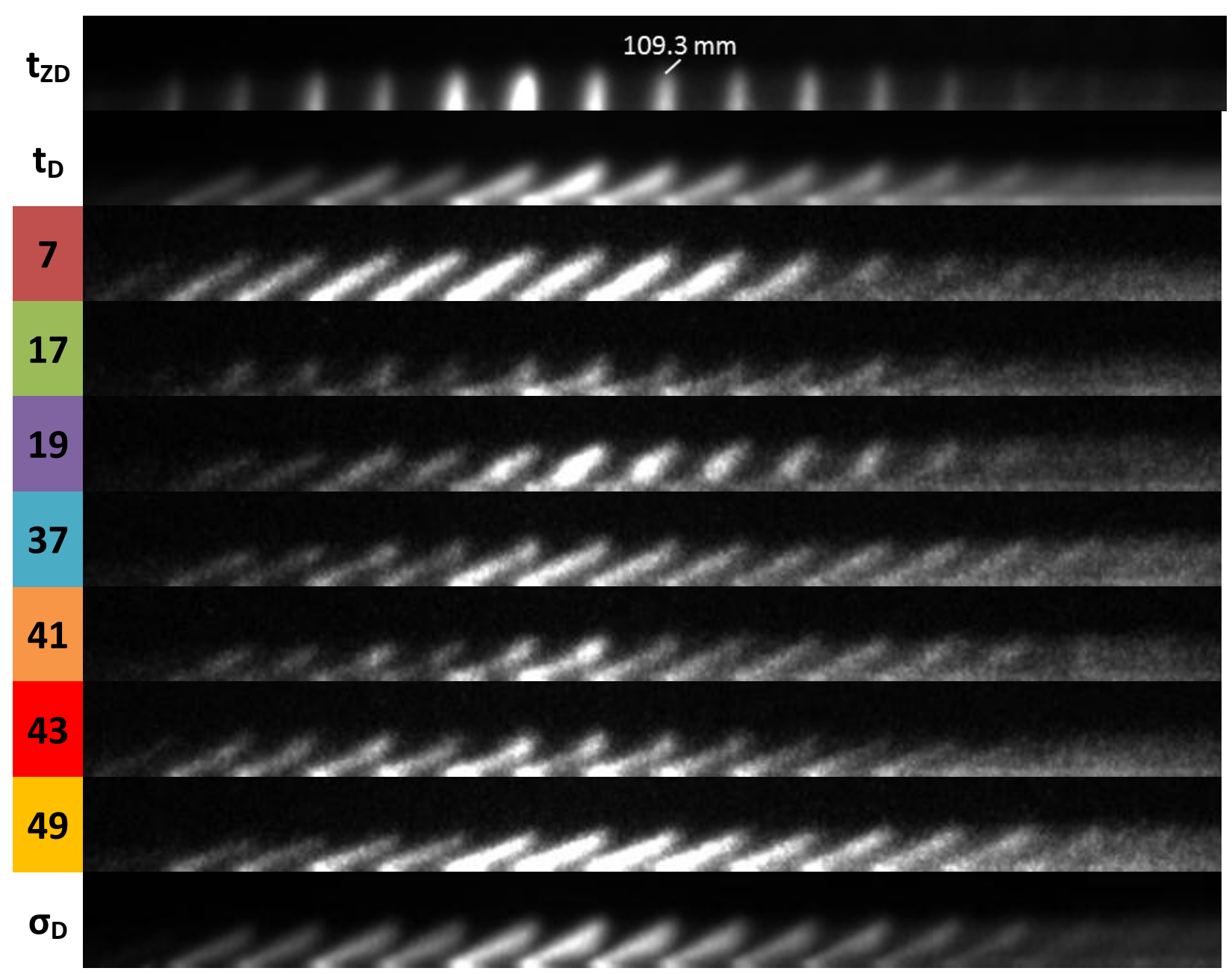

Figure A17. Run 16 (top) 150-shot average zero-delay image $\left(t_{z D}\right), 150$-shot average delay image $\left(t_{D}\right)$, single-shot delayed images, and (bottom) 150-shot standard deviation of delayed images $\left(\sigma_{D}\right)$. Images at $z=-4.5 \mathrm{~mm}$ off of centerline. 


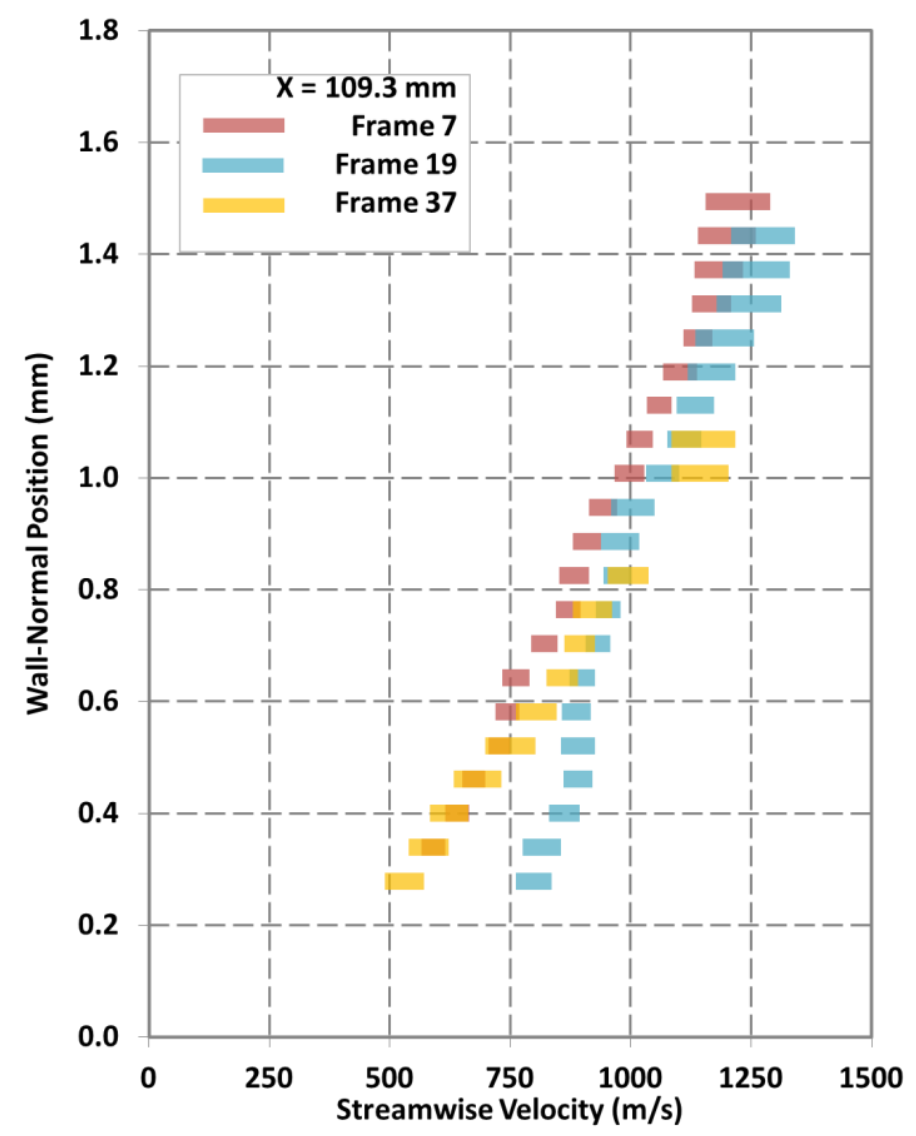

Figure A18. Run 16 single-shot velocity profiles at $109.3 \mathrm{~mm}$ downstream of leading edge, $z=-4.5 \mathrm{~mm}$ from centerline. 


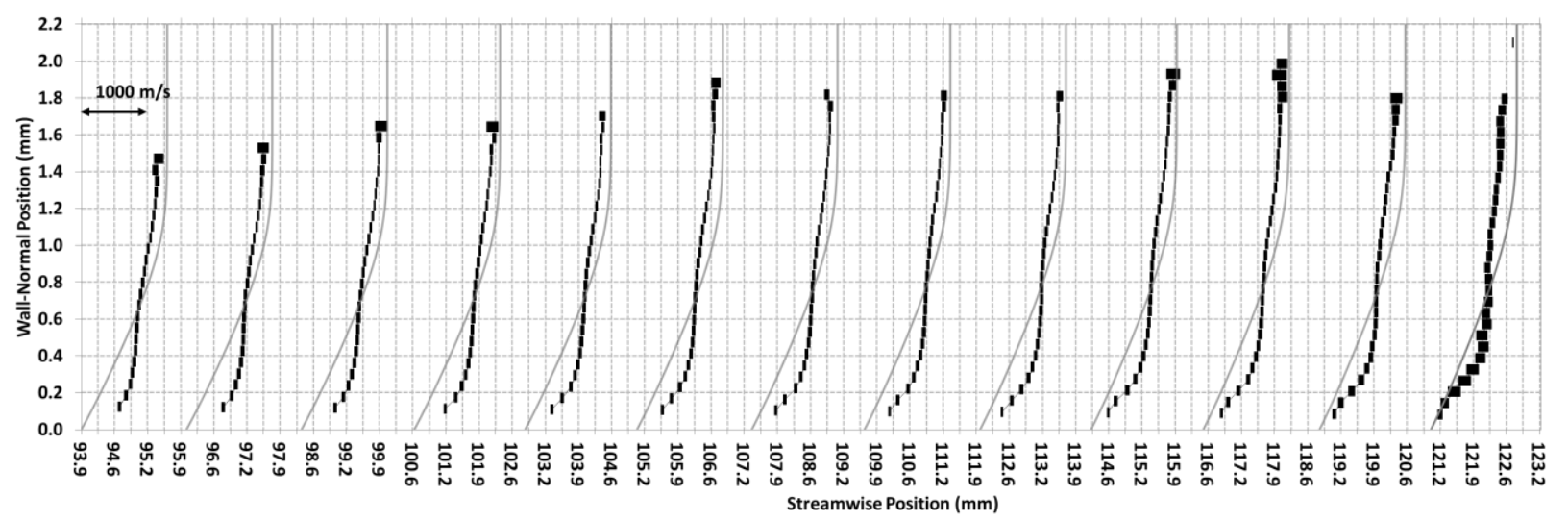

(a)

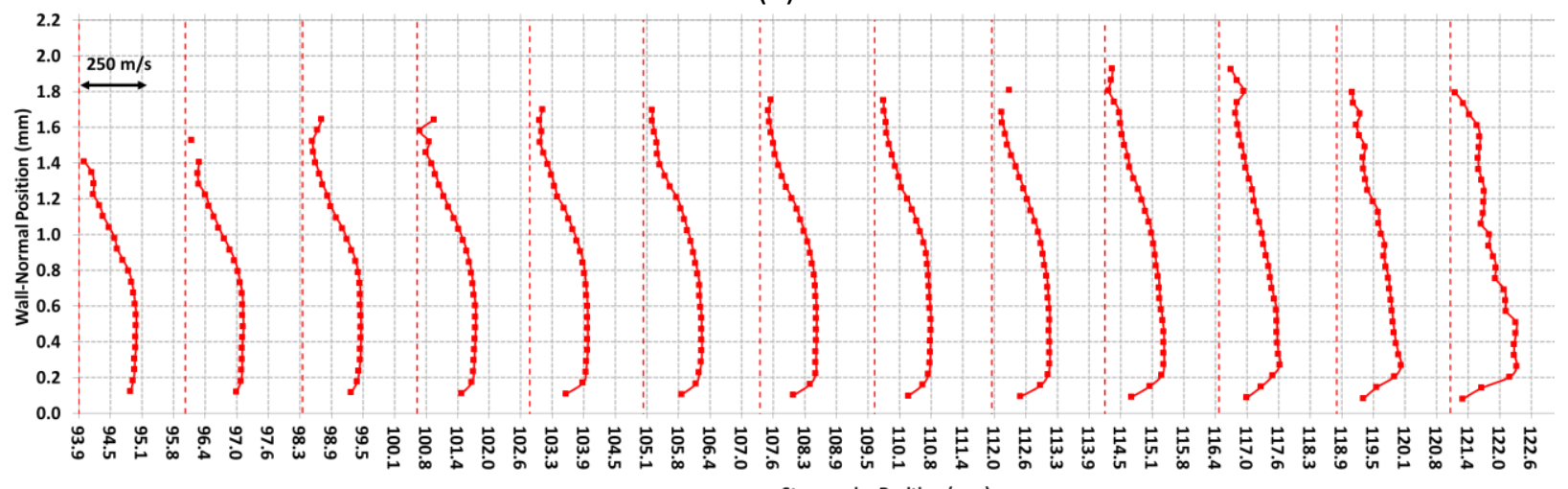

(b)

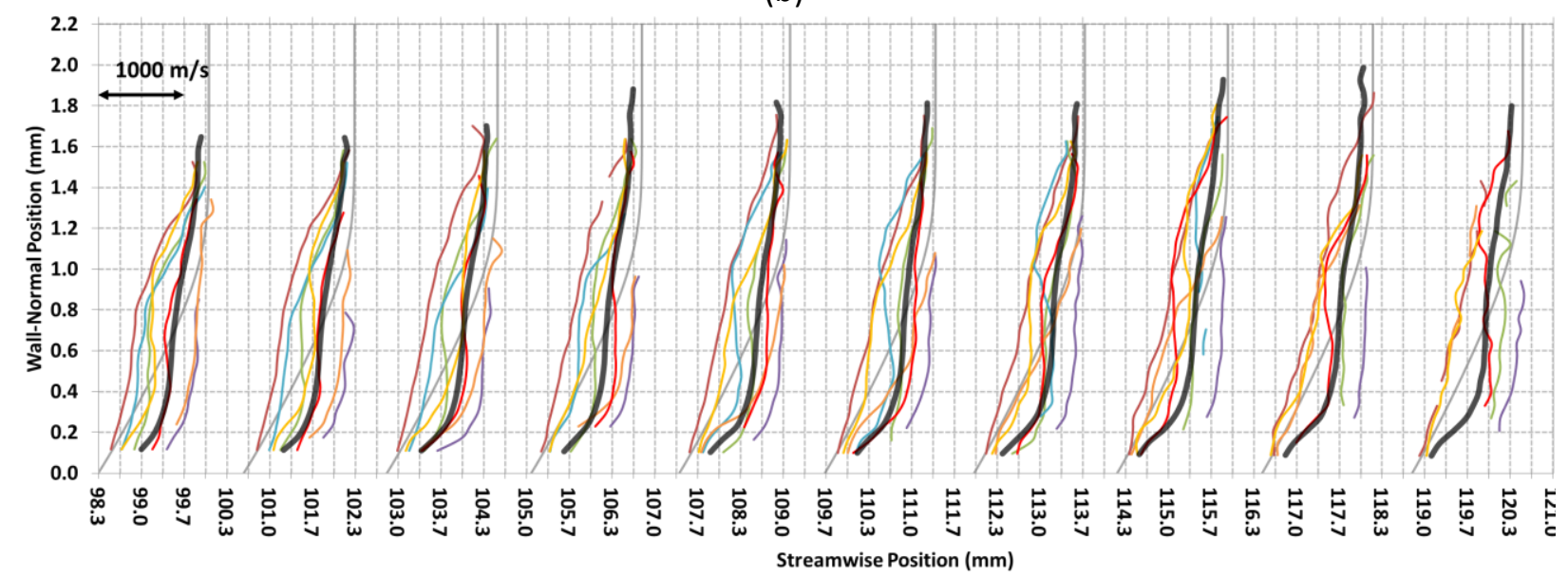

(c)

Figure A19. Run 14 (a) mean, (b) fluctuating, and (c) single-shot velocity profiles. $k / \delta_{L}=0.86, R_{k k}=1698$. Profiles taken along centerline. 


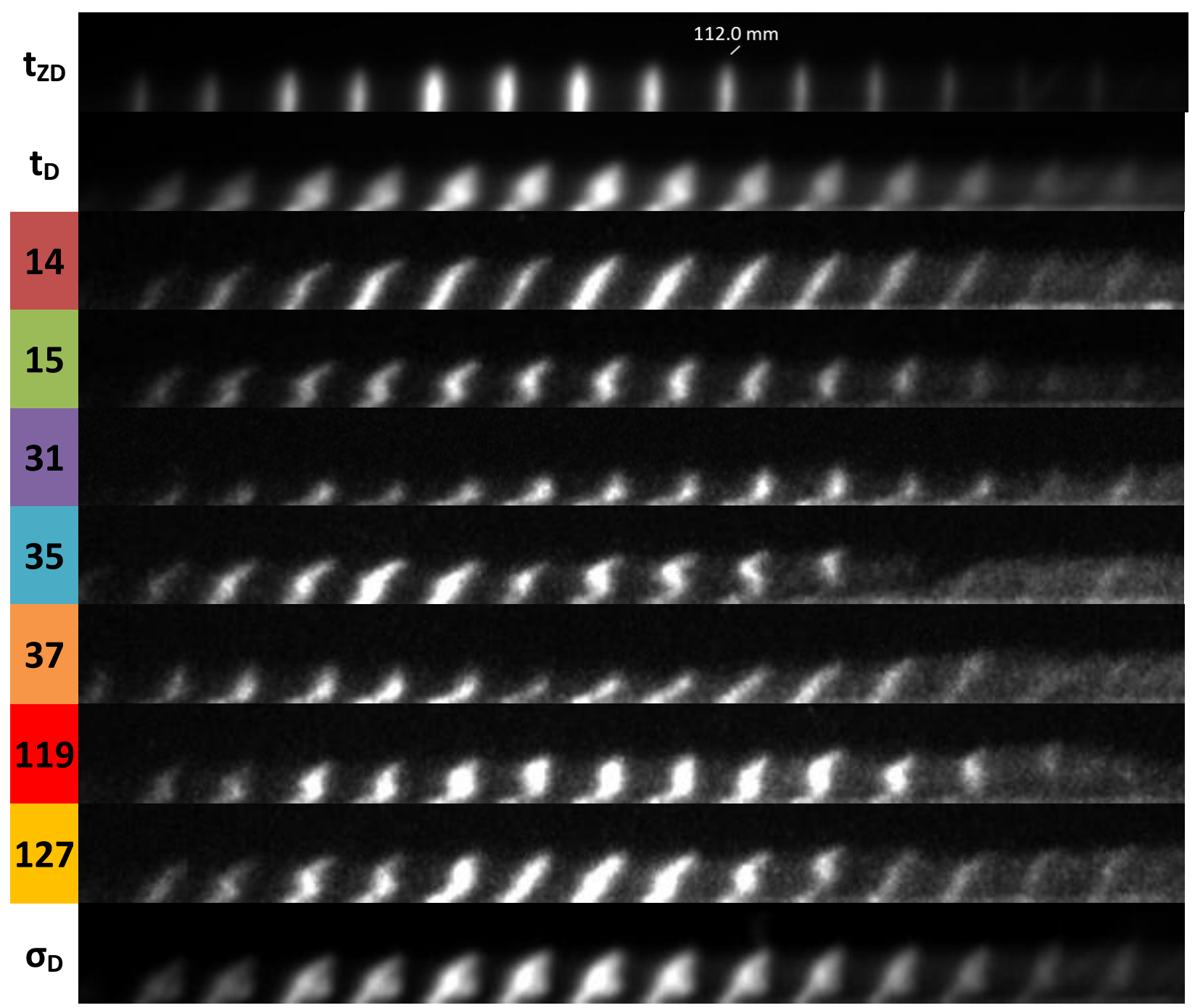

Figure A20. Run 14 (top) 292-shot average zero-delay image ( $\left.t_{\mathrm{zD}}\right)$, 292-shot average delay image $\left(t_{D}\right)$, single-shot delayed images, and (bottom) 292-shot standard deviation of delayed images $\left(\sigma_{D}\right)$. Images along centerline. 


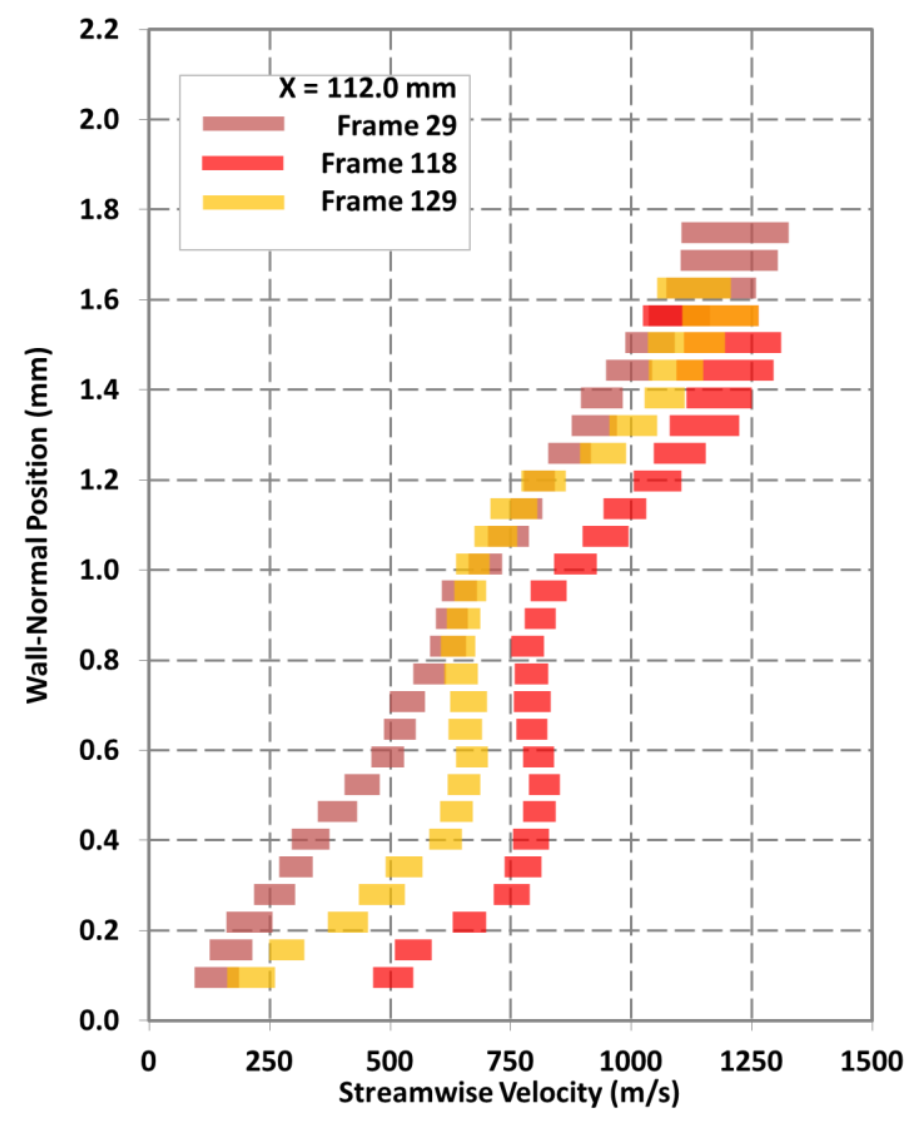

Figure A21. Run 14 single-shot velocity profiles at $112.0 \mathrm{~mm}$ downstream of leading edge, along centerline. 


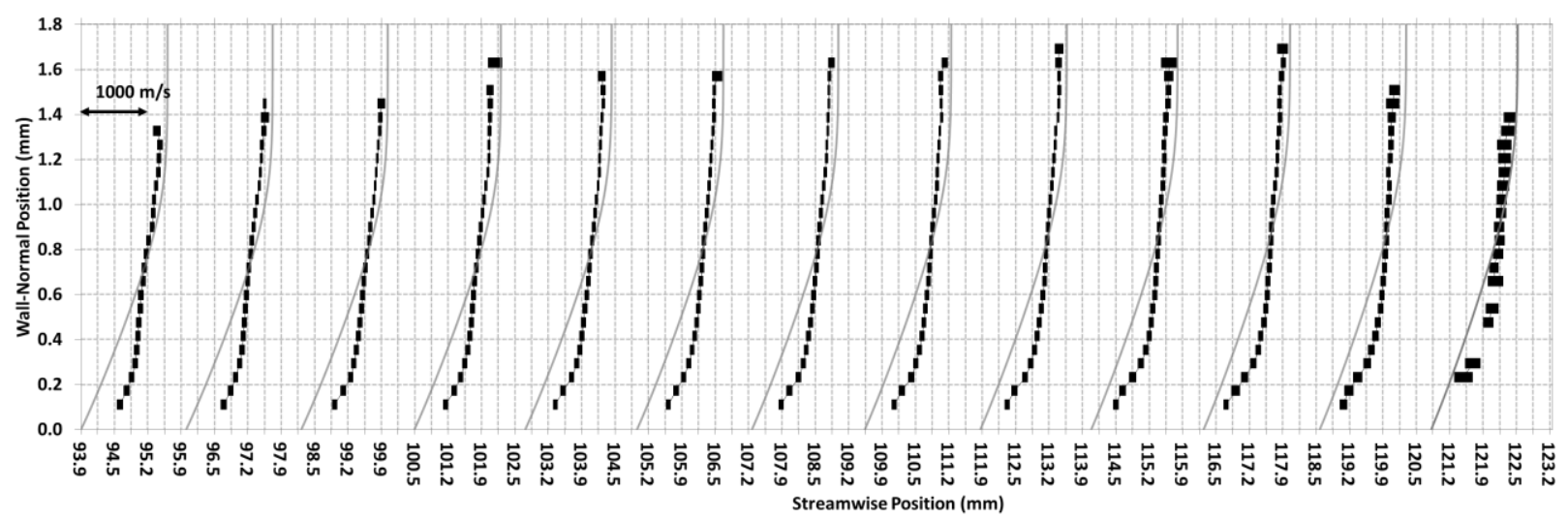

(a)

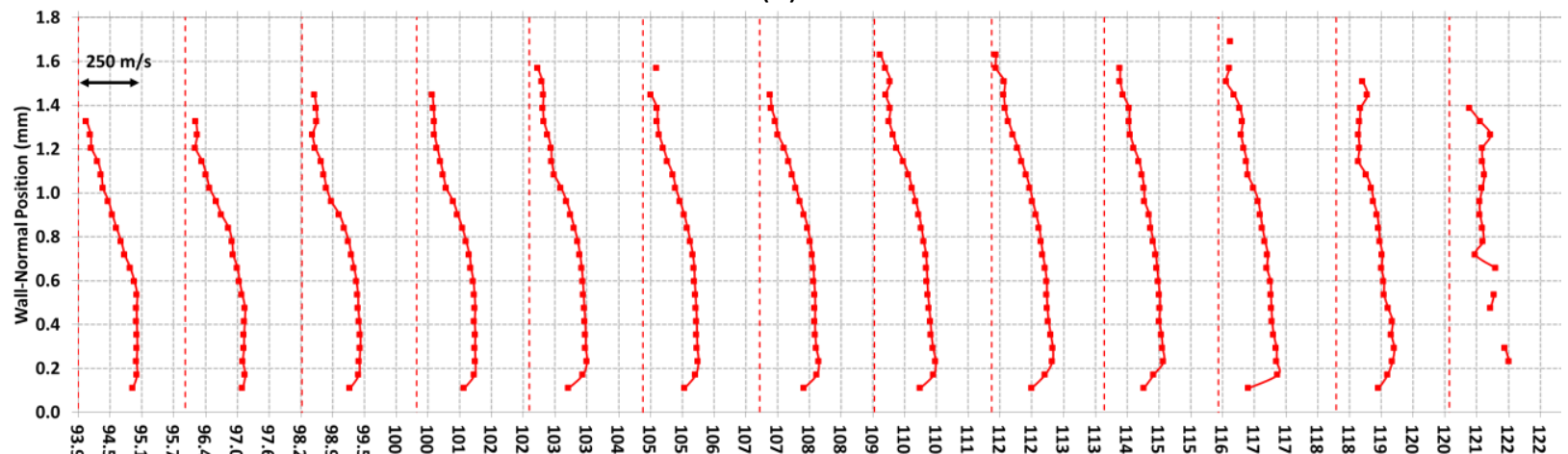

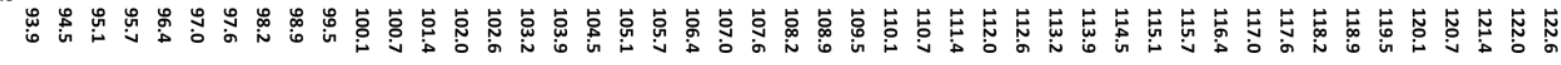

(b)

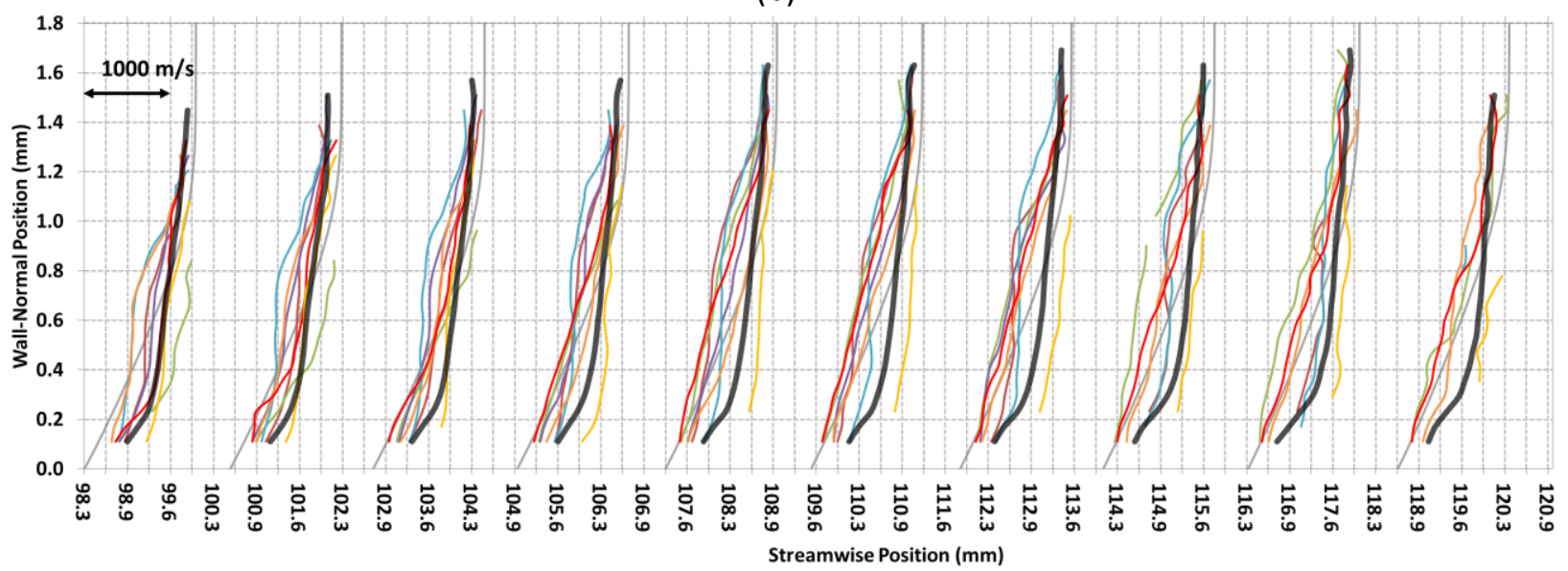

(c)

Figure A22. Run 14 (a) mean, (b) fluctuating, and (c) single-shot velocity profiles. $k / \delta_{L}=0.87, R_{k k}=1798$. Profiles taken at $z=-4.5 \mathrm{~mm}$ off of centerline. 


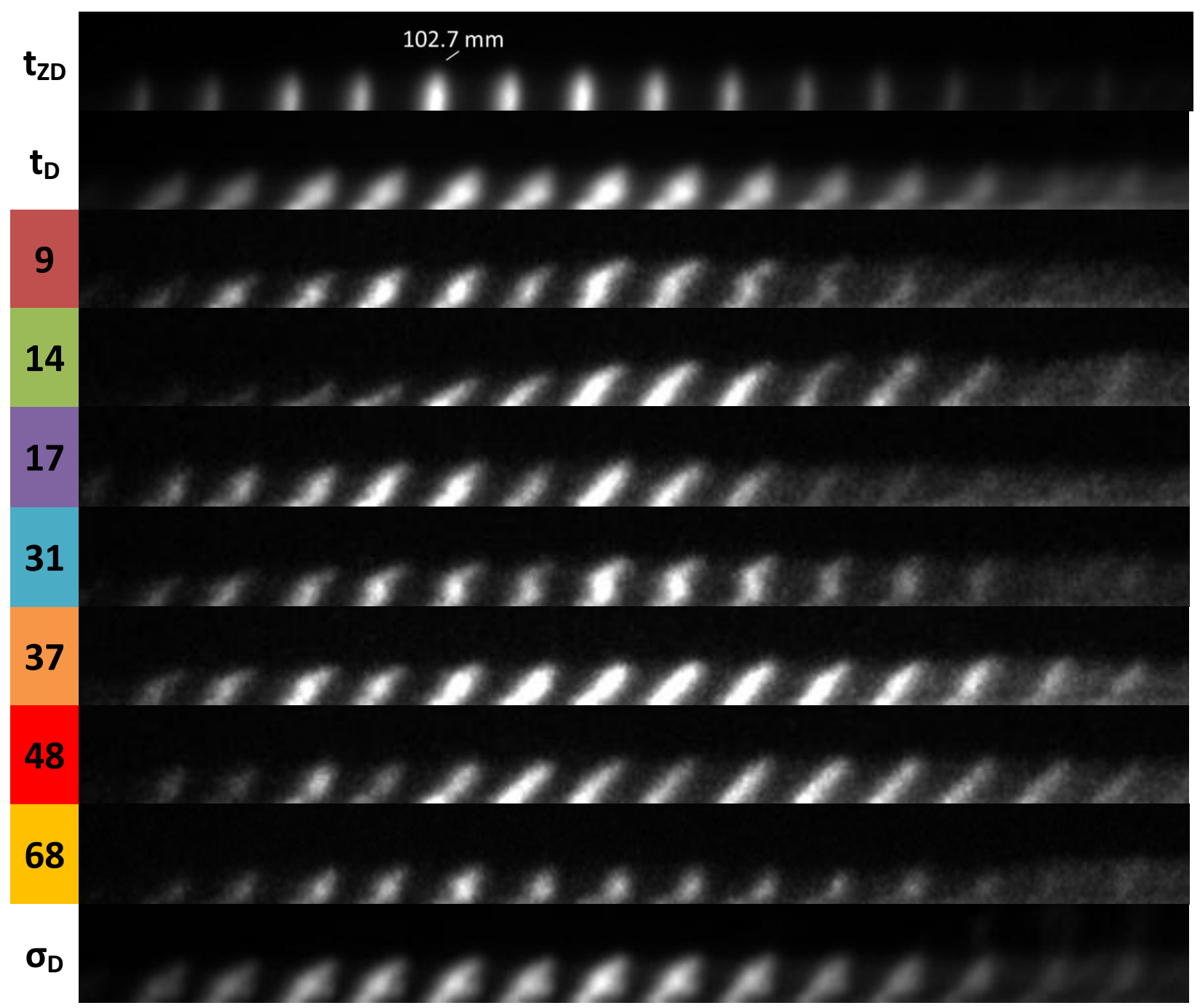

Figure A23. Run 14 (top) 150-shot average zero-delay image $\left(t_{z D}\right), 150$-shot average delay image $\left(t_{D}\right)$, single-shot delayed images, and (bottom) 150-shot standard deviation of delayed images $\left(\sigma_{D}\right)$. Images at $z=-4.5 \mathrm{~mm}$ off of centerline. 


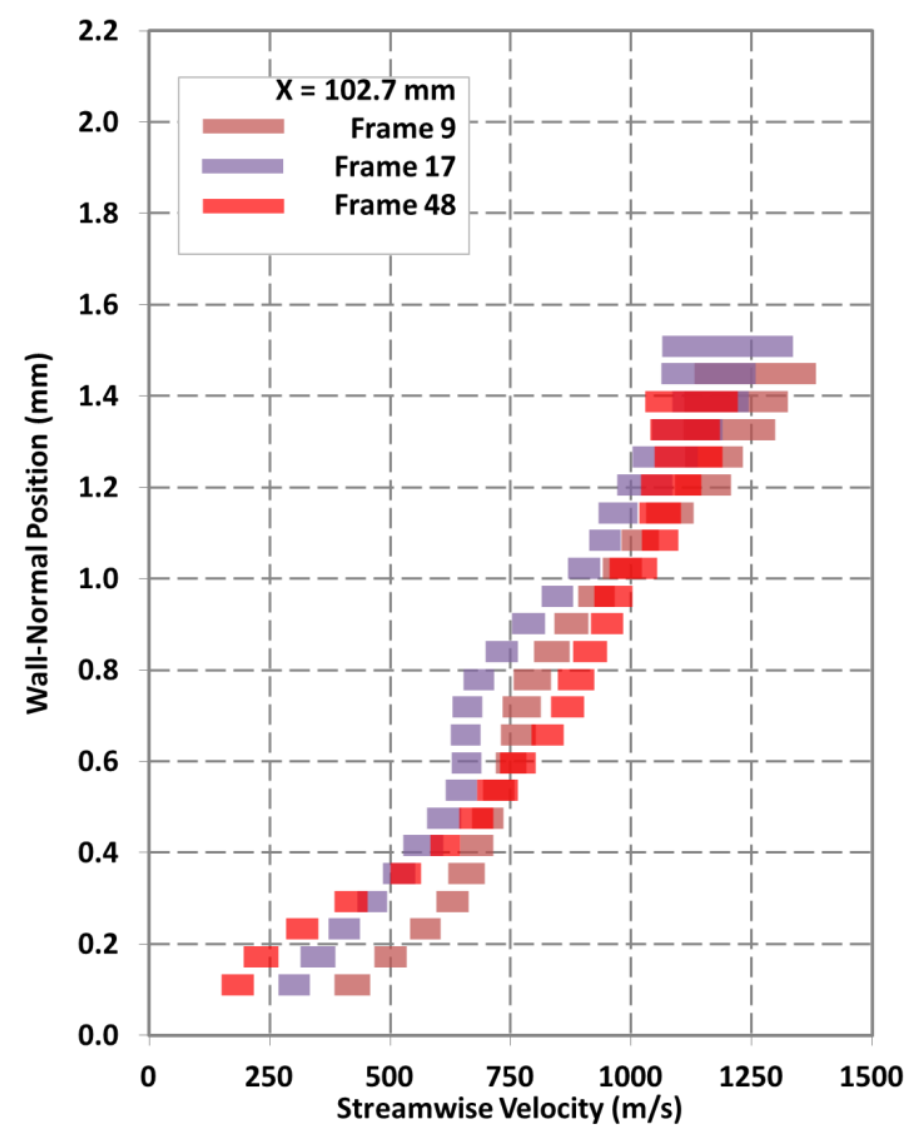

Figure A24. Run 14 single-shot velocity profiles at $102.7 \mathrm{~mm}$ downstream of leading edge, $z=-4.5 \mathrm{~mm}$ off of centerline. 


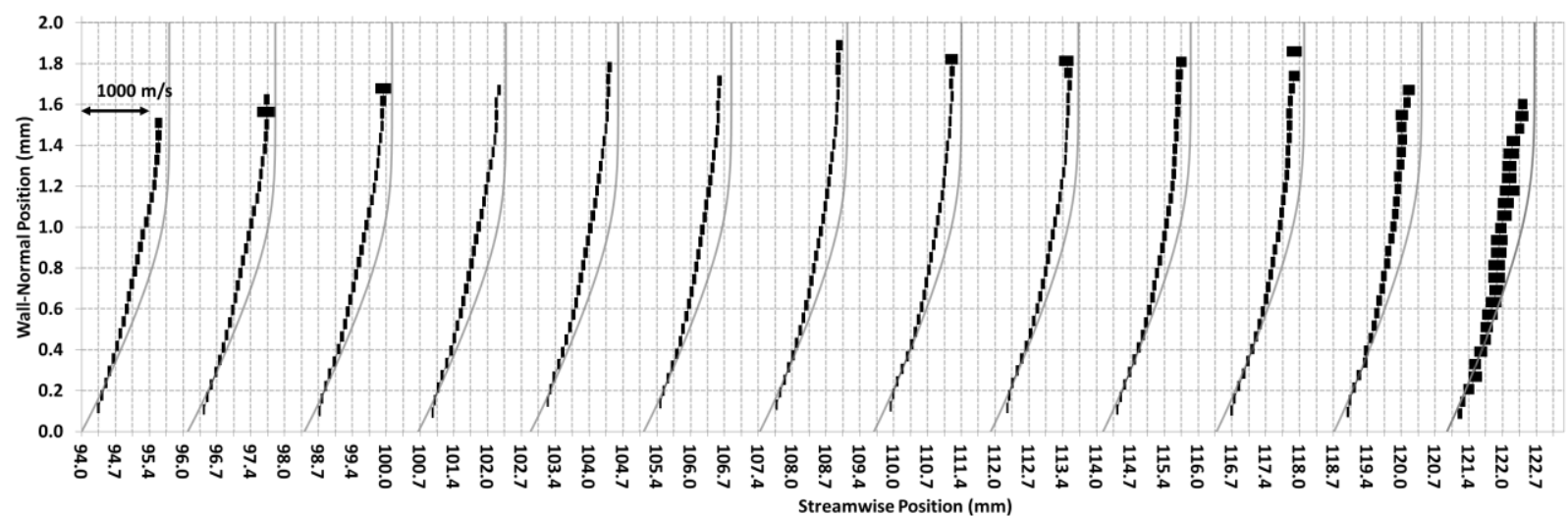

(a)

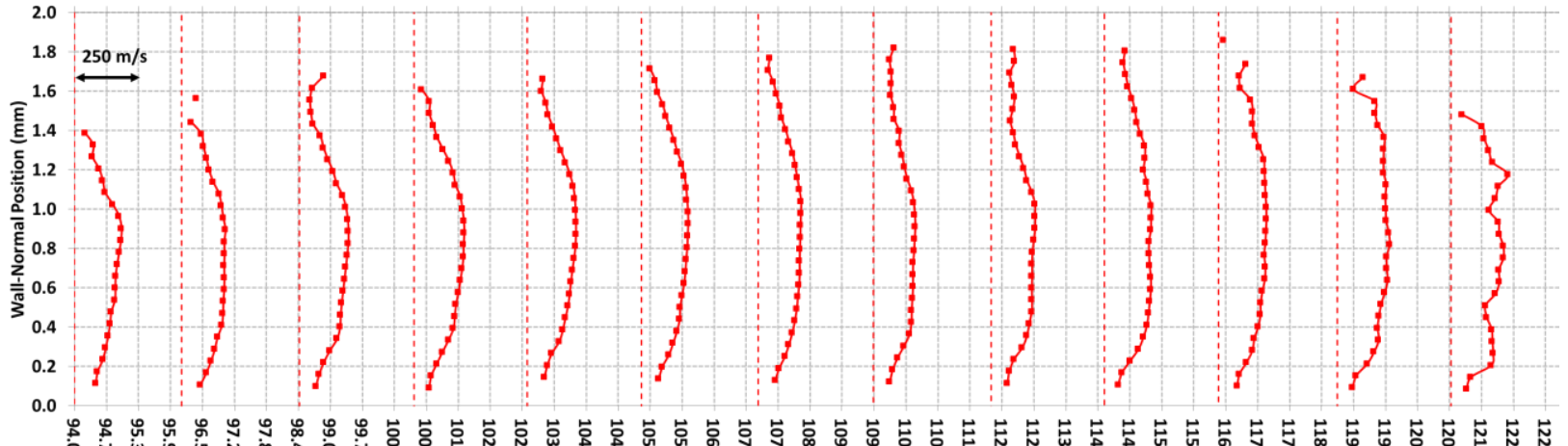

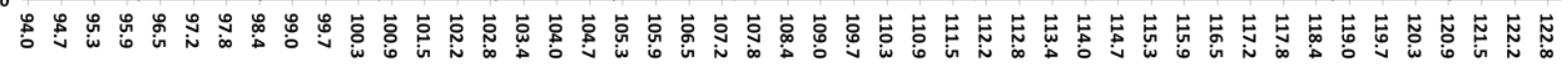

(b)

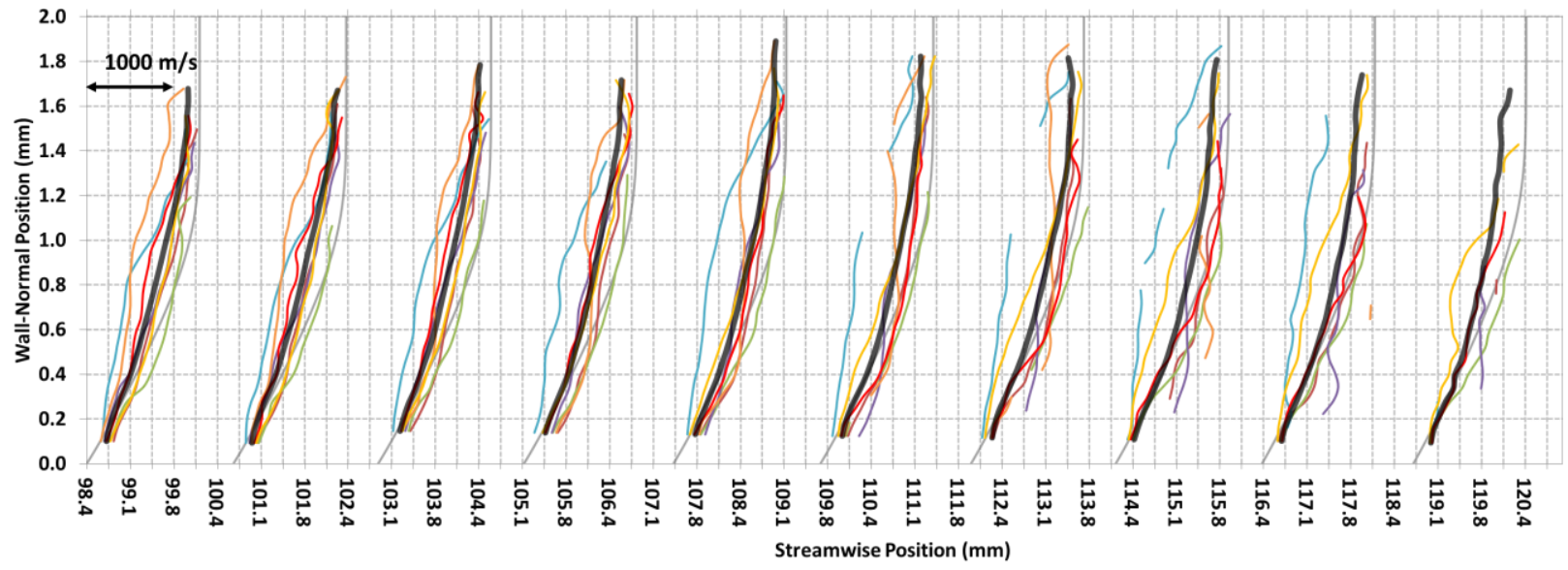

(c)

Figure A25. Run 14 (a) mean, (b) fluctuating, and (c) single-shot velocity profiles. $k / \delta_{L}=0.88, R_{k k}=1891$. Profiles taken at $z=-6.0 \mathrm{~mm}$ off of centerline. 


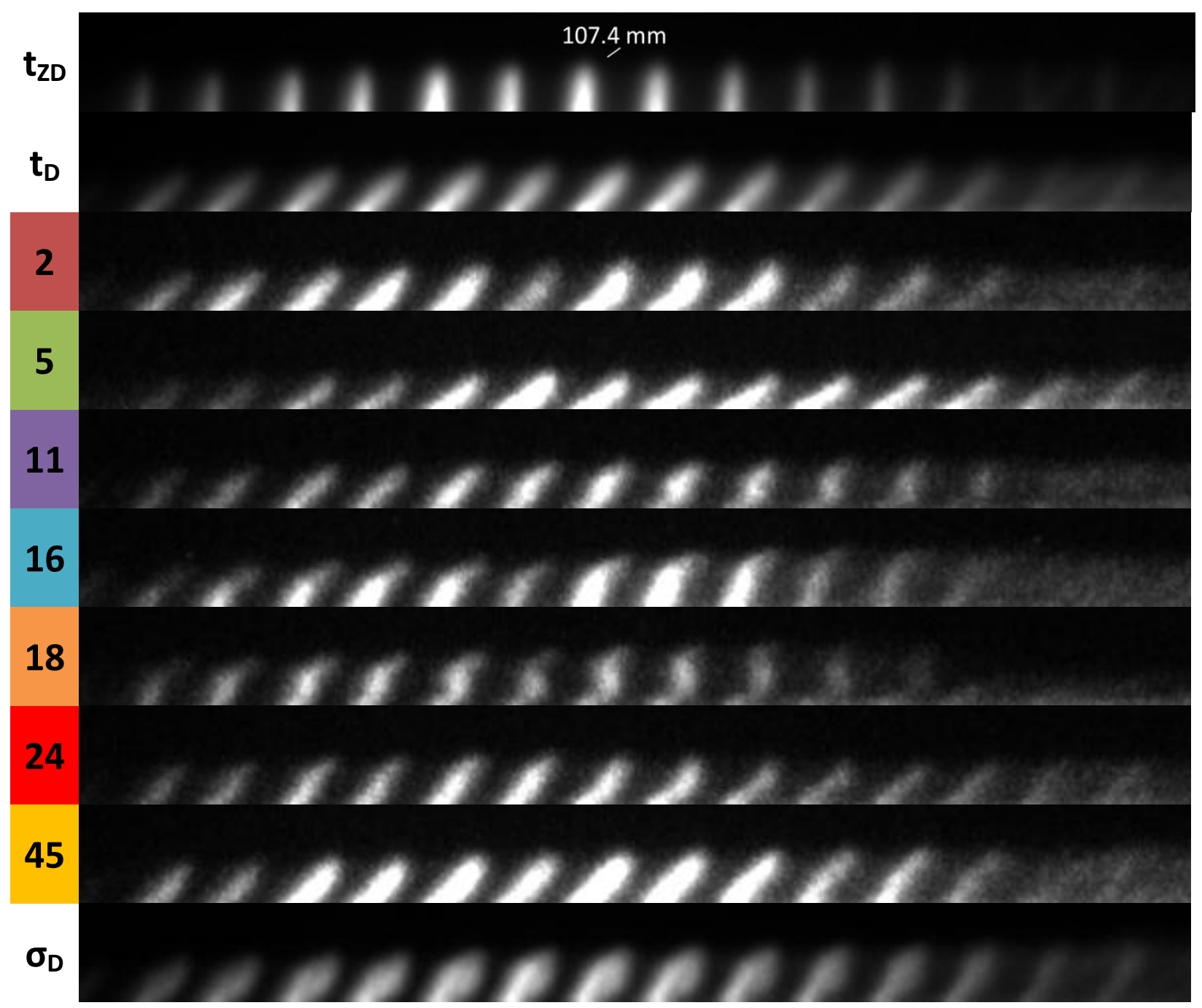

Figure A26. Run 14 (top) 149-shot average zero-delay image $\left(t_{z D}\right), 149$-shot average delay image $\left(t_{D}\right)$, single-shot delayed images, and (bottom) 149-shot standard deviation of delayed images $\left(\sigma_{D}\right)$. Images at $z=-6.0 \mathrm{~mm}$ off of centerline. 


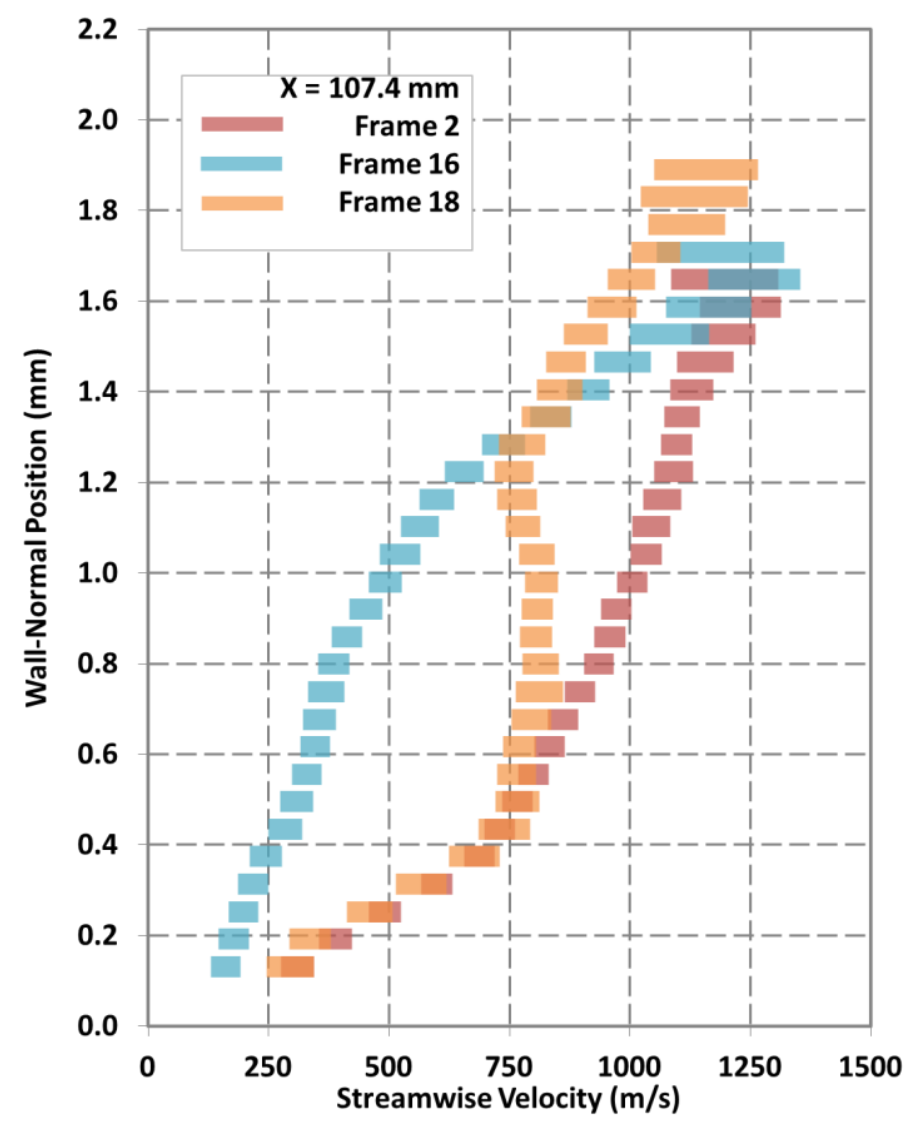

Figure A27. Run 14 single-shot velocity profiles at $107.4 \mathrm{~mm}$ downstream of leading edge, $z=-6.0 \mathrm{~mm}$ off of centerline. 


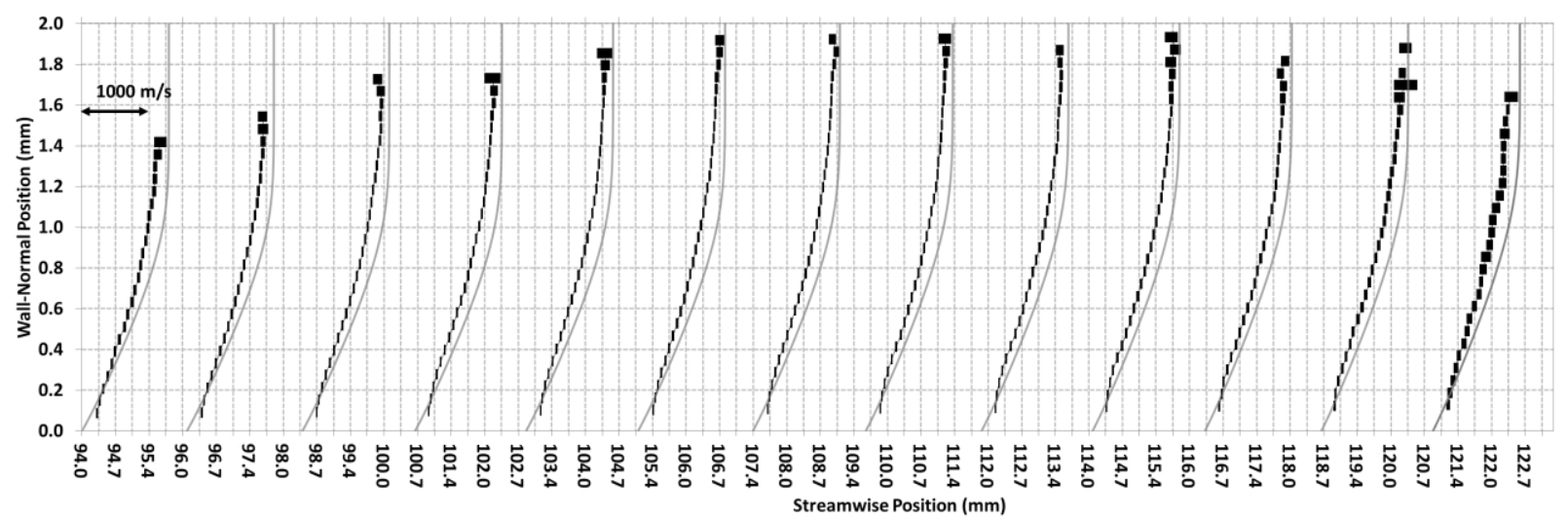

(a)

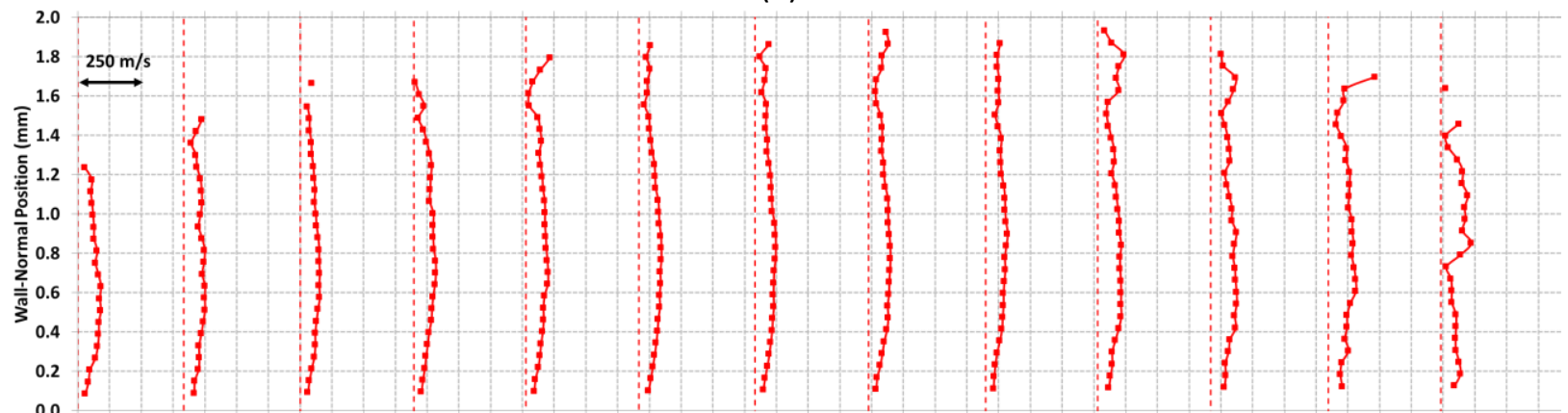

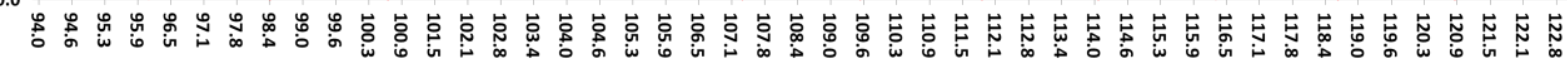

(b)

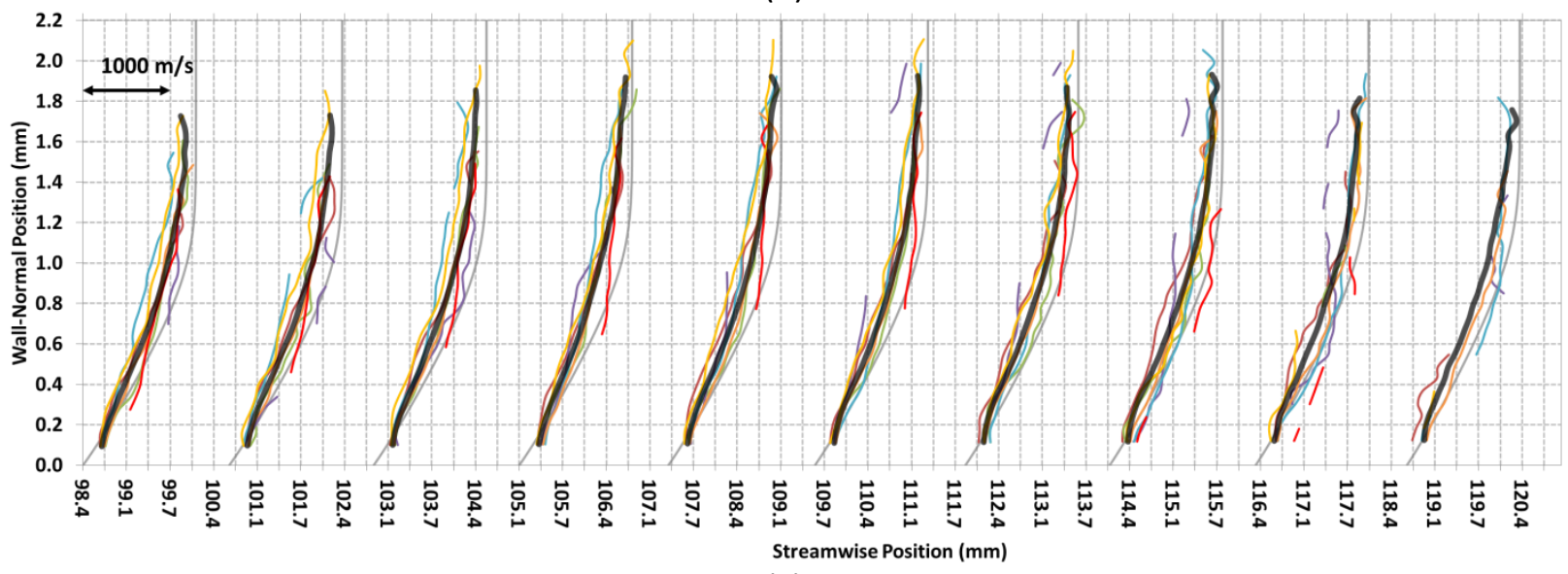

(c)

Figure A28. Run 14 (a) mean, (b) fluctuating, and (c) single-shot velocity profiles. $k / \delta_{L}=0.90, R_{k k}=1999$. Profiles taken at $z=-7.5 \mathrm{~mm}$ off of centerline. 


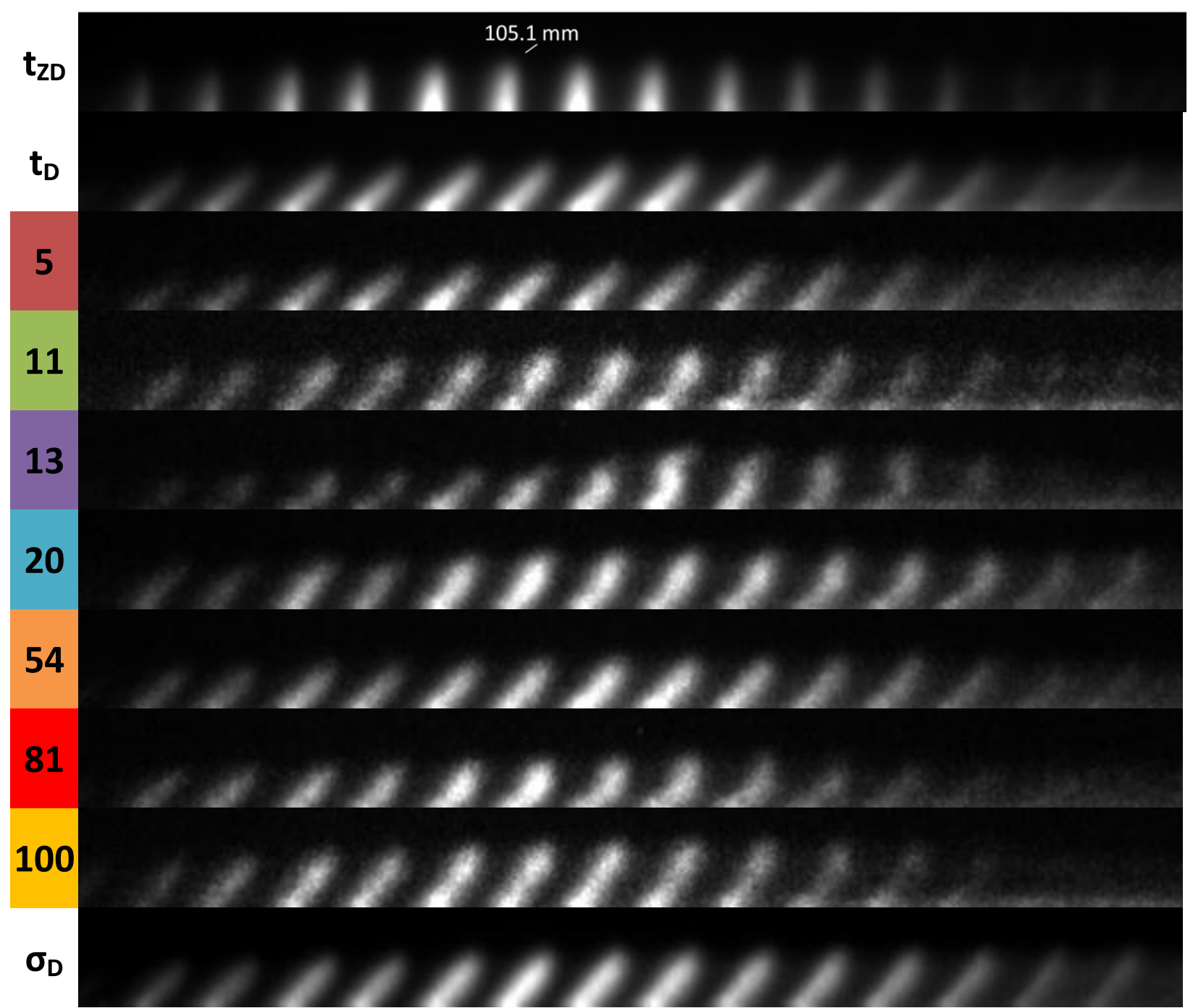

Figure A29. Run 14 (top) 150-shot average zero-delay image $\left(t_{z \mathrm{D}}\right)$, 150-shot average delay image $\left(t_{\mathrm{D}}\right)$, single-shot delayed images, and (bottom) 150-shot standard deviation of delayed images $\left(\sigma_{D}\right)$. Images at $z=-7.5 \mathrm{~mm}$ off of centerline. 


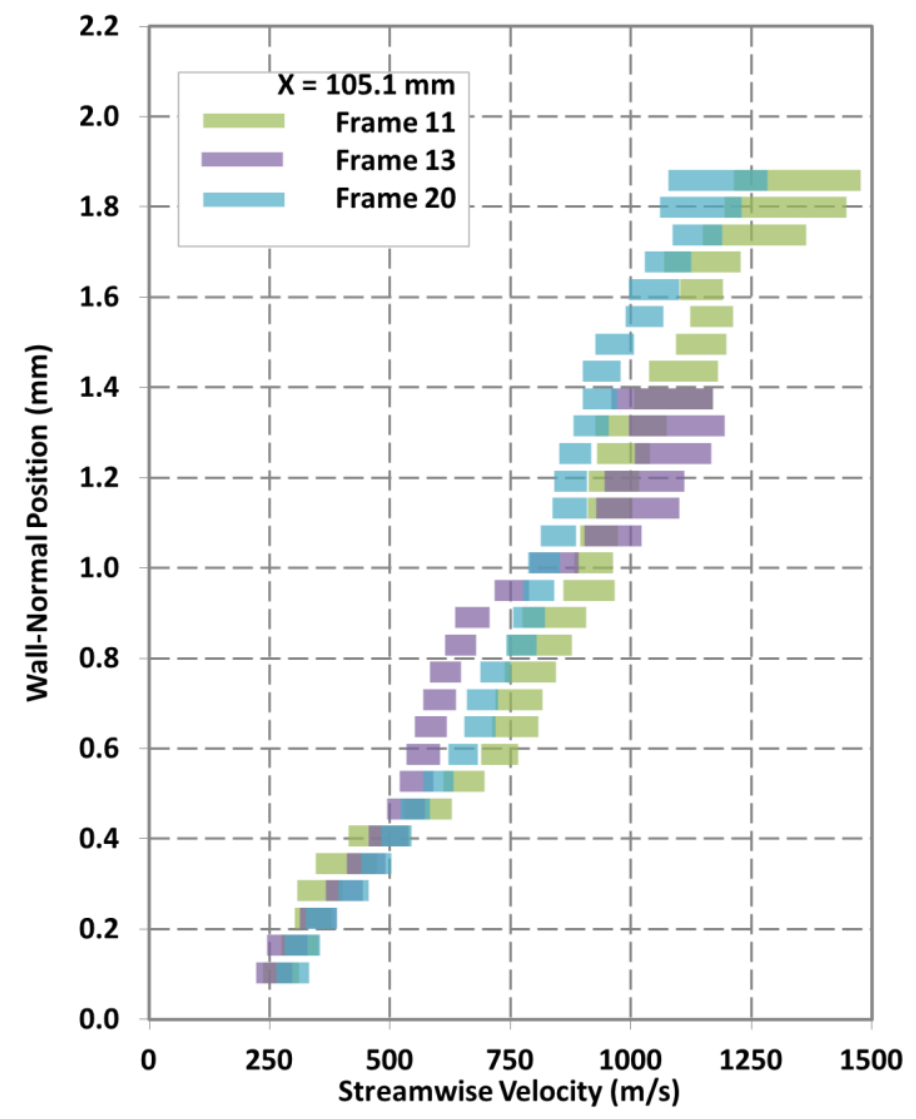

Figure A30. Run 14 single-shot velocity profiles at $105.1 \mathrm{~mm}$ downstream of leading edge, $z=-7.5 \mathrm{~mm}$ off of centerline. 


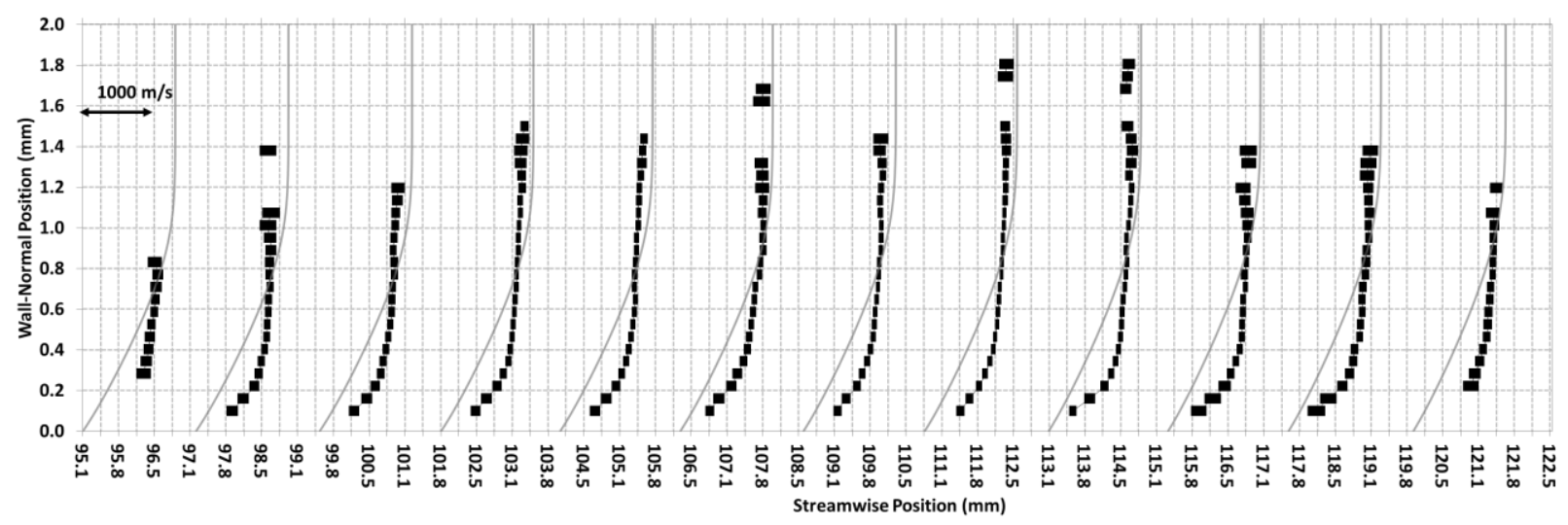

(a)

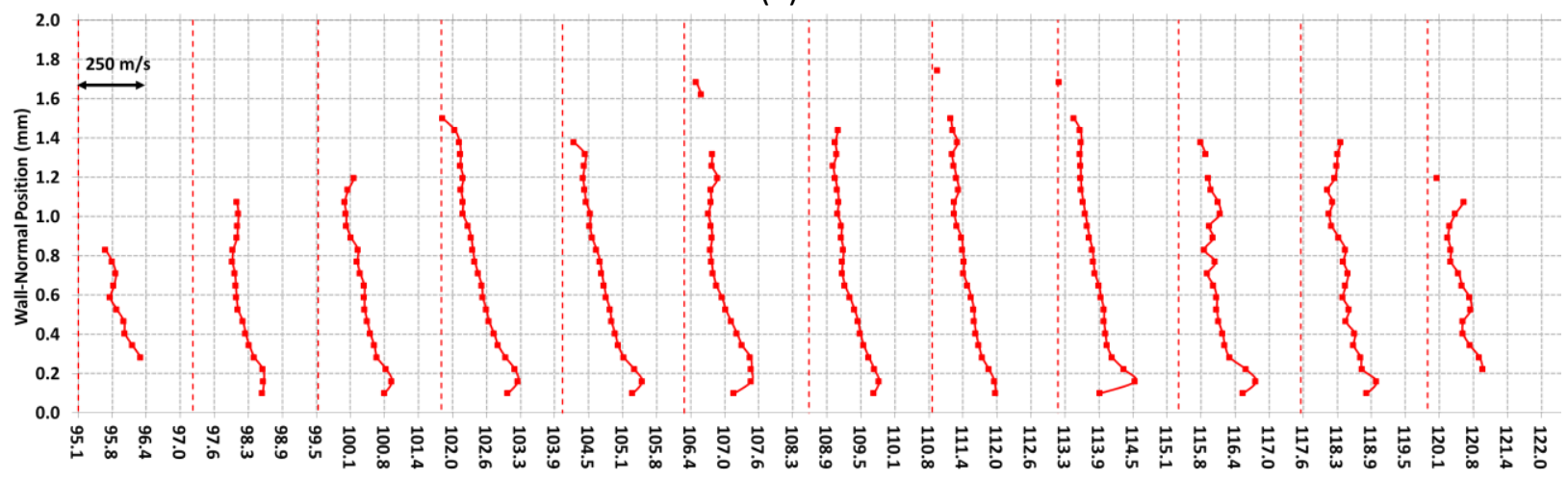

(b)

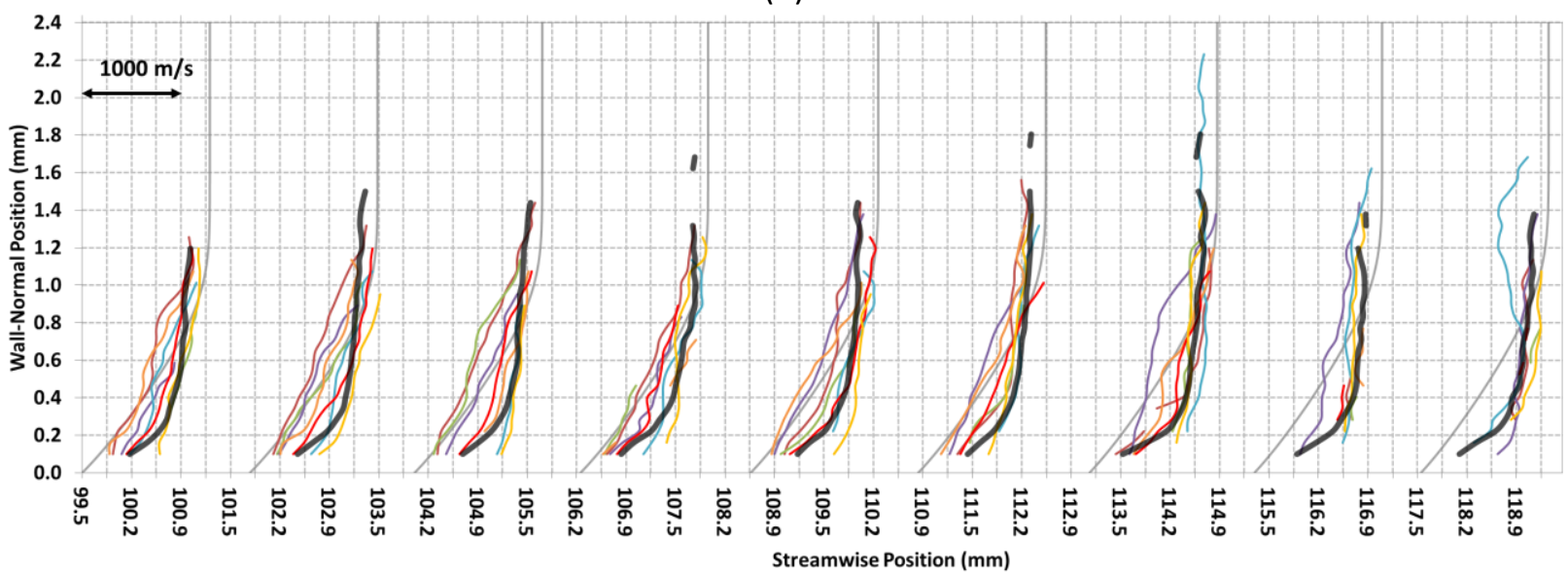

(c)

Figure A31. Run 13 (a) mean, (b) fluctuating, and (c) single-shot velocity profiles. $k / \delta_{L}=1.89, R_{k k}=5535$. Profiles taken at $z=-3.5 \mathrm{~mm}$ off of centerline. 


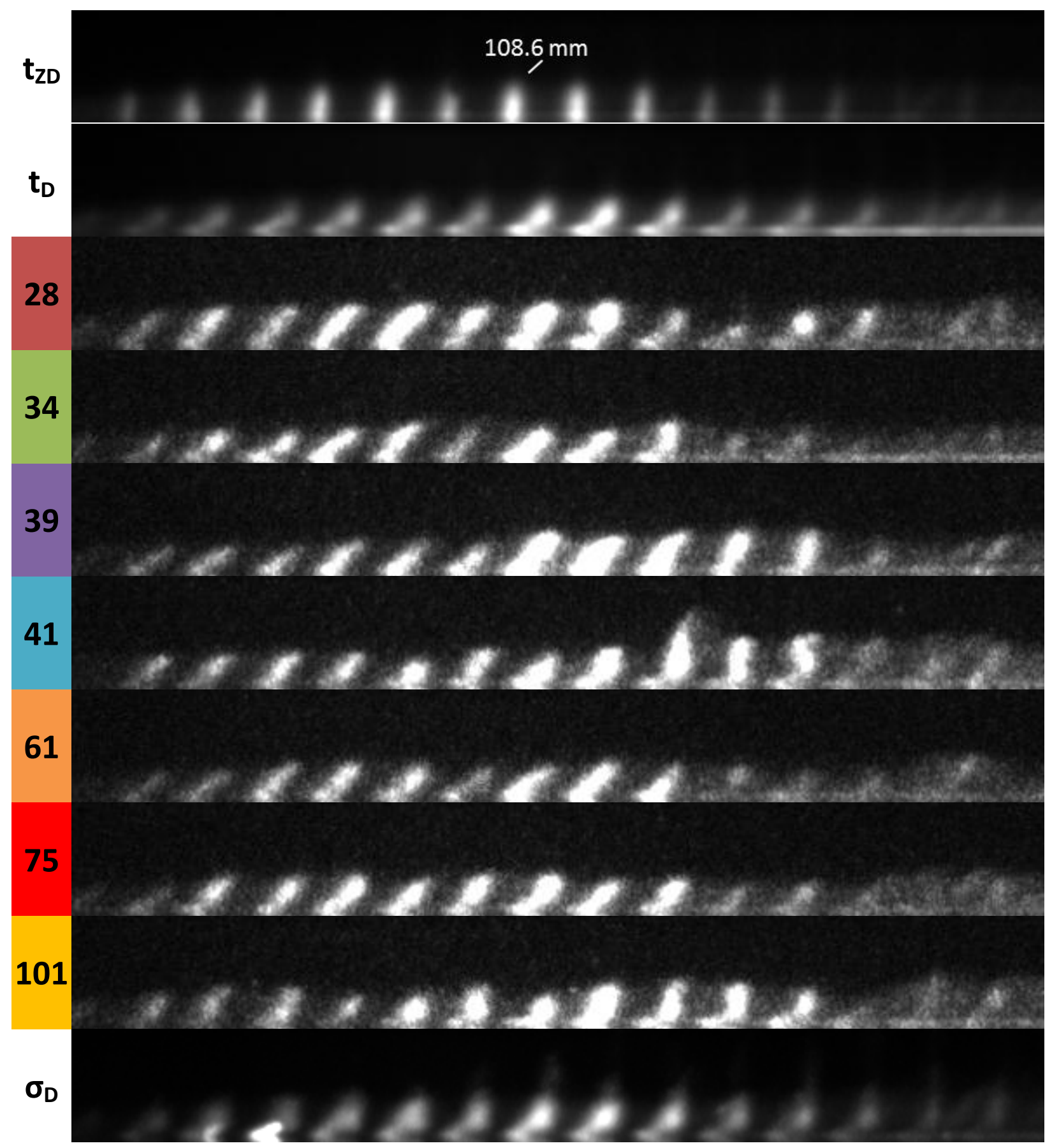

Figure A32. Run 13 (top) 155-shot average zero-delay image ( $\left.t_{2 \mathrm{D}}\right)$, 155-shot average delay image $\left(\mathrm{t}_{\mathrm{D}}\right)$, single-shot delayed images, and (bottom) 155-shot standard deviation of delayed images $\left(\sigma_{D}\right)$. Images at $z=-3.5 \mathrm{~mm}$ off of centerline. 


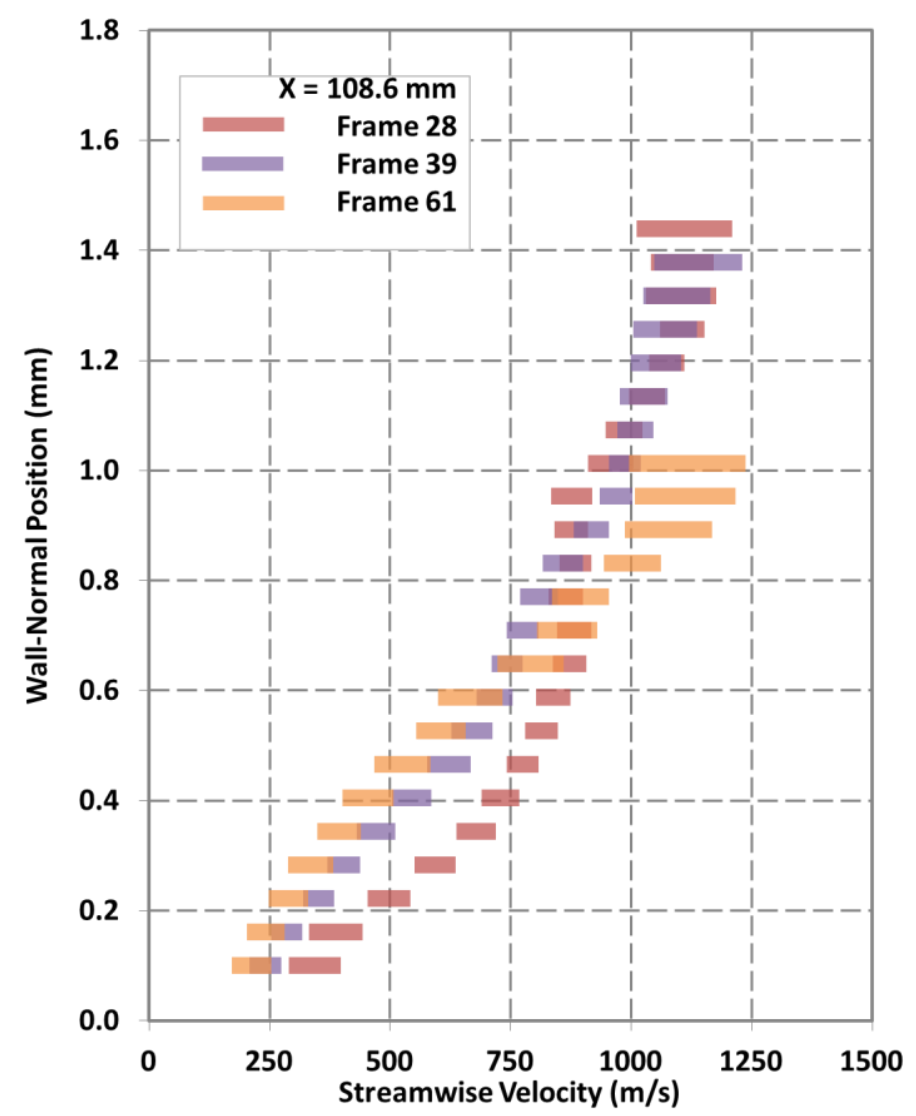

Figure A33. Run 13 single-shot velocity profiles at $108.6 \mathrm{~mm}$ downstream of leading edge, $z=-3.5 \mathrm{~mm}$ from centerline. 


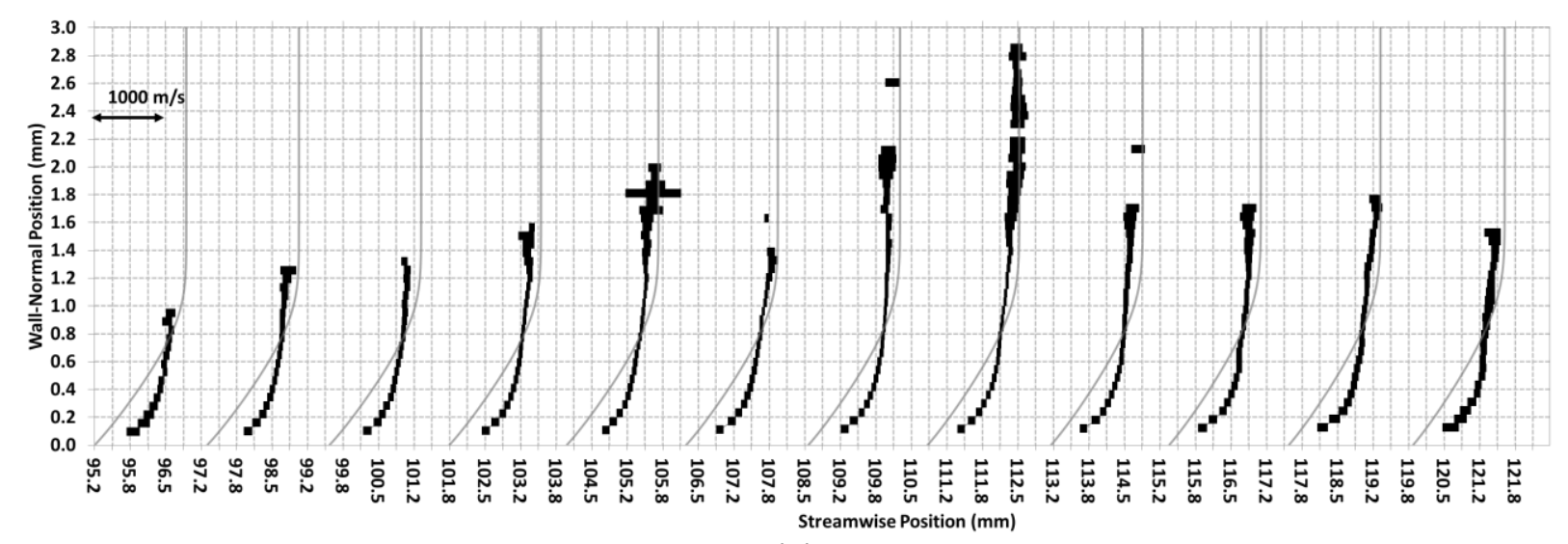

(a)

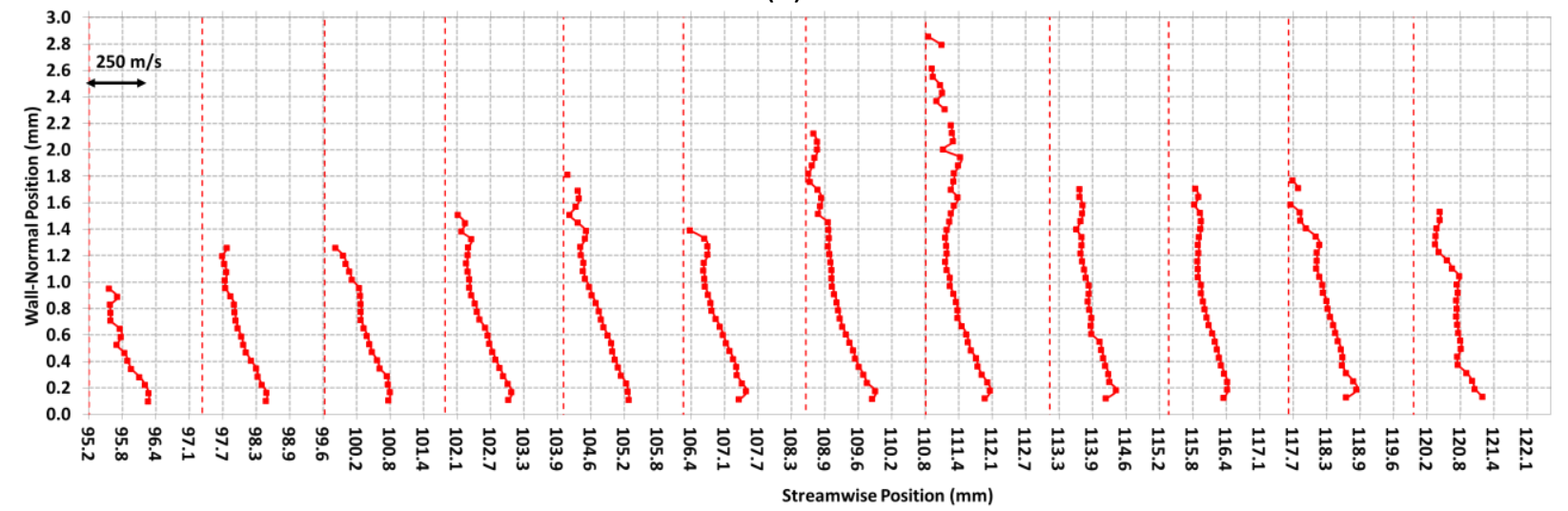

(b)

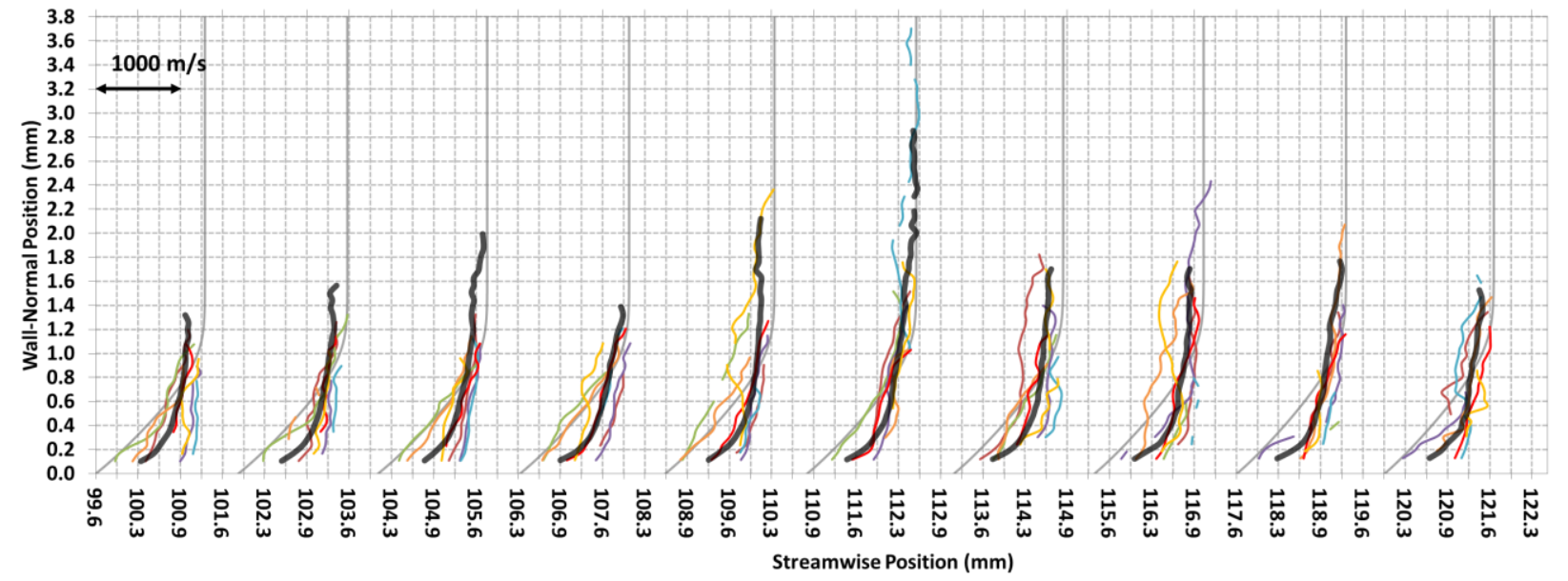

(c)

Figure A34. Run 13 (a) mean, (b) fluctuating, and (c) single-shot velocity profiles. $k / \delta_{L}=1.86, R_{k k}=5296$. Profiles taken at $z=-4.5 \mathrm{~mm}$ off of centerline. 


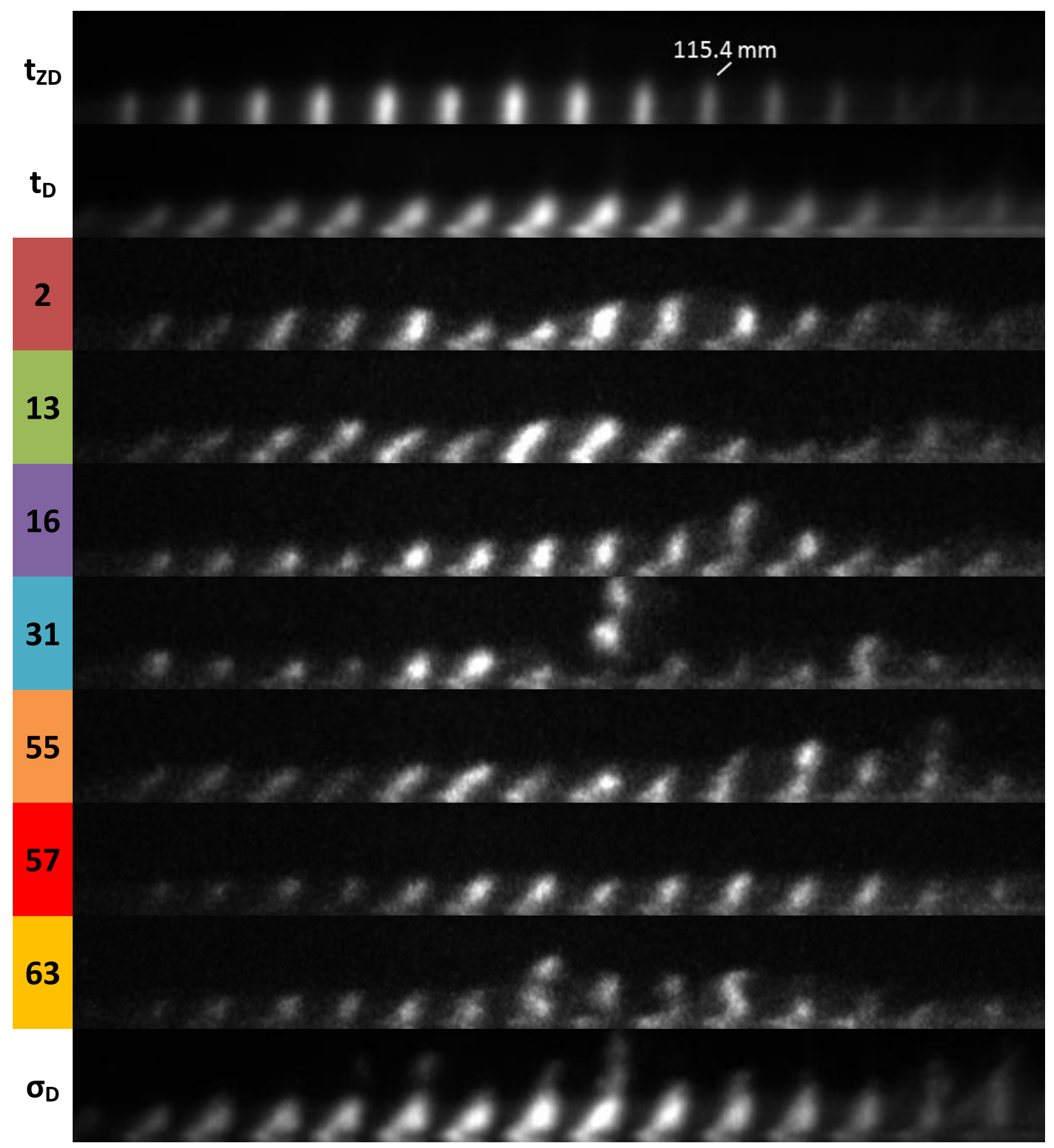

Figure A35. Run 13 (top) 150-shot average zero-delay image $\left(t_{z D}\right), 150$-shot average delay image $\left(t_{D}\right)$, single-shot delayed images, and (bottom) 150-shot standard deviation of delayed images $\left(\sigma_{D}\right)$. Images at $z=-4.5 \mathrm{~mm}$ off of centerline. 


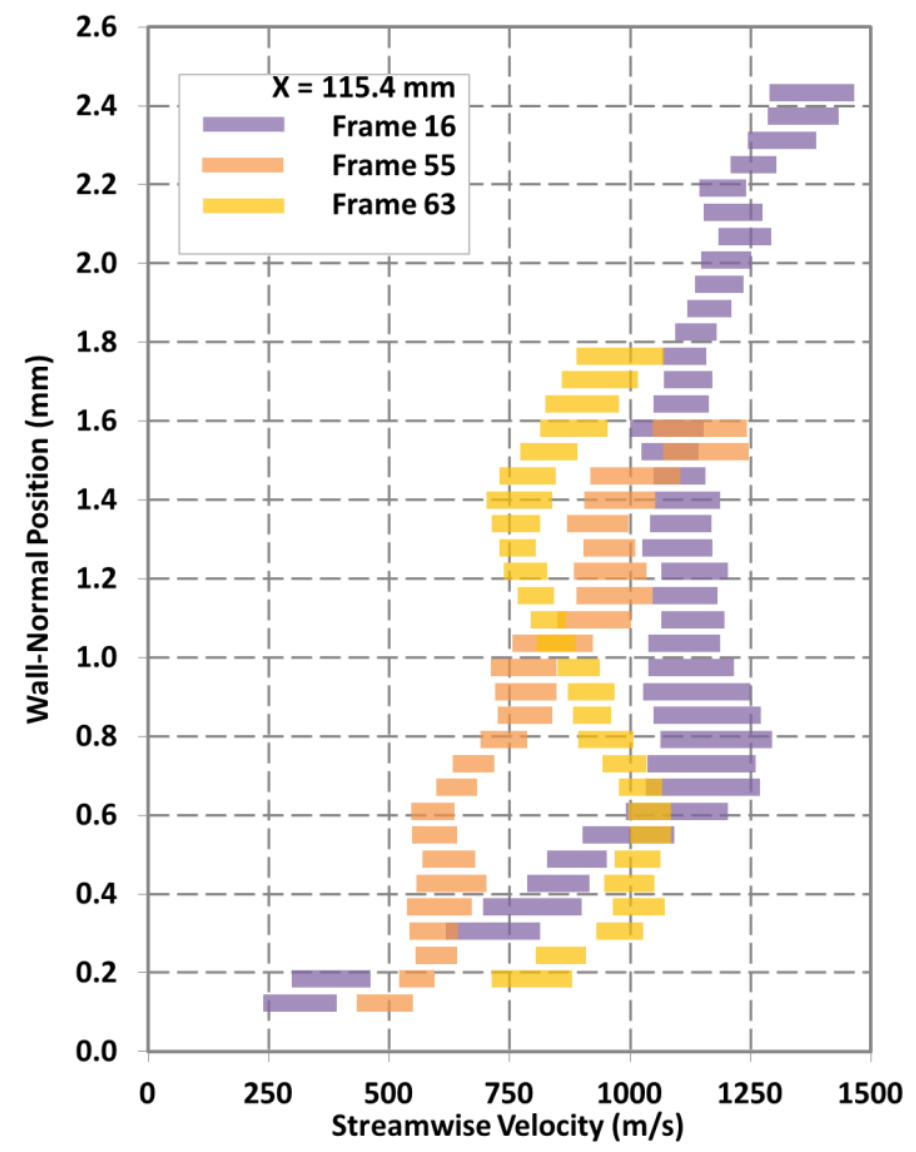

Figure A36. Run 13 single-shot velocity profiles at $115.4 \mathrm{~mm}$ downstream of leading edge, $z=-4.5 \mathrm{~mm}$ from centerline. 


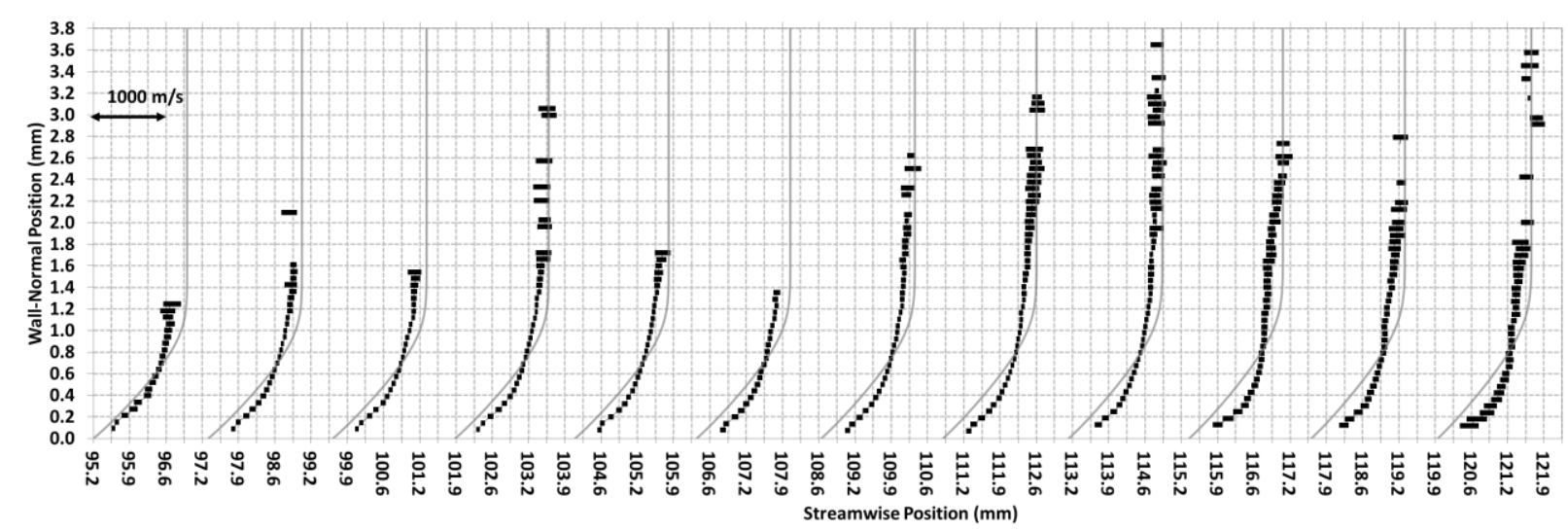

(a)

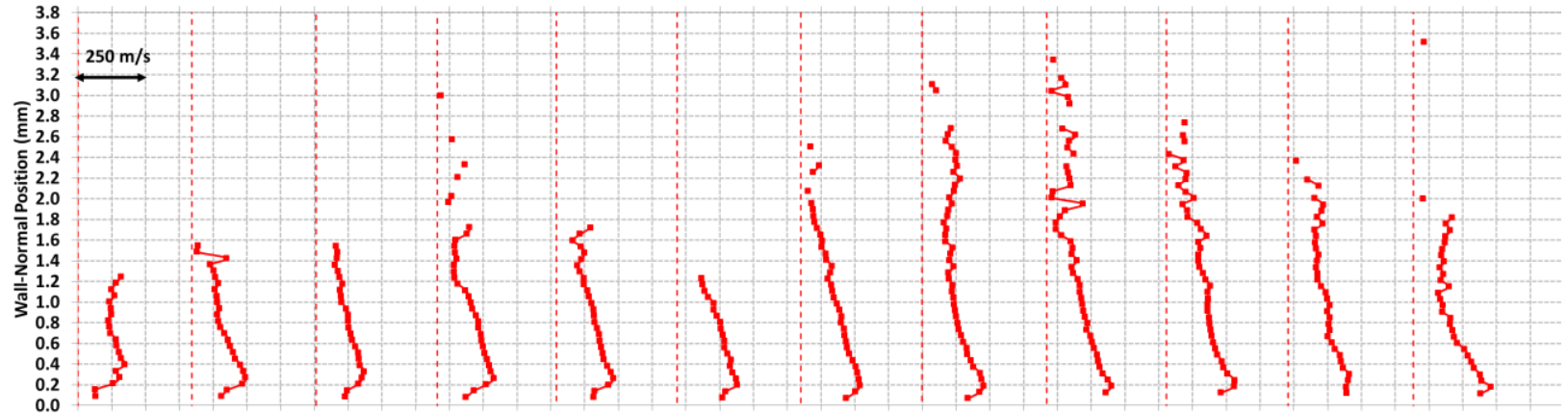

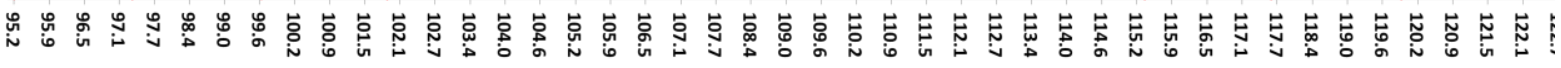

(b)

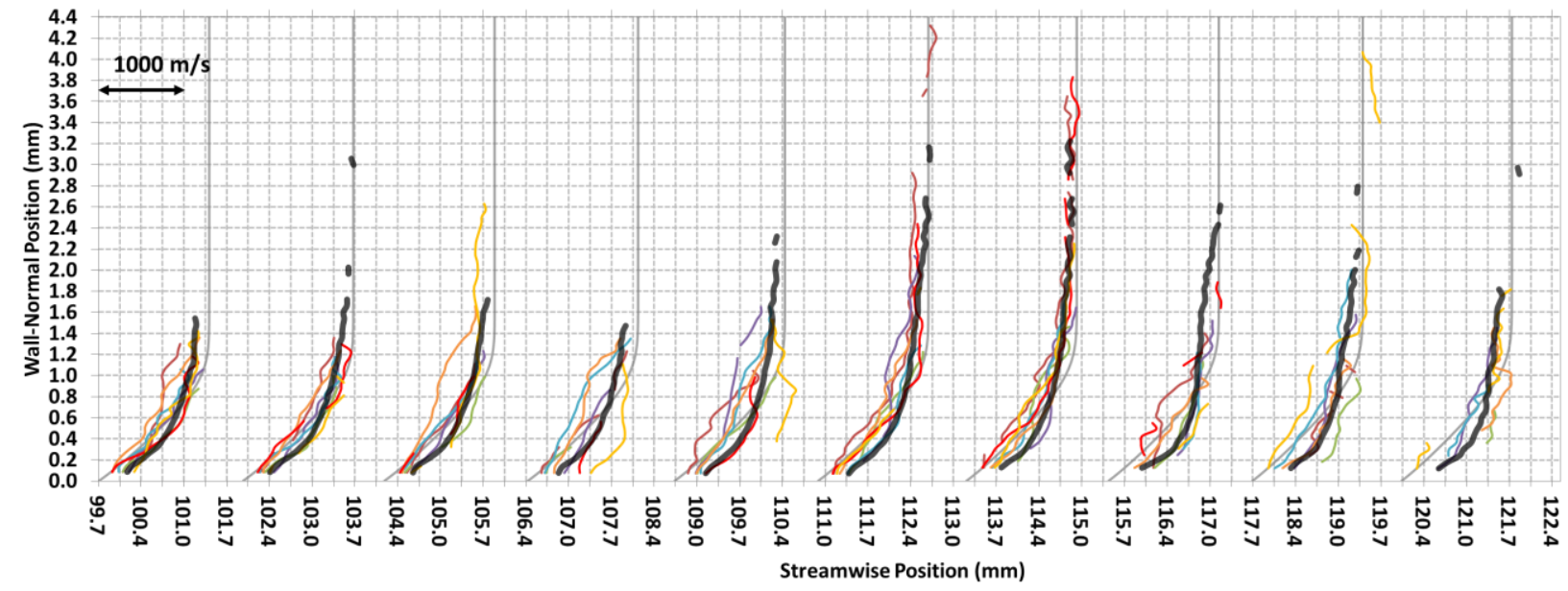

(c)

Figure A37. Run 13 (a) mean, (b) fluctuating, and (c) single-shot velocity profiles. $k / \delta_{\mathrm{L}}=1.83, \mathrm{Re}_{\mathrm{kk}}=5072$. Profiles taken at $z=-5.5 \mathrm{~mm}$ off of centerline. 


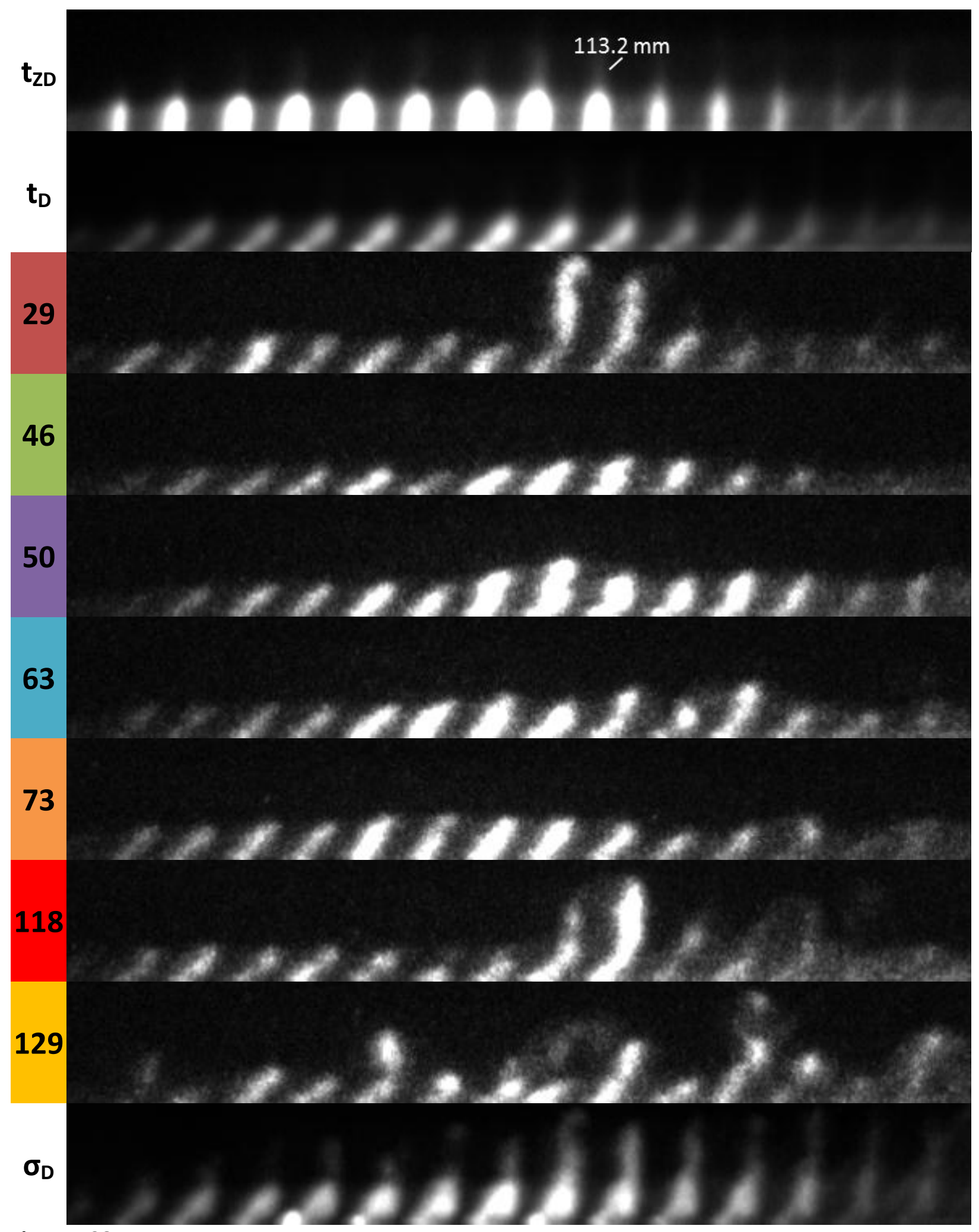

Figure A38. Run 13 (top) 150-shot average zero-delay image ( $\left.t_{\mathrm{zD}}\right)$, 150-shot average delay image $\left(t_{\mathrm{D}}\right)$, single-shot delayed images, and (bottom) 150-shot standard deviation of delayed images $\left(\sigma_{D}\right)$. Images at $z=-5.5 \mathrm{~mm}$ off of centerline. 


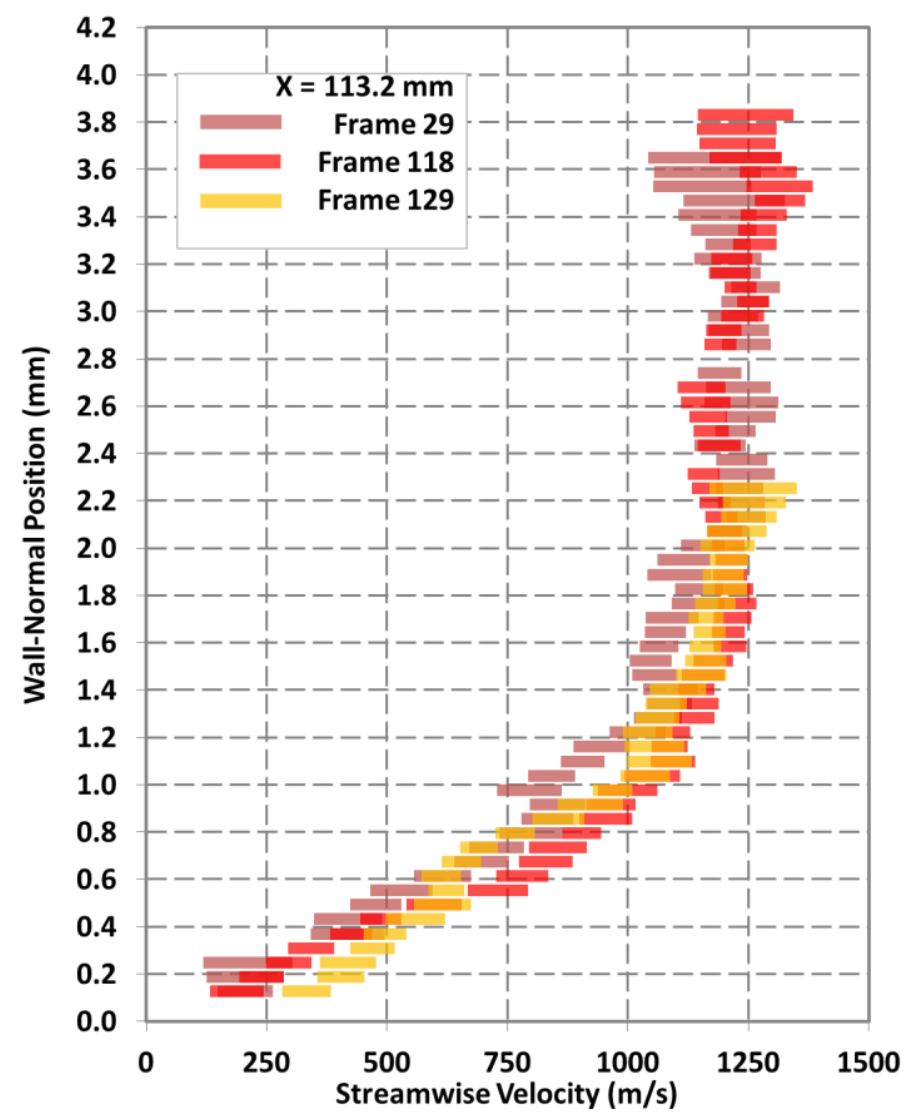

Figure A39. Run 13 single-shot velocity profiles at $113.2 \mathrm{~mm}$ downstream of leading edge, $z=-5.5 \mathrm{~mm}$ from centerline. 


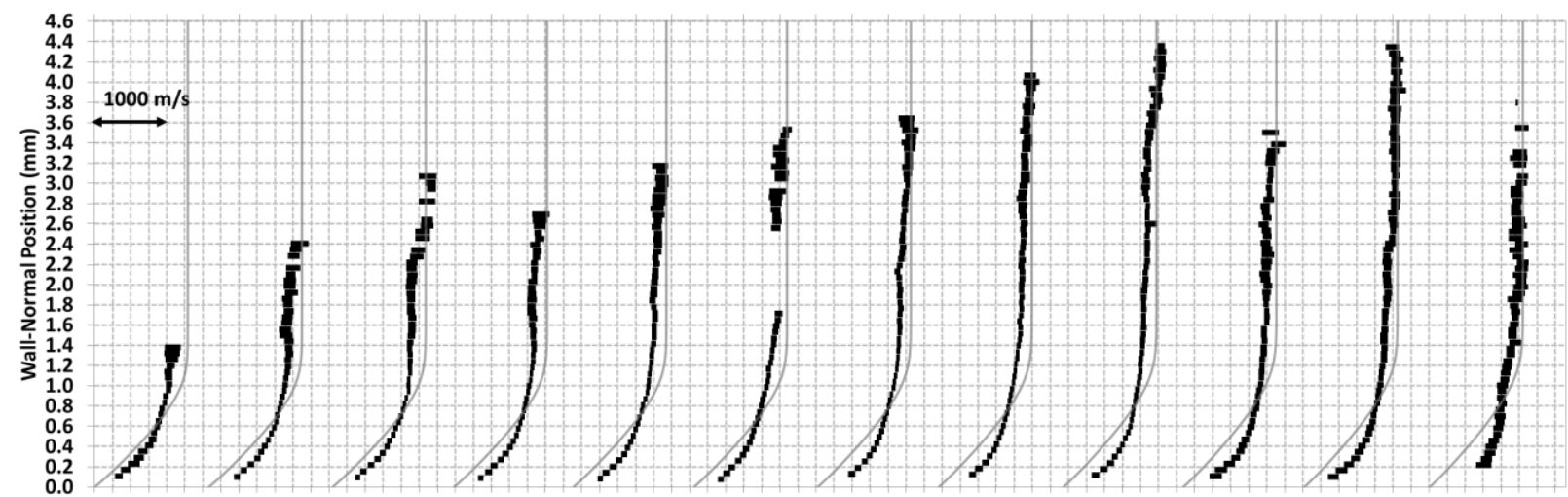

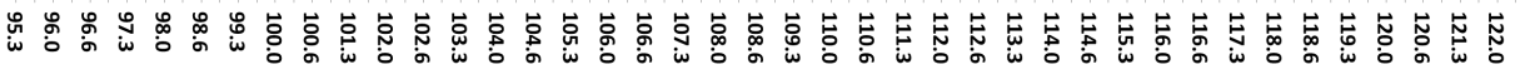

(a)

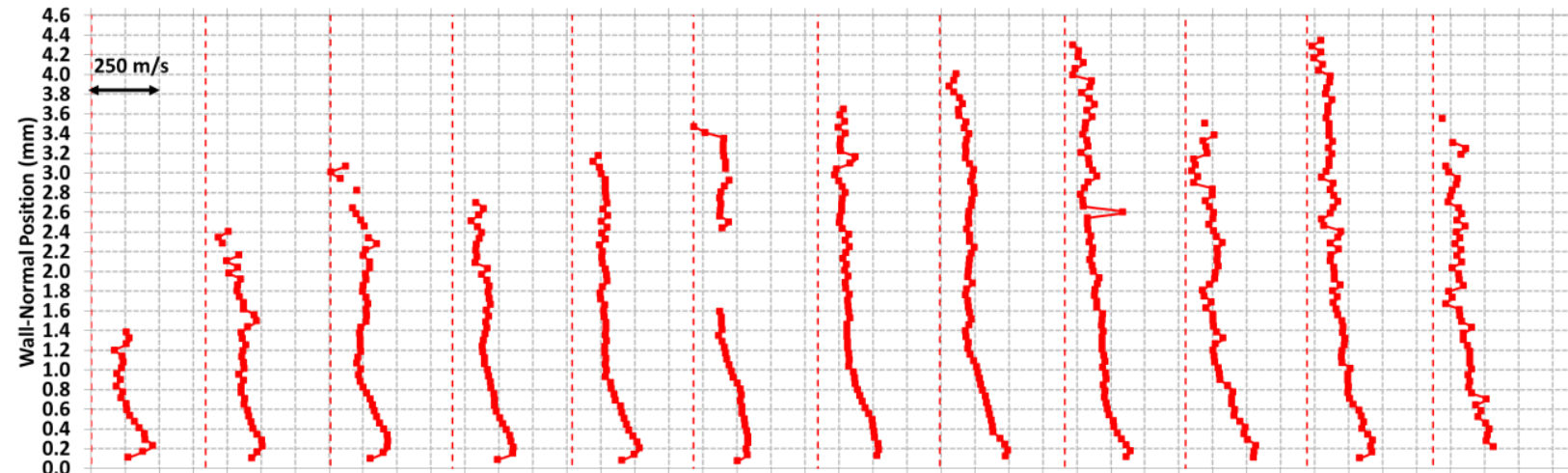

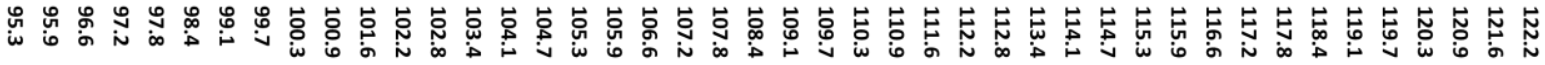

Streamwise Position (mm)

(b)

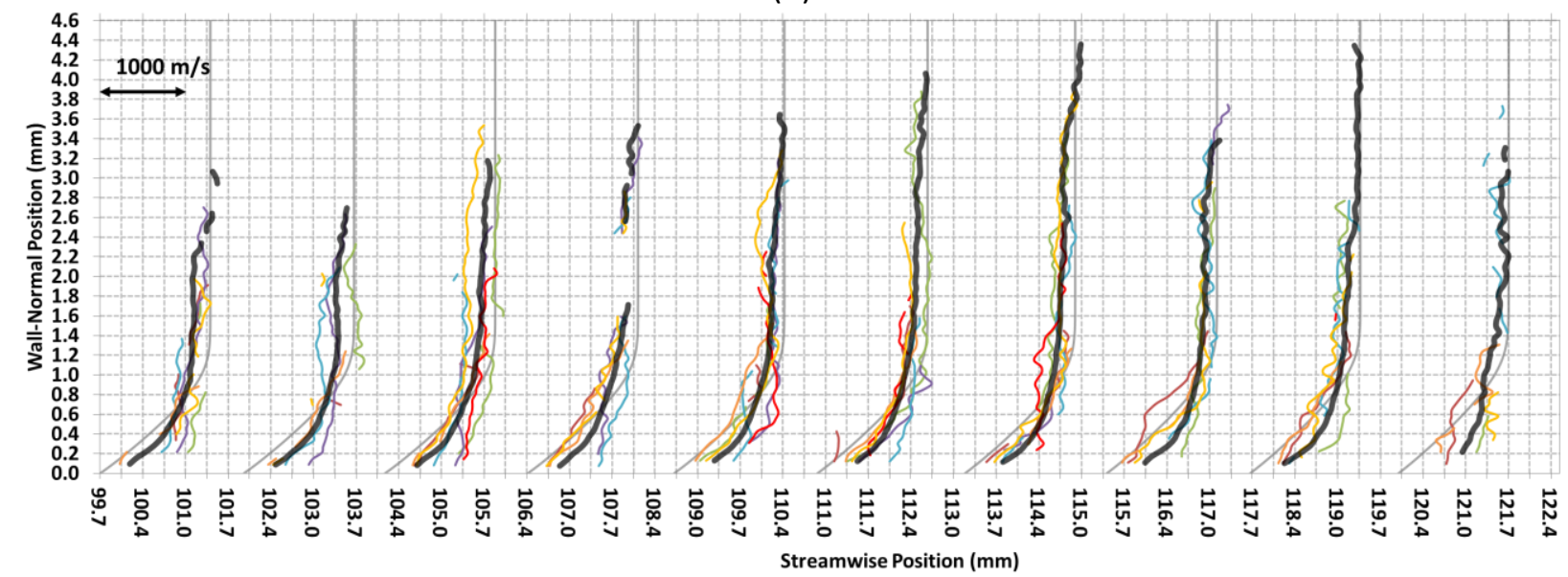

(c)

Figure A40. Run 13 (a) mean, (b) fluctuating, and (c) single-shot velocity profiles. $k / \delta_{L}=1.80, R_{k k}=4881$. Profiles taken at $z=-6.5 \mathrm{~mm}$ off of centerline. 


\section{$113.2 \mathrm{~mm}$}

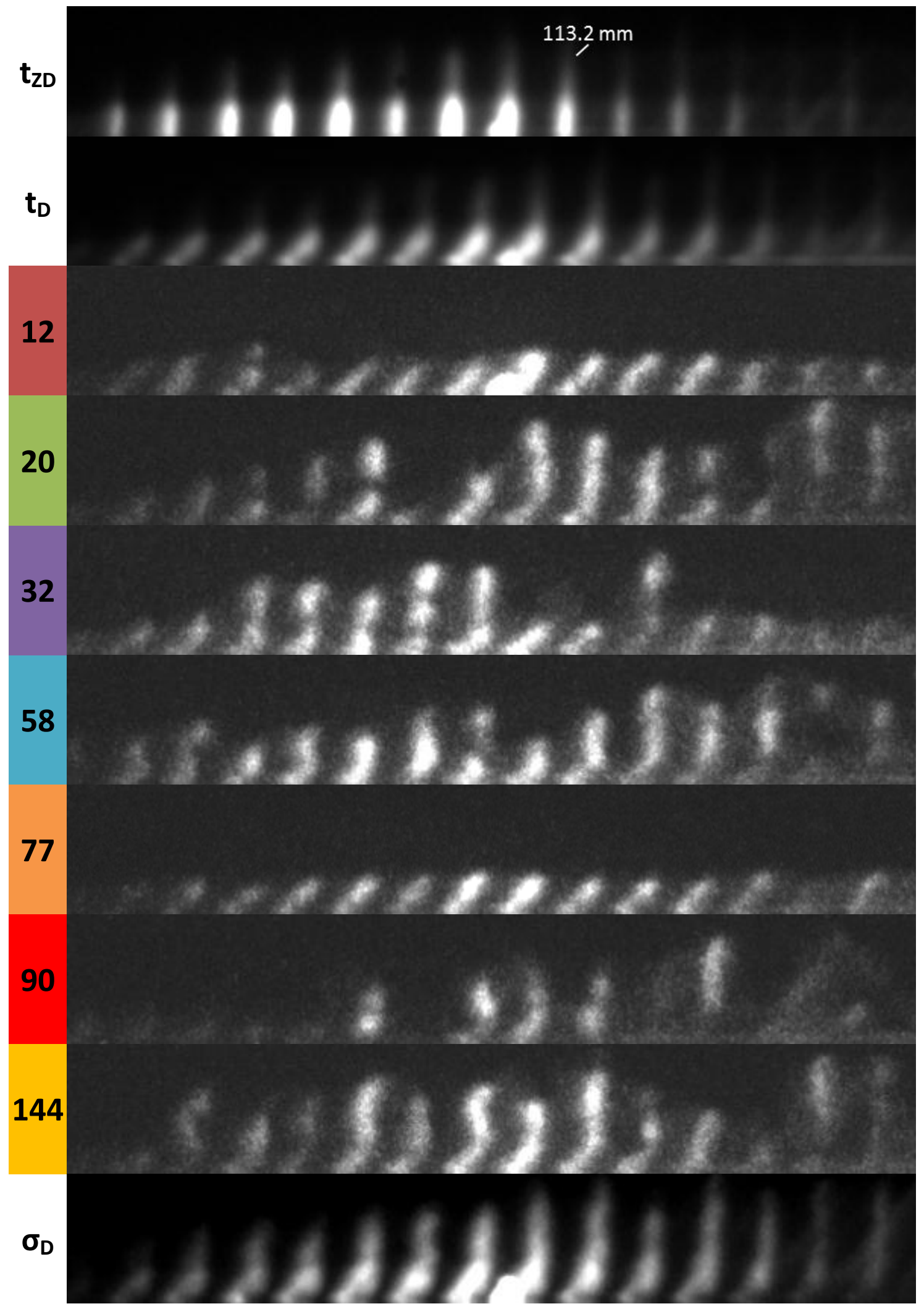

Figure A41. Run 13 (top) 149-shot average zero-delay image $\left(t_{z D}\right)$, 149-shot average delay image $\left(t_{D}\right)$, single-shot delayed images, and (bottom) 149-shot standard deviation of delayed images $\left(\sigma_{D}\right)$. Images taken at $z=-6.5 \mathrm{~mm}$ off of centerline. 


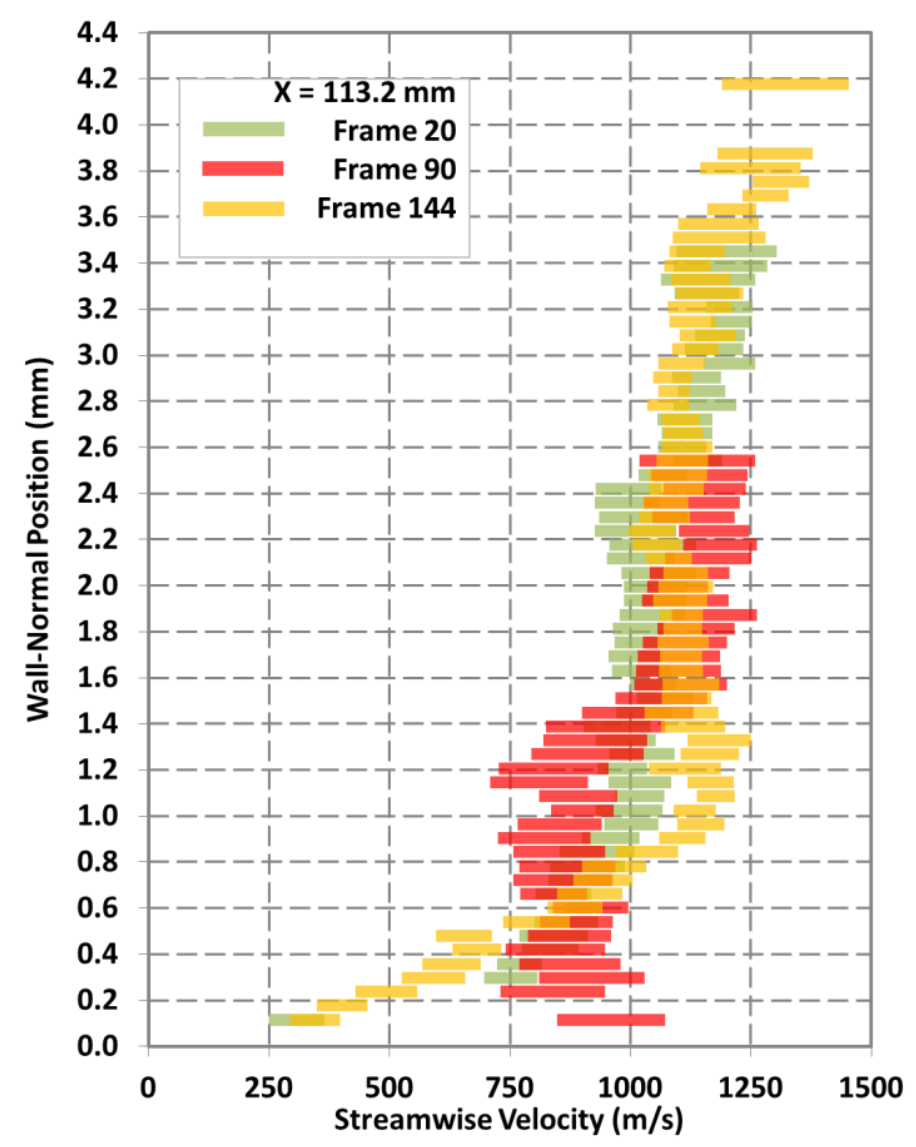

Figure A42. Run 13 single-shot velocity profiles at $113.2 \mathrm{~mm}$ downstream of leading edge, $z=-6.5 \mathrm{~mm}$ off of centerline. 


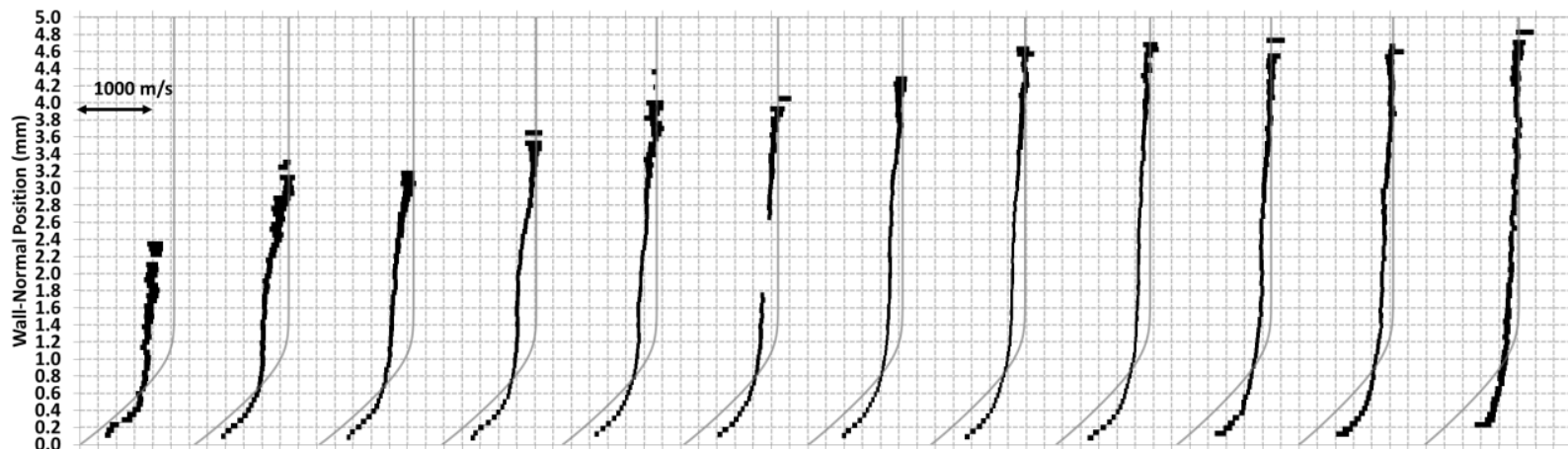

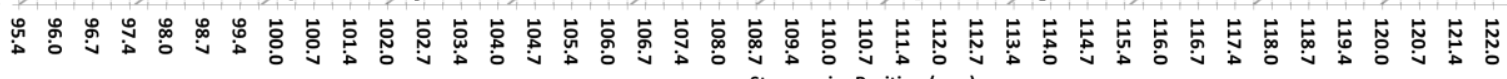

(a)

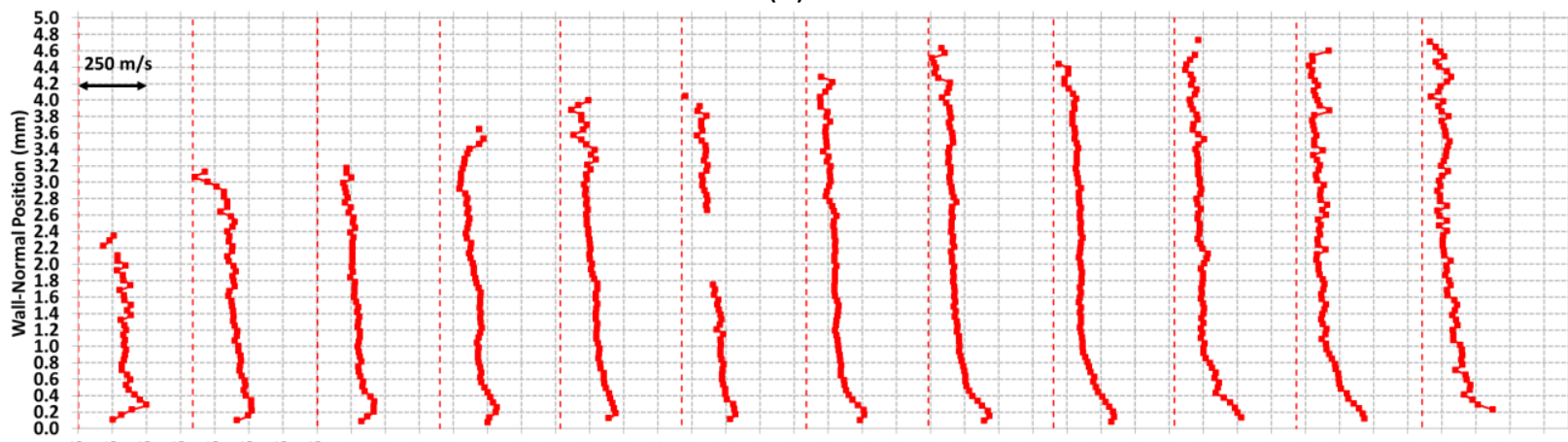

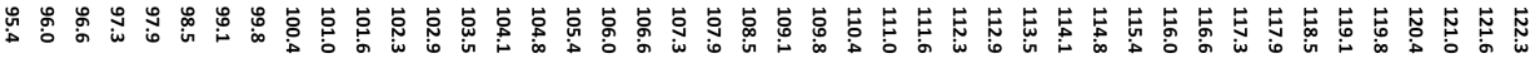

(b)

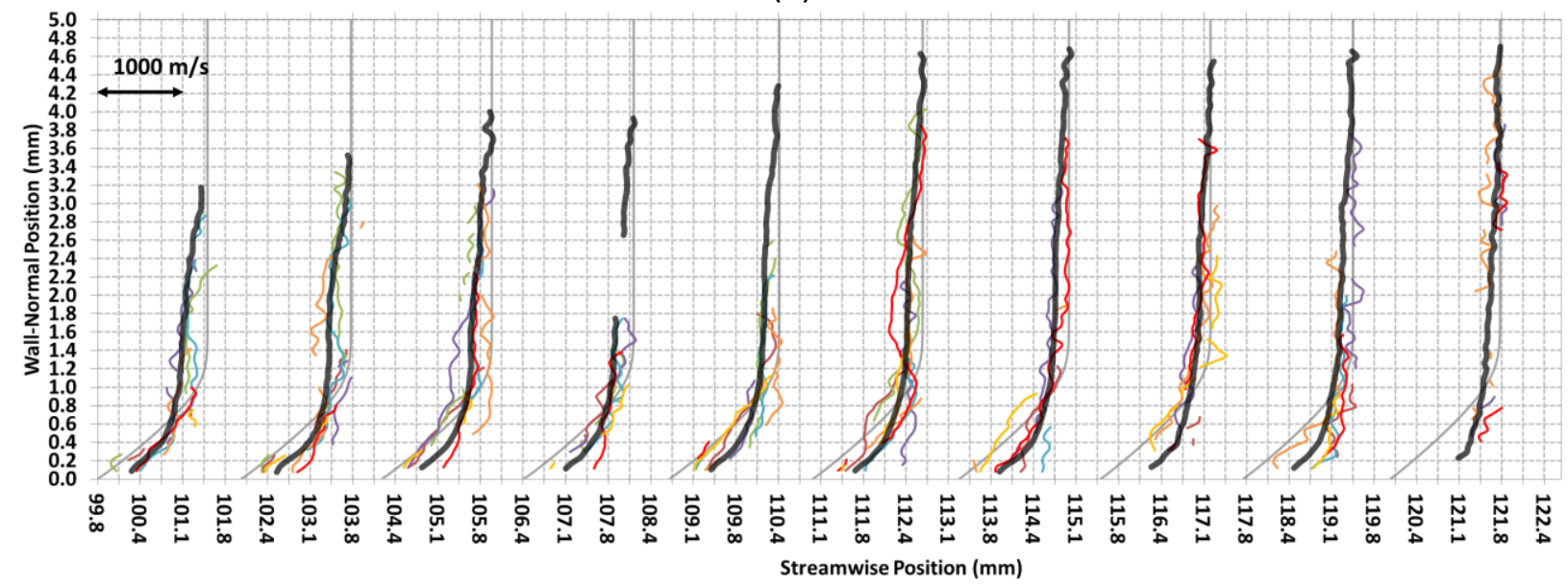

(c)

Figure A43. Run 13 (a) mean, (b) fluctuating, and (c) single-shot velocity profiles. $k / \delta_{L}=1.76, \mathrm{Re}_{\mathrm{kk}}=4665$. Profiles taken at $z=-7.5 \mathrm{~mm}$ off of centerline. 


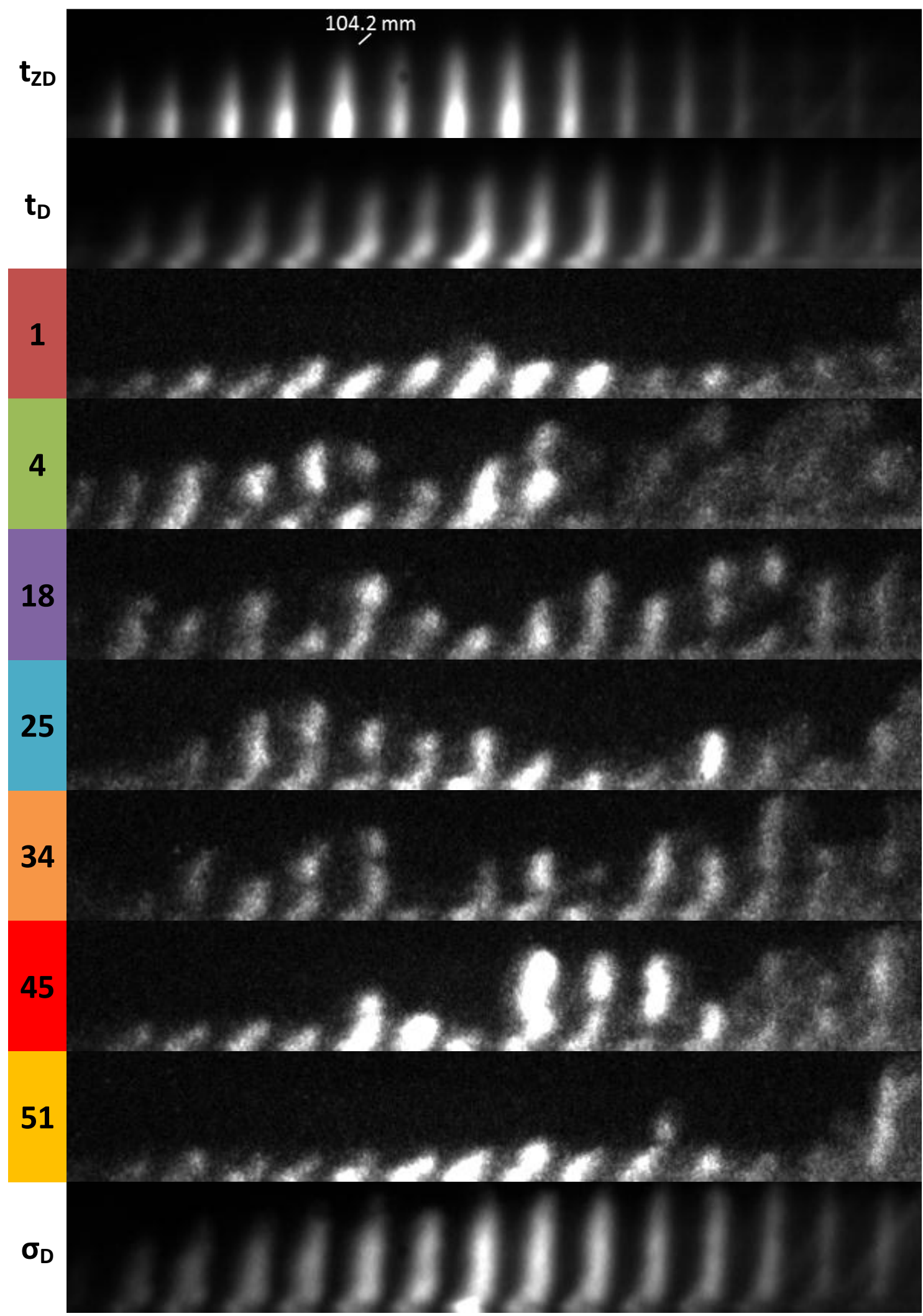

Figure A44. Run 13 (top) 275-shot average zero-delay image ( $\left.t_{z D}\right)$, 275-shot average delay image $\left(t_{D}\right)$, single-shot delayed images, and (bottom) 275-shot standard deviation of delayed images $\left(\sigma_{D}\right)$. Images taken at $z=-7.5 \mathrm{~mm}$ off of centerline. 


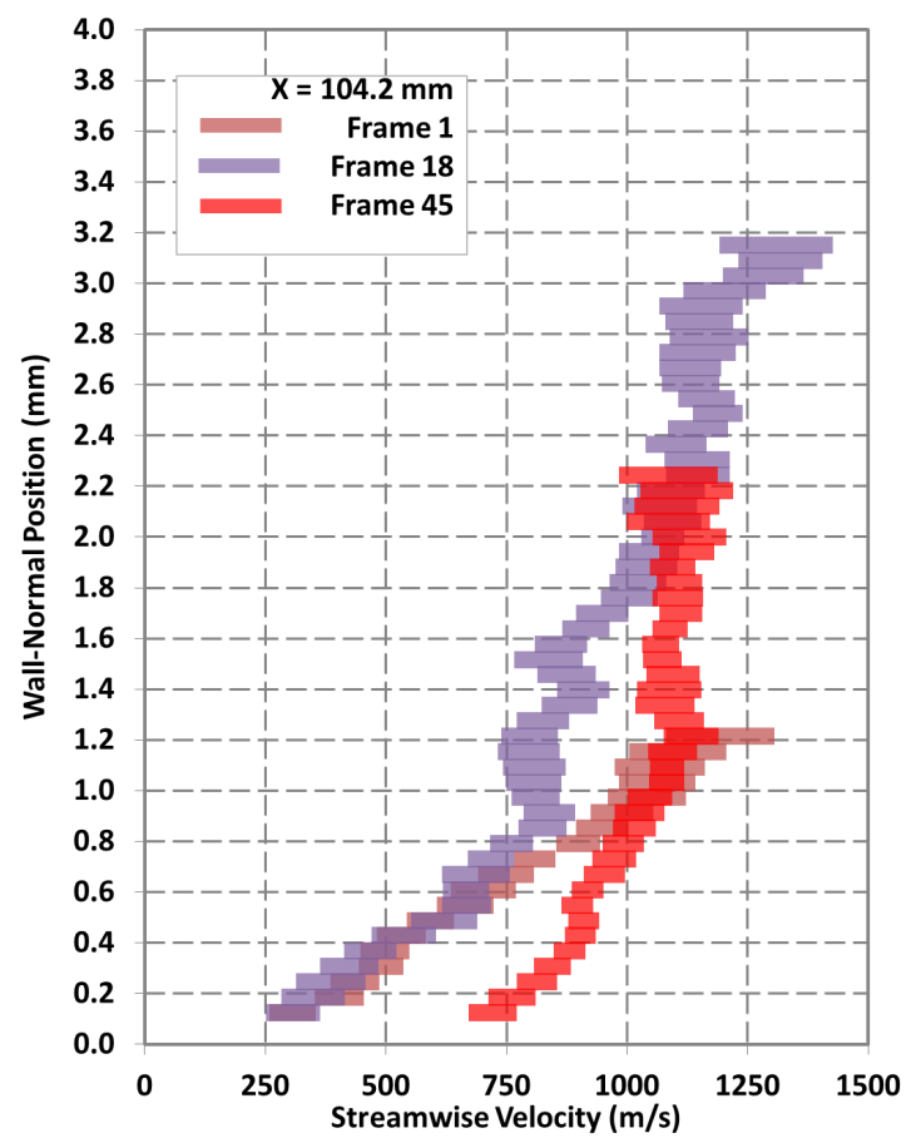

Figure A45. Run 13 single-shot velocity profiles at $104.2 \mathrm{~mm}$ downstream of leading edge, $z=-7.5 \mathrm{~mm}$ off of centerline. 